\title{
Progress towards High-Efficiency and Stable Tin-Based Perovskite Solar Cells
}

\author{
Syed Afaq Ali Shah ${ }^{1}$, Muhammad Hassan Sayyad ${ }^{2}$, Karim Khan ${ }^{1}{ }^{\mathbb{D}}$, Kai Guo ${ }^{3}{ }^{\mathbb{D}}$, Fei Shen ${ }^{1}$, \\ Jinghua Sun ${ }^{1}$, Ayesha Khan Tareen ${ }^{1}$, Yubin Gong ${ }^{4}$ and Zhongyi Guo ${ }^{1,3, *(D)}$ \\ 1 School of Electrical Engineering \& Intelligentizaion, Dongguan University of Technology, Dongguan 523808, \\ China; Ali.shah82@hotmail.com (S.A.A.S.); karim_khan_niazi@yahoo.com (K.K.); shenfei@hfut.edu.cn (F.S.); \\ sunjh@dgut.edu.cn (J.S.); chemistayesha@yahoo.com (A.K.T.) \\ 2 Faculty of Engineering Sciences, Ghulam Ishaq Khan Institute of Engineering Sciences and Technology, Topi, \\ District Swabi, Khyber Pakhtunkhwa 23640, Pakistan; sayyad@giki.edu.pk \\ 3 School of Computer and Information, Hefei University of Technology, Hefei 230009, China; \\ kai.guo@hfut.edu.cn \\ 4 National Key Lab on Vacuum Electronics, University of Electronic Science and Technology of \\ China (UESTC), Chengdu 610054, China; ybgong@uestc.edu.cn \\ * Correspondence: guozhongyi@hfut.edu.cn; Tel.: +86-186-5515-1981
}

Received: 3 September 2020; Accepted: 29 September 2020; Published: 29 September 2020

\begin{abstract}
Since its invention in 2009, Perovskite solar cells (PSCs) has attracted great attention because of its low cost, numerous options of efficiency enhancement, ease of manufacturing and high-performance. Within a short span of time, the PSC has already outperformed thin-film and multicrystalline silicon solar cells. A current certified efficiency of $25.2 \%$ demonstrates that it has the potential to replace its forerunner generations. However, to commercialize PSCs, some problems need to be addressed. The toxic nature of lead which is the major component of light absorbing layer, and inherited stability issues of fabricated devices are the major hurdles in the industrialization of this technology. Therefore, new researching areas focus on the lead-free metal halide perovskites with analogous optical and photovoltaic performances. Tin being nontoxic and as one of group IV(A) elements, is considered as the most suitable alternate for lead because of their similarities in chemical properties. Efficiencies exceeding 13\% have been recorded using Tin halide perovskite based devices. This review summarizes progress made so far in this field, mainly focusing on the stability and photovoltaic performances. Role of different cations and their composition on device performances and stability have been involved and discussed. With a considerable room for enhancement of both efficiency and device stability, different optimized strategies reported so far have also been presented. Finally, the future developing trends and prospects of the PSCs are analyzed and forecasted.
\end{abstract}

Keywords: Perovskite Solar Cells (PSCs); lead free; nanomaterial; photovoltaic; renewable energy

\section{Introduction}

For the ever-growing global energy consumption and rapidly depleting fossil fuels reserves, production of energy from clean, sustainable, and renewable energy sources is necessary. Solar radiation is an unlimited form of clean and renewable energy. Its low cost and efficient harvesting can endlessly fuel our civilization. To date, the conventional silicon based solar cells have dominated the photovoltaic (PV) market because of its superior stability and high power conversion efficiency (PCE). Its highest efficiency surpassing $26 \%$ recorded at standard test conditions [1]. However, the initial production cost associated with silicon wafers used in this technology was very high. Finding alternative technologies to Si solar cells, which can compete in providing high PCE, excellent stability, high reproducibility and low cost, are still challenges for scientific community. 
In a short span of less than 10 years, organo-metal halide perovskites (OMHPs) have emerged as a champion photovoltaic technology. Its solution processed fabrication, lower manufacturing cost and high PCE, made perovskite solar cell a promising future photovoltaic technology $[2,3]$. The OMHPs are group of materials with a formula of $\mathrm{ABX}_{3}$, where $\mathrm{A}$ and $\mathrm{B}$ represent cations of different sizes and $\mathrm{X}$ represent an anion. For perovskite solar cell (PSC), the most commonly used small organic-inorganic cations (A), are methyl-ammonium $\mathrm{CH}_{3} \mathrm{NH}_{3}{ }^{+}$[4,5], formamidinium $\mathrm{NH}_{2} \mathrm{CH}_{3} \mathrm{NH}_{2}{ }^{+}$[6,7], and cesium $\mathrm{Cs}[8,9] . \mathrm{Pb}^{2+}, \mathrm{Ge}^{2+}$ and $\mathrm{Sn}^{2+}$ all belonging to the group-IV(A) family, are widely reported as a divalent metal cation (B) $[10,11]$. Whereas $\mathrm{F}^{-}, \mathrm{Cl}^{-}, \mathrm{Br}^{-}$and $\mathrm{I}^{-}$are the most used monovalent halogen anions $(\mathrm{X})$ in PSCs [12].

Known for their exceptional optoelectronic properties, perovskite materials were subject of investigation in the late 19th century for their potential applications in light emitting diodes (LEDs) and field effect transistors (FETs) [13,14]. In 2009, Miyasaka and coworkers for the first time employed these materials in solar cells [15]. By successfully using of $\mathrm{CH}_{3} \mathrm{NH}_{3} \mathrm{PbBr}_{3}$ and $\mathrm{CH}_{3} \mathrm{NH}_{3} \mathrm{PbI}_{3}$ as a sensitizer in Dye-sensitized solar cells (DSSCs), efficiencies of 3.13\% and 3.81\% were obtained respectively [15]. These efficiencies were further elevated to $6.54 \%$ in 2011 , when Lee et al., sensitized $3.6 \mu \mathrm{m}$-thick $\mathrm{TiO}_{2}$ films with quantum dots of $\mathrm{CH}_{3} \mathrm{NH}_{3} \mathrm{PbI}_{3}$ employing quantum-dot sensitized solar cell (QDSSC) architecture [16]. However, the fabricated devices degraded within minutes because the corrosive redox electrolyte dissolved the QDs. This forced the researchers to focus on all solid state perovskite devices. The very first all solid state perovskite based solar cell was reported in 2012 [17], where the liquid electrolyte was replaced by organic hole transport material, spiro-OMeTAD. This significantly improved the stability of perovskite devices with elevating efficiency to exceed 9\% [17]. From then on many notable groups and researchers around the globe joined the perovskite fever [18] by reporting different device architectures such as mesoscopic n-i-p [19], plannar n-i-p [20], inverted mesoscopic $p-i-n[21]$ and inverted plannar p-i-n [22]. One major factor deciding the performance of the PSC was the quality of perovskite films. To achieve high quality perovskite films many different depositing techniques were reported such as one-step solution deposition [23], two-steps solution deposition [24], vapor assisted deposition [25], thermal vapor deposition [26], blade coating [27], ink jet printing [28], spray coating [29], slot die coating, screen printing and other emerging techniques [30]. To enhance the stability and overall PCE of the devices, many different approaches had been investigated, such as solvent engineering, process engineering, band gap engineering and contact engineering [31].

Within a decade the overall PCE of perovskite solar cell has dramatically improved from $3.81 \%$ in 2009 to $25.2 \%$ in 2019 [32]. Lead ( $\mathrm{Pb})$ was used as a divalent metal cation in almost all high-performance devices [33]. The toxicity of lead is an established fact, and risk of lead being inevitably accumulating in the food chain increases many folds with lead hallide making water soluble lead compounds overtime [34]. It is therefore necessary, and compelling to common sense that perovskite solar cells must go lead free. With a smaller ionic radius of $73(\mathrm{pm})$, a lower electronegativity and more covalent nature than $\mathrm{Pb}^{2+}, \mathrm{Ge}^{2+}$ was thoroughly investigated by Stoumpos et al., as a potential candidate for replacing lead in PSCs [35]. The germanium perovskites crystallize in trigonal crystal structure having a bandgap of $1.9 \mathrm{eV}$ for $\mathrm{MAGeI}_{3}$ [36]. Although the theoretical calculated efficiency for $\mathrm{CsGeI}_{3}$ is $27.9 \%$ [37], practically the efficiency remained under $1 \%$ for all germanium based PSCs because of the poor film quality and instability of the $\mathrm{Ge}^{2+}$ ion towards oxidation to $\mathrm{Ge}^{4+}[11,35]$. Gratzel and group replaced $\mathrm{Pb}$ with $\mathrm{Cu}$ only to achieve a meager efficiency of $0.017 \%$ [38]. High effective mass of holes, low absorption coefficients and the low intrinsic conductivity of the employed perovskite layer proved to be the main causes of poor performance.

Tin (Sn) has emerged as the most promising alternative to lead because of the same isoelectronic configuration of $\mathrm{s}^{2} \mathrm{p}^{2}$, and has considerably high mobilities $\left[10^{2}-10^{3} \mathrm{~cm}^{2}\left(\mathrm{~V}^{-1} \mathrm{~s}^{-1}\right)\right]$ when used in perovskites as compared to conventional lead based perovskites [10-10 $\mathrm{cm}^{2}\left(\mathrm{~V}^{-1} \mathrm{~s}^{-1}\right)$ ] [39]. However, the facile formation of $\mathrm{Sn}$ vacancies along with stability of $\mathrm{Sn}$ in $2^{+}$oxidation state is in question. In the presence of oxygen $\mathrm{Sn}^{2+}$ is known to be oxidized to $\mathrm{Sn}^{4+}$ oxidation state [40]. The oxidized $\mathrm{Sn}^{4+}$ behave 
as a p-type dopant, and with a concentration of even less than $0.1 \%$ it has drastic effects on PCE of the device [41].

Eyeing large scale modules and commercialization of Sn based PSCs, device stability and performance must be addressed simultaneously. This review will focus on important breakthroughs reported for Sn based perovskite from 2014 to 2020 for aforementioned parameters. Factors playing key role in device performance enhancement will be discussed. Role of different cations and their composition as reported since 2014 will be summarized. Furthermore possibilities and challenges for large scale application of Sn based PSCs are profoundly summarized.

\section{Methylammonium Tin Halides $\left(\mathrm{CH}_{3} \mathrm{NH}_{3} \mathrm{SnX} \mathrm{X}_{3}, \mathrm{X}=\mathrm{I}, \mathrm{Br}, \mathrm{Cl}\right)$}

In 2014 Snaith and coworkers reported the very first methylammonium tin iodide $\left(\mathrm{CH}_{3} \mathrm{NH}_{3} \mathrm{SnI}_{3}\right)$ based completely lead free PSC [42]. An efficiency of $6.4 \%$ was recorded for the best performing device. The perovskite layer was deposited by spin coating a solution having equimolar quantities of $\mathrm{CH}_{3} \mathrm{NH}_{3} \mathrm{I}$ and $\mathrm{SnI}_{2}$ prepared in degassed $\mathrm{N}$-dimethylformamide (DMF). Having a small band gap of $1.23 \mathrm{eV}$, the open circuit voltage $\left(\mathrm{V}_{\mathrm{OC}}\right)$ for the best performing device showed a remarkable value of $0.88 \mathrm{~V}$, with estimated loss of only $0.35 \mathrm{eV}$. A mobility of $1.6 \mathrm{~cm}^{2} \mathrm{~V}^{-1} \mathrm{~s}^{-1}$ with diffusion length of $30 \mathrm{~nm}$ was calculated for $\mathrm{CH}_{3} \mathrm{NH}_{3} \mathrm{SnI}_{3}$ perovskite films. While a diffusion length of almost $1 \mu \mathrm{m}$ was reported for the lead based counterparts of $\mathrm{MASnI}_{3}$ [43]. It was observed that for Sn based perovskites the diffusion lengths can be increased up to $1 \mu \mathrm{m}$ by suppressing background concentration of holes. All devices were fabricated in inert environment and properly encapsulated to minimize the exposure of perovskite layers to oxygen and humidity. While stability of $\mathrm{Sn}$ based perovskites remained an issue, high PCE (6.4\%) paved the way for further research.

In the same year Stoumpos et al., reported an overall PCE of $5.73 \%$ for band gap engineered $\mathrm{MASnI}_{3-\mathrm{x}} \mathrm{Br}_{\mathrm{x}}$ based perovskite devices [44]. It was observed that the conduction band edge of $\mathrm{MAPbI}_{3}$ is $0.23 \mathrm{eV}$ higher than that of $\mathrm{MASnI}_{3}$, which was why devices fabricated with the later has lower open circuit voltage compared to $\mathrm{MAPbI}_{3}$. In order to increase the $\mathrm{V}_{\mathrm{OC}}$ of $\mathrm{Sn}$ based perovskite devices, band gap was tuned by substituting bromide atoms for iodide atoms. These band gap tuned perovskites were synthesized in nitrogen glove box by mixing stoichiometric amounts of MAX and $\operatorname{SnX}_{2}(X=B r, I)$, finely homogenized in a mortar. Followed by sealing in silica ampules under $1 \times 10^{-4}$ mbar vacuum and heated to $200^{\circ} \mathrm{C}$.

The absorption onset of these hybrid halide perovskites can be tuned by proper substitution of bromide atoms, using $\mathrm{MASnI}_{3}$ having smallest optical band gap of $1.3 \mathrm{eV}$, and $\mathrm{MASnBr}_{3}$ with the largest optical band gap of $2.15 \mathrm{eV}$. An increase in $\mathrm{V}_{\mathrm{OC}}$ was observed with increasing Br content. $A \mathrm{~V}_{\mathrm{OC}}$ of $0.68 \mathrm{~V}$ was recorded for $\mathrm{MASnI}_{3}$ which increased up to $0.88 \mathrm{~V}$ for $\mathrm{MASnBr}_{3}$ based device. However, the short circuit current density (JSC) showed an opposite trend and decreased from $16.30 \mathrm{~mA} \cdot \mathrm{cm}^{-2}$ for $\mathrm{MASnI}_{3}$ to $8.26 \mathrm{~mA} \cdot \mathrm{cm}^{-2}$ for $\mathrm{MASnBr}_{3}$ [44]. The best PCE of $5.73 \%$ was recorded for device with $\mathrm{MASnIBr}_{2}$, having a $\mathrm{V}_{\mathrm{OC}}$ of $0.82 \mathrm{~V}$, JSC of $12.30 \mathrm{~mA} \cdot \mathrm{cm}^{-2}$ and Fill Factor (FF) of 0.57 . A considerable high photovoltaic performance and atmospheric stability still remained a major concern for these devices. However, when sealed with surlyn films and stored in nitrogen glove box, the fabricated cells retained $80 \%$ of their initial photovoltaic performance in the first $12 \mathrm{~h}$, which was very encouraging. By applying advanced sealing techniques the stability can further be significantly improved.

In an attempt to enhance the perovskite film quality and morphology, in 2015 Kanatzidis group reported a solvent mediated crystallization for $\mathrm{MASnI}_{3}$ based PSCs [45]. By doing so, they achieved a highly uniform and pin hole free perovskite films, with a JSC reaching to $21 \mathrm{~mA} \cdot \mathrm{cm}^{-2}$ and overall PCE of $3.15 \%$. Two major factors governing photovoltaic performance of Sn based PCSs are self-doping and film quality. The Sn perovskites were prone to easily decomposed in isopropanol along a fast reaction rate between methylammonium iodide and $\mathrm{SnI}_{2}$ films. This lead to an uncontrolled crystallization process of Sn perovskite films resulting in a poor film quality with presence of micron sized pinholes $[45,46]$. 
$\mathrm{Sn}^{2+}$ has greater Lewis Acidity than $\mathrm{Pb}^{2+}[47]$ resulting in a fast reaction dynamics between $\mathrm{SnI}_{2}$ and MAI. When using DMF as a solvent, for the same concentrations MASnI $_{3}$ will crystallize more rapidly than $\mathrm{MAPbI}_{3}$ while making perovskite films. This rapid crystallization gives rise to defects in perovskite films. To address this issue Kanatzidis and coworkers employed solvent engineering, where they used dimethyl sulfoxide (DMSO) because of its strongly coordinated nature, relatively high boiling point $\left(189^{\circ} \mathrm{C}\right)$ than $\mathrm{DMF}$ and a low saturated vapor pressure $\left(0.42\right.$ Torr at $\left.20^{\circ} \mathrm{C}\right)$ [47]. Two different perovskite films were prepared by using DMF and DMSO as solvents. The films prepared with DMF crystallized rapidly during spin coating resulting in a dark brown color. However, uniform and light yellow films were obtained during spin coating when DMSO was used as a solvent, which were then annealed at $100{ }^{\circ} \mathrm{C}$ for $15 \mathrm{~min}$ to obtain a black perovskite film.

These results were further confirmed by comparing the XRD patterns of both films before and after thermal annealing as shown in Figure 1. Annealing has no effect on the prepared films by using DMF as a solvent, as all the peaks corresponding to tetragonal $\mathrm{MASnI}_{3}$ phase in space group $\mathrm{P} 4 \mathrm{~mm}$, were observed before and after annealing. This confirms the films were crystallized before annealing and showed no change afterwards. While in films made with DMSO a totally different reflection pattern was observed before annealing, which corresponded to neither the starting materials nor expected perovskite films. The DMSO was known to form $\mathrm{MAPbI}_{3}$.DMSO complex when used for lead based perovskite films [48]. Hence it was assumed that this pattern correspond to a similar intermediate solvated phase. Careful investigations of XRD pattern of this solvated phase revealed the presence of $\mathrm{SnI}_{2}$.3DMSO, acting as a cation instead of $\mathrm{CH}_{3} \mathrm{NH}_{3}{ }^{+}$cation. Figure $1 \mathrm{c}$ shows the Fourier transform infrared spectroscopy (FTIR) spectra of $\mathrm{C}-\mathrm{S}$ and $\mathrm{S}-\mathrm{O}$ stretching vibrations from the $\mathrm{Sn}^{2+}$-coordinated DMSO solvent at 960 and $1012 \mathrm{~cm}^{-1}$, respectively. After annealing this phase disappeared and was converted to $\mathrm{MASnI}_{3}$. Compared to DMF, the DMSO as a solvent in perovskite films yielded much smoother, homogeneous and pin hole free perovskite films due to its controlled crystallization. Perovskite devices based on these films showed an overall PCE of $3.15 \%$, with extraordinary JSC of $21 \mathrm{~mA} \cdot \mathrm{cm}^{-2}$ and a moderate $\mathrm{V}_{\mathrm{OC}}$ of $320 \mathrm{mV}$.

In a similar attempt, Bein and coworkers proved the usefulness of 1,4-dioxane mixed with methanol as a solvent for preparing high quality, pin hole free $\mathrm{MASnI}_{3}$ perovskite films [49]. They choose a one-step spin coating route to prepare the perovskite films with precursors already dissolved in a mixture of $\mathrm{MeOH}$ :Dioxane. The perovskite was formed instantly after dropping the solution on spin coater because of the high vapor pressures of both $\mathrm{MeOH}$ and Dioxane. When compared with devices fabricated from DMF and DMSO as a solvent, device fabricated with $\mathrm{MeOH}$ :Dioxane mixture as a solvent yielded better photovoltaic results because of enhanced quality films and suppressed p-doping. An overall PCE of 1.05\% was recorded for device fabricated with MeOH:Dioxane mixture which was considerably higher than that of devices fabricated with DMF and DMSO as solvents. While this method addressed issues of defects in thin films high background carrier density was still a major factor limiting PCE.

To reduce high background carrier density Kanatzidis and group proposed a process of reducing vapor atmosphere while preparing Sn based perovskite devices [50]. An overall PCE of 3.89\% was achieved for $\mathrm{MASnI}_{3}$ based devices employing this technique. Perovskite layer was prepared by spin coating a solution of $\mathrm{MASnI}_{3}$ in the presence of hydrazine vapors. Hydrazine is a well-known reagent, which will reduce metal oxides and metal salts to pure metals. It is also used to reduce surrounding oxygen levels. The Sn perovskite films, when grown in the hydrazine atmosphere showed a reduction in $\mathrm{Sn}^{4+}$ impurities along with suppressing unfavorable reduction of $\mathrm{Sn}^{2+}$.

By reducing $\mathrm{Sn}^{4+}$ to $\mathrm{Sn}^{2+}, \mathrm{Sn}^{2+}$ vacancies are reduced, resulting in lowering p-type conductivity in perovskite films. Also the lower amount of $\mathrm{Sn}^{2+}$ vacancies resulted a decrease in anion antisite and cation antisite formation, further contributing to lowering of p-type self-doping [50]. Using this technique the $\mathrm{Sn}^{4+} / \mathrm{Sn}^{2+}$ ratio was reduced by $45.8 \%$ compared to the ratios without using hydrazine atmosphere. This work was a significant step towards high performing $\mathrm{MASnI}_{3}$ based devices, but stability remained a challenge. 

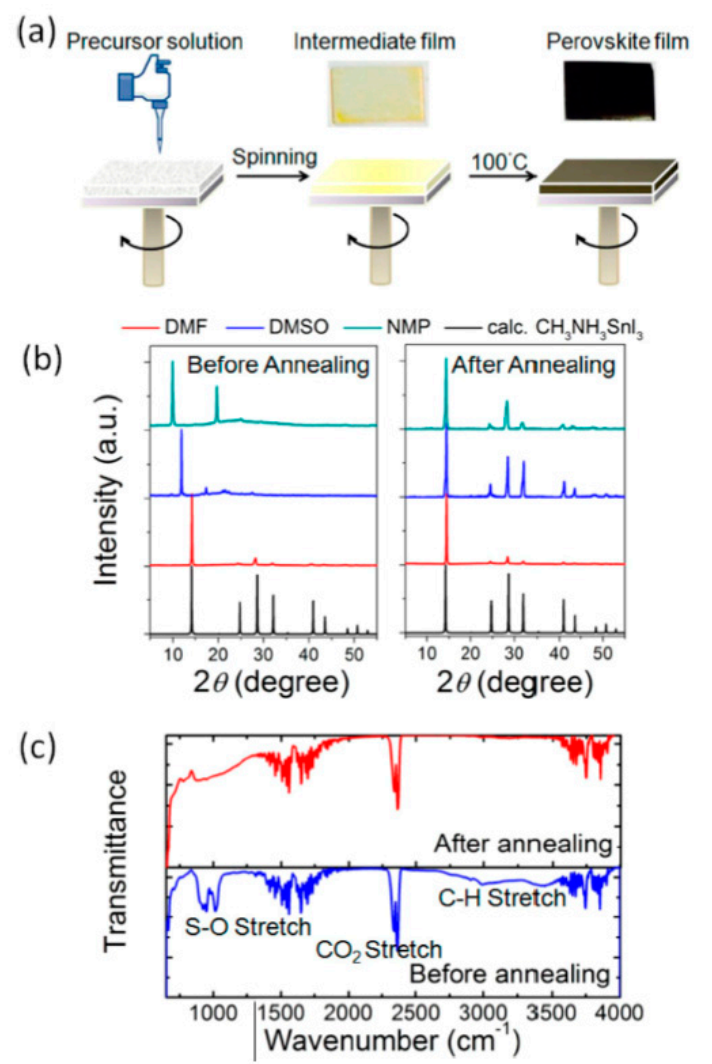

Figure 1. (a) Perovskite films prepared using DMSO as a solvent before and after annealing employing single step spin coating technique; (b) XRD patterns of the perovskite films using different solvents before (left) annealing and after (right) thermal treatment at $100{ }^{\circ} \mathrm{C}$ for $15 \mathrm{~min}$; (c) FTIR spectra of the perovskite films deposited from a solution of DMSO before (Bottom) and after annealing (Top). At $960 \mathrm{~cm}^{-1}$ the characteristic $\mathrm{C}-\mathrm{S}$ and at $1012 \mathrm{~cm}^{-1}, \mathrm{C}-\mathrm{O}$ stretching vibrations arising from $\mathrm{Sn}^{2+}$ - coordinated DMSO solvent can be seen before annealing. Adapted with permission from [45]. Copyright (C) 2015, American Chemical Society.

Kanatzidis and coworkers also suggested a low temperature vapor assisted solution process (LT-VASP) for minimizing p-type doping, reducing short circuiting and enhancing film quality for Sn based perovskites [51,52]. An overall PCE of $1.86 \%$ was reported for the best performing device. This method yielded better surface morphologies of perovskite films with great reproducibility and enhanced air stability. However, the first considerably stable $\mathrm{MASnI}_{3}$ based perovskite films were reported by Horn et al. [53], where they used a two-step fabricating technique. These films showed remarkable stability as compared to all the earlier reported $\mathrm{MASnI}_{3}$ films both in air and in nitrogen glove box. These stable perovskite films were obtained by depositing $\mathrm{SnI}_{2}$ on FTO substrates using thermal evaporation of $\mathrm{SnI}_{2}$ at a slow rate $\left(2 \mathrm{~nm} \min ^{-1}\right)$ in a vacuum. Followed by spin coating a solution of MAI in 2-propanol. Morphological studies as shown in Figure 2 revealed a higher coverage of substrate with perovskite crystals as compared to films synthesized using solution based processes.

Significant variations were observed in the sizes of perovskite crystals as the concentration of MAI solution changed. Few large crystals of 3-4 $\mu \mathrm{m}$ size were present, while rest of the substrate was covered by small 100-200 nm sized crystals when a $6 \mathrm{mg} \mathrm{mL}^{-1}$ solution of MAI was used. An increasing trend of crystal size was observed as concentration of MAI was increased however the crystal size again decreased for MAI solution with concentration of $40 \mathrm{mg} \mathrm{mL}^{-1}$ [53]. When exposed to air for an hour no visible change was observed in the color confirming the superior stability of these films with respect to films reported earlier. A 20 days old sample stored in nitrogen glove box showed no signs of degradation as no MAI or $\mathrm{SnI}_{2}$ were present in it. Furthermore, when illuminated for 
40 min along with exposure to air for $2 \mathrm{~h}$ these perovskite films retained $80 \%$ of their absorbance at $550 \mathrm{~nm}$ and no noticeable change in color was observed.

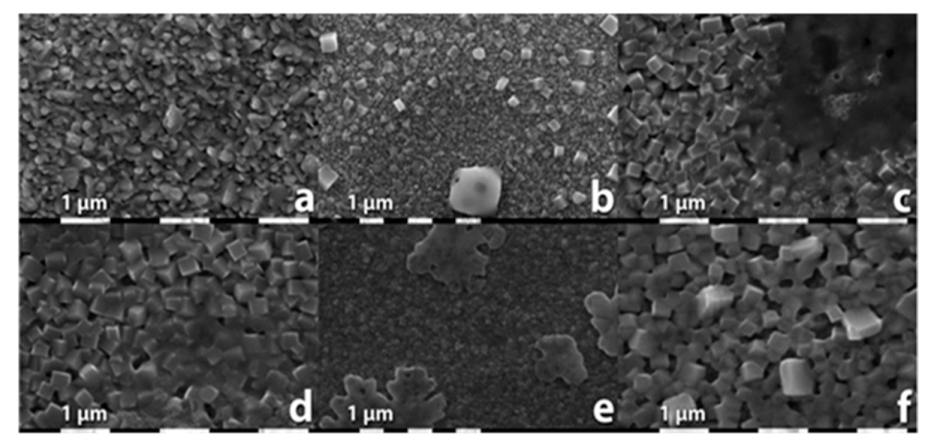

Figure 2. Images of different films as seen under SEM (a) Vapor-deposited $100 \mathrm{~nm}$ thick $\mathrm{SnI}_{2}$ film; (b) $\mathrm{MASnI}_{3}$ films prepared from a solution of $6 \mathrm{mg} \mathrm{mL}^{-1}$ using spin-coating technique (before annealing); (c) $10 \mathrm{mg} \mathrm{mL}^{-1}$; (d) $20 \mathrm{mg} \mathrm{mL}^{-1}$; (e) $40 \mathrm{mg} \mathrm{mL}^{-1} \mathrm{MAI}$ solutions; (f) and a MASnI 3 perovskite film prepared using $20 \mathrm{mg} \mathrm{mL}^{-1} \mathrm{MAI}$ followed by thermal treatment at $80^{\circ} \mathrm{C}$ for $10 \mathrm{~min}$. Adapted with permission from [53]. Copyright (C) 2015, WILEY-VCH Verlag GmbH \& Co. KGaA, Weinheim.

The stability of $\mathrm{MASnI}_{3}$ based devices was significantly increased by incorporating 5 -ammonium valeric acid iodide (5-AVAI) in $\mathrm{MASnI}_{3}$ films. Shigeeda et al., reported a very slow oxidation rate for MASnI $_{3}$ crystals when added with 5-AVAI [54]. When XRD patterns of films fabricated using just $\mathrm{MASnI}_{3}$ and films fabricated using $\mathrm{MASnI}_{3}$ : 5-AVAI was compared. It was observed that for pure $\mathrm{MASnI}_{3}$ films after $64.3 \mathrm{~h}$ half of the cubic phase has oxidized. Moreover most of the cubic phase is oxidized just after $88.5 \mathrm{~h}$. However, in the case of 5-AVAI: MASnI films (1:20) it took $113.5 \mathrm{~h}$ to oxidize half of the cubic phase, which was significant improvement in the device stability.

To further enhance the stability of $\mathrm{MASnI}_{3}$ based perovskite devices, Adachi and group reported a unique method of combining anti-solvents with miscibilities, which are different than that of the precursor solvent [55]. Using this technique they significantly improved the coverage of the perovskite films. An overall PCE of $2.14 \pm 0.35 \%$ was reported for planar perovskite solar cells prepared using these films. Morphology of perovskite film being a key player in deciding the overall performance of device, Adachi and coworkers controlled the crystallization of perovskite films using the SB method. In the SB method, anti-solvent bath was used to extract the good solvent in the precursor solution employing miscibility processes, where the miscibility between the solvents influences the extraction speed. By controlling the solvent extraction, growing of perovskite film is controlled. This method is also reported for $\mathrm{Pb}$ based perovskite solar cells and has been proved very effective in having smooth pin hole free perovskite films [56]. For MASnI 3 based perovskite devices the fabricated PSCs remained stable for over $200 \mathrm{~h}$ without degrading under standard 1 Sun illumination.

The stability of encapsulated devices based on $\mathrm{MASnI}_{3}$ reached $500 \mathrm{~h}$ when Yamada et al., used $\mathrm{SnF}_{2}$ incorporated $\mathrm{MASnI}_{3}$ perovskite films [57]. Hao et al., previously used $\mathrm{SnF}_{2}$ doping in $\mathrm{MASnI}_{3}$ films to increase carrier diffusion length up to $500 \mathrm{~nm}$ [58]. Yamada and group reported a bandgap of $1.25 \mathrm{eV}$ for $\mathrm{SnF}_{2}$ doped $\mathrm{MASnI}_{3}$ films, while films without $\mathrm{SnF}_{2}$ doping showed an absorption edge that was significantly blue shifted. This blue shifted absorption edge in pure $\mathrm{MASnI}_{3}$ films was assigned to unintentional p-type doping. $\mathrm{SnF}_{2}$ addition increased the photocarrier lifetime by one order of magnitude. These encapsulated devices showed a PCE of $1.94 \%$ with an astonishing stability of $500 \mathrm{~h}$ under 1 Sun illumination [57].

The real breakthrough for stable methylammonium tin hallide based devices was reported in 2017 by Mohanta et al. [59] where they synthesized methyammonium mixed tri-halide tin $\left(\mathrm{MASnIBr}_{2-\mathrm{x}} \mathrm{Cl}_{\mathrm{x}}\right)$ perovskites. Mohanta and group fabricated perovskite devices based on these films on a carbon based mesoscopic structure, making it free from both lead and hole transporting layer (HTM). Equimolar solution of MAI and $\mathrm{SnCl}_{2} / \mathrm{SnBr}_{2}$ were mixed in DMF. While keeping MAI at $100 \%$ the molar ratios 
of $\mathrm{SnCl}_{2} / \mathrm{SnBr}_{2}$ were varied from $0 / 100,10 / 90,25 / 75,50 / 50,75 / 25$ and 100/0 to vary $\mathrm{I} / \mathrm{Br} / \mathrm{Cl}$ ratios in perovskite films. The $\mathrm{Eg}=1.81 \mathrm{eV}$ along with spectral onset close to $700 \mathrm{~nm}$ was observed for films having $0 \% \mathrm{SnCl}_{2}\left(\mathrm{MASnIBr}_{2}\right)$. A blue shift was observed as the ratio of $\mathrm{SnCl}_{2}$ increased from 0 to $25 \%$, confirming the presence of $\mathrm{Cl}$ within $\mathrm{Sn}$ perovskite films. A significant red shift was observed when $\mathrm{SnCl}_{2} / \mathrm{SnBr}_{2}$ ratio was increased to $50 / 50$. Further increase in the ratios resulted in further red shift of absorption onset of perovskite films with the spectral edge touching $1000 \mathrm{~nm}$ for films made with $0 \% \mathrm{SnBr}_{2}$ and $100 \% \mathrm{SnCl}_{2}$ [59]. This technique resulted in having tin perovskite films with different proportions of halides such as $\mathrm{MASnIBr}_{2}, \mathrm{MASnIBr}_{1.5} \mathrm{Cl}_{0.5}$ and $\mathrm{MASnIBr}{ }_{1.8} \mathrm{Cl}_{0.2}$ producing PCE of $2.18 \%, 1.87 \%$ and $3.11 \%$ respectively. The best performance parameters were obtained for devices having MASnIBr ${ }_{1.8} \mathrm{Cl}_{0.2}$ as perovskite. A J $\mathrm{JSC}_{\mathrm{SC}}$ of $13.99 \mathrm{~mA} \cdot \mathrm{cm}^{-2}$ with a $\mathrm{V}_{\mathrm{OC}}$ of $380 \mathrm{mV}$ and a FF of 0.573 was recorded for this device. With a $3.11 \%$ PCE the encapsulated device remained stable for over 2000 $\mathrm{h}$ which is quite remarkable.

The highest efficiency reported till date for $\mathrm{MASnI}_{3}$ based PSCs is $7.78 \%$, achieved through ion exchange/insertion reactions approach [60]. Song and group employed a very unique strategy of using $\mathrm{SnF}_{2}$ and MAI as precursors for $\mathrm{MASnI}_{3}$ perovskite films through ion exchange/insertion reactions. This unique method resulted in the formation of a very high quality perovskite film, having large amount of $\mathrm{SnF}_{2}$ and very low concentration of $\mathrm{Sn}^{4+}$ [60]. The conversion steps are as follows:

$$
\begin{gathered}
\mathrm{SnF}_{2}+2 \mathrm{CH}_{3} \mathrm{NH}_{3} \mathrm{I} \rightarrow \mathrm{SnI}_{2}+2 \mathrm{CH}_{3} \mathrm{NH}_{3} \mathrm{~F} \\
\mathrm{CH}_{3} \mathrm{NH}_{3} \mathrm{~F} \rightarrow \mathrm{CH}_{3} \mathrm{NH}_{2} \uparrow+\mathrm{HF} \uparrow \\
\mathrm{SnI}_{2}+\mathrm{CH}_{3} \mathrm{NH}_{3} \mathrm{I} \rightarrow \mathrm{CH}_{3} \mathrm{NH}_{3} \mathrm{SnI}_{3}
\end{gathered}
$$

In the very first step of the perovskite film formation an ion exchange reaction took place between gaseous $\mathrm{CH}_{3} \mathrm{NH}_{3} \mathrm{I}$ and a solid state $\mathrm{SnF}_{2}$, generating the intermediate $\mathrm{SnI}_{2}$ and byproduct $\mathrm{CH}_{3} \mathrm{NH}_{3} \mathrm{~F}$. The byproduct is then removed via evaporation in the second step; while in the third step gaseous MAI reacted with $\mathrm{SnI}_{2}$ to form the perovskite. It was observed that as the time of ion exchange/insertion reaction was increased from $5 \mathrm{~min}$ to $40 \mathrm{~min}$ the size of $\mathrm{MASnI}_{3}$ crystals also increased forming a compact pinhole free perovskite film as shown in Figure 3. The perovskite films with excess $\mathrm{SnF}_{2}$ obtained through this method were used in planner heterojunction structure (ITO/PEDOT:PSS/MASnI $3 / \mathrm{PC}_{61} \mathrm{BM} / \mathrm{BCP} / \mathrm{Ag}$ ) PSCs. Champion device produced an overall PCE of $7.78 \%$ with a stability of over $200 \mathrm{~h}$ for un-encapsulated devices tested under continuous 1 Sun illumination in $\mathrm{N}_{2}$ atmosphere. Such a high efficiency with considerable stability is a very promising sign for the future of lead free perovskite devices. Table 1 summarizes the performance of best MA tin halide (s) based devices reported until 2020. Table 2 summarizes how the stability for MA tin based perovskite has shown increasing trend over the last few years.

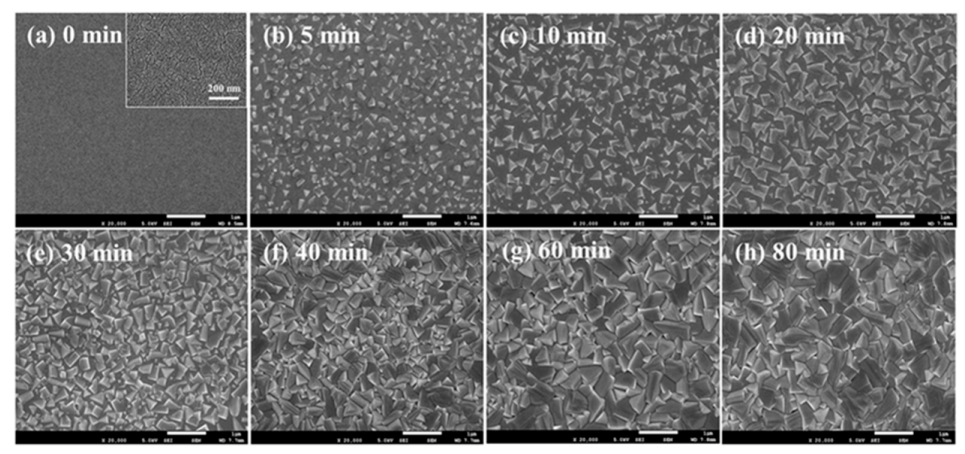

Figure 3. Surface SEM images of (a) pristine $\mathrm{SnF}_{2} / \mathrm{PEDOT}$ :PSS film, and treated by the ion exchange/ insertion reaction for; (b) $5 \mathrm{~min}$; (c) $10 \mathrm{~min}$; (d) $20 \mathrm{~min}$; (e) $30 \mathrm{~min}$; (f) $40 \mathrm{~min}$; (g) $60 \mathrm{~min}$; (h) $80 \mathrm{~min}$. Adapted with permission from [60]. Copyright (C) 2020 The Authors. Published by WILEY-VCH Verlag $\mathrm{GmbH} \& \mathrm{Co}$. KGaA, Weinheim. 
Table 1. Performance of best MA tin halide (s) based devices reported until 2020.

\begin{tabular}{|c|c|c|c|c|c|c|c|}
\hline Year & Device Architecture & $\begin{array}{l}\text { Perovskite Film Fabrication } \\
\text { Technique/PEROVSKITE Film }\end{array}$ & $\begin{array}{c}\mathrm{JSC}_{\mathrm{SC}} \\
\left(\mathrm{mA} \cdot \mathrm{cm}^{-2}\right)\end{array}$ & $\begin{array}{l}\mathrm{V}_{\mathrm{OC}} \\
(\mathrm{V})\end{array}$ & FF & $\begin{array}{l}\text { EFF } \\
(\%)\end{array}$ & Ref. \\
\hline 2014 & 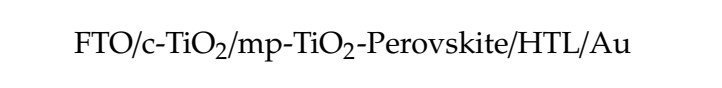 & $\begin{array}{l}\text { Spin Coating using DMF as } \\
\text { solvent/MASnI } 3\end{array}$ & 16.8 & 0.88 & 0.42 & 6.4 & [42] \\
\hline 2014 & 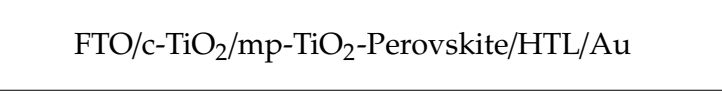 & $\begin{array}{l}\text { Spin Coating using DMF as } \\
\text { solvent/MASnI } I_{3-x} B_{x}\end{array}$ & 12.3 & 0.82 & 0.57 & 5.73 & [44] \\
\hline 2015 & $\mathrm{FTO} / \mathrm{c}-\mathrm{TiO}_{2} / \mathrm{mp}^{-\mathrm{TiO}_{2}}$-Perovskite/Au & $\begin{array}{c}\text { Spin Coating } \\
+ \text { Annealing using DMSO as } \\
\text { solvent/MASnI }_{3}\end{array}$ & 21.4 & 0.32 & 0.46 & 3.15 & [45] \\
\hline 2016 & $\mathrm{FTO} / \mathrm{c}-\mathrm{TiO}_{2} / \mathrm{mp}^{-\mathrm{TiO}_{2}}$-Perovskite/Au & LT-VASP/ $\mathrm{MASnI}_{3}$ & 17.8 & 0.273 & 0.39 & 1.86 & [51] \\
\hline 2016 & ITO/PEDOT:PSS/Poly-TPD/MASnI $/ \mathrm{C}_{60} / \mathrm{BCP} / \mathrm{Ag}$ & Thermal evaporation/MASnI 3 & 12.1 & 0.377 & 0.366 & 1.7 & [61] \\
\hline 2017 & ITO/PEDOT:PSS/MASnI $3 / \mathrm{C}_{60} / \mathrm{BCP} / \mathrm{Ag}$ & $\begin{array}{l}\text { SB Method using DMSO as } \\
\text { solvent/MASnI } 3: \mathrm{SnF}_{2}\end{array}$ & $11.82 \pm 1.20$ & $0.45 \pm 0.01$ & $0.40 \pm 0.03$ & $2.14 \pm 0.35$ & [55] \\
\hline 2017 & $\begin{array}{c}\mathrm{FTO} / \mathrm{c}-\mathrm{TiO}_{2} / \mathrm{mp}-\mathrm{TiO}_{2} \text {-perovskite/perovskite } \\
\text { capping layer/PTAA/Au }\end{array}$ & $\begin{array}{c}\text { Spin Coating in Hydrazine } \\
\text { environment using DMSO as } \\
\text { Solvent/MASnI } \\
\text {. }\end{array}$ & 19.92 & 0.377 & 0.517 & 3.89 & [50] \\
\hline 2017 & $\mathrm{FTO} / \mathrm{c}-\mathrm{TiO}_{2} / \mathrm{mp}$ - $\mathrm{TiO}_{2}$-perovskite/ PTAA/Au & $\begin{array}{c}\text { Spin Coating } \\
+ \text { Annealing using DMSO as } \\
\text { solvent/MASnI } 3: \mathrm{SnF}_{2}\end{array}$ & 26.1 & 0.25 & 0.30 & 1.94 & [57] \\
\hline 2017 & $\mathrm{FTO} / \mathrm{c}-\mathrm{TiO}_{2} / \mathrm{mp}-\mathrm{TiO}_{2}$-perovskite/ $\mathrm{Al}_{2} \mathrm{O}_{3}$-Perovskite/C & $\begin{array}{l}\text { Spin Coating using DMF as } \\
\text { solvent/MASnIBr }{ }_{2-\mathrm{x}} \mathrm{Cl}_{\mathrm{x}}\end{array}$ & 13.99 & 0.38 & 0.573 & 3.11 & [59] \\
\hline 2020 & $\begin{array}{l}\text { ITO/PEDOT:PSS/MASnI } / \\
\text { PC }_{61} \text { BM/BCP/Ag }\end{array}$ & $\begin{array}{l}\text { Ion exchange/insertion } \\
\text { reactions/MASnI } \\
\end{array}$ & 20.68 & 0.57 & 0.66 & 7.78 & [60] \\
\hline 2020 & ITO/PEDOT:PSS/Perovskite/PCBM/PEI/Ag & $\begin{array}{l}\text { Spin Coating in Nitrogen } \\
\text { environment/MASnI }\end{array}$ & 12.47 & 0.57 & 0.44 & 3.13 & [62] \\
\hline
\end{tabular}


Table 2. Stability of MA tin halide(s) based perovskites.

\begin{tabular}{|c|c|c|c|c|}
\hline Year & Device Architecture & Testing Environment & Stability & Ref. \\
\hline 2014 & $\mathrm{FTO} / \mathrm{c}-\mathrm{TiO}_{2} / \mathrm{mp}-\mathrm{TiO}_{2}-\mathrm{MASnI}_{3-\mathrm{x}} \mathrm{Br}_{\mathrm{x}} / \mathrm{HTL} / \mathrm{Au}$ & $\begin{array}{l}\text { Devices were stored in nitrogen } \\
\text { glove box and were sealed with } \\
\text { Surlyn films }\end{array}$ & $\begin{array}{l}\text { Retained almost } 80 \% \text { of initial } \\
\text { performance for } 12 \mathrm{~h}\end{array}$ & [44] \\
\hline 2016 & $\begin{array}{l}\text { Two step process of vapor deposition }+ \text { solution } \\
\text { based technique to obtain } \mathrm{CH}_{3} \mathrm{NH}_{3} \mathrm{SnI}_{2} \text { films }\end{array}$ & $\begin{array}{l}\text { Exposed to air and continuous } \\
\text { illumination }\end{array}$ & $\begin{array}{l}\text { Films retained almost } 80 \% \text { of } \\
\text { their initial absorbance for } 2 \mathrm{~h}\end{array}$ & [53] \\
\hline 2016 & 5-AVAI:MASnI ${ }_{3}$ films (1:20) & Exposed to air & $113.5 \mathrm{~h}$ & [54] \\
\hline 2017 & $\begin{array}{l}\text { ITO/PEDOT:PSS/MASnI } 3 / \\
\text { C } 60_{60} / \mathrm{BCP} / \mathrm{Ag}\end{array}$ & Under 1 Sun illumination & $\begin{array}{l}\text { Devices retained } 50 \% \text { of their } \\
\text { initial efficiencies for } 200 \mathrm{~h}\end{array}$ & [55] \\
\hline 2017 & $\mathrm{FTO} / \mathrm{c}-\mathrm{TiO}_{2} / \mathrm{mp}-\mathrm{TiO}_{2}-\mathrm{MASnI}_{3}: \mathrm{SnF}_{2} / \mathrm{PTAA} / \mathrm{Au}$ & $\begin{array}{c}\text { Encapsulated devices were kept } \\
\text { under } 1 \text { Sun illumination in } \\
\text { ambient conditions, }\end{array}$ & Devices were stable for $500 \mathrm{~h}$ & [57] \\
\hline 2017 & 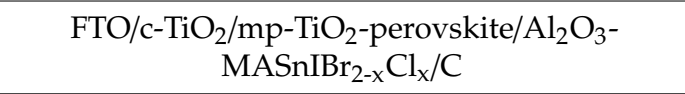 & $\begin{array}{l}\text { Encapsulated devices while } \\
\text { being stored }\end{array}$ & $\begin{array}{l}\text { Retained } 90 \% \text { of their } \\
\text { efficiencies for } 2000 \mathrm{~h}\end{array}$ & [59] \\
\hline 2020 & $\begin{array}{l}\text { ITO/PEDOT:PSS/MASnI } / \\
\quad \text { PC }_{61} \mathrm{BM} / \mathrm{BCP} / \mathrm{Ag}\end{array}$ & $\begin{array}{l}\text { Un-encapsulated device under } \\
\text { continuous } 1 \text { Sun illumination } \\
\text { in inert environment }\end{array}$ & $\begin{array}{l}\text { Retained almost } 70 \% \text { of initial } \\
\text { performance for } 200 \mathrm{~h}\end{array}$ & {$[60]$} \\
\hline
\end{tabular}


Although, the MA based lead free perovskite devices produced some excellent efficiencies with considerable stability, the lack of control over p-doping has made it very difficult to have high level of reproducibility. Theoretical calculations performed on MA tin based perovskites confirmed that perovskite with MA are more likely to be oxidized than that of perovskites having $\mathrm{NH}_{2} \mathrm{CH}_{3} \mathrm{NH}_{2}{ }^{+}$ (FA) as cation [63]. The MA has smaller ionic sizes compared to FA, resulting in a strong antibonding coupling between Sn-s I-p, which consequently results in very high hole densities [64]. In order to have high efficiencies with excellent stability and reproducibility it is therefore necessary to explore other options instead of MA as a cation in lead free perovskite solar cells [62].

\section{Formamidinium Tin Halides ( $\mathrm{FASn} \mathrm{X}_{3}, \mathrm{X}=\mathrm{I}, \mathrm{Br}, \mathrm{Cl}$ )}

The $\mathrm{MAPbI}_{3}$ was known to undergo a phase transition at $56^{\circ} \mathrm{C}$, changing its shape from tetragonal to cubic [65]. However, when MA was replaced by $\mathrm{NH}_{2} \mathrm{CH}_{3} \mathrm{NH}_{2}{ }^{+}$(FA), the resulting perovskite $\mathrm{FAPbI}_{3}$, does not show any phase transition until $150^{\circ} \mathrm{C}$. This enhancement of stability can be attributed to a comparatively rigid perovskite structure resulted from enhanced $\mathrm{H}$ bonding between organic cation and inorganic matrix [66]. Expecting the same for Sn perovskites, the very first work on formamidinium based tin perovskite was reported by Krishnamoorthy et al. [67] in 2015. An energy band gap of $1.41 \mathrm{eV}$, with a red shifted absorption onset $(880 \mathrm{~nm})$ compared to $\mathrm{FAPbI}_{3}$ was observed for $\mathrm{FASnI}_{3}$ perovskites. When left overnight, the color of pure $\mathrm{FASnI}_{3}$ solution changed from yellow to orange. To solve this issue $\mathrm{SnF}_{2}$ was added to the pure $\mathrm{FASnI}_{3}$ solution in different molar ratios. Addition of $\mathrm{SnF}_{2}$ not only increased the stability but also short circuit current of perovskite devices. The best $\mathrm{FASnI}_{3}$ perovskite films were realized with films having $20 \mathrm{~mol} \% \mathrm{SnF}_{2}$.

Perovskite devices fabricated with these films produced $\mathrm{J}_{\mathrm{sc}}$ of $12.4 \mathrm{~mA} \cdot \mathrm{cm}^{-2}, \mathrm{~V}_{\mathrm{oc}}$ of $262 \mathrm{mV}, \mathrm{FF}$ of 0.44 and overall PCE of $1.41 \%$. To increase the JSC of FASnI 3 based PSCs Koh and group increased the thickness of mesoporous $\mathrm{TiO}_{2}$ from $350 \mathrm{~nm}$ to $500 \mathrm{~nm}$ [67]. This significantly reduced charge carrier recombinations inside the active material by providing more charge transfer sites. For the best performing device with $500 \mathrm{~nm}$ thick mesoporous $\mathrm{TiO}_{2}$ layer, a short circuit current density of $24.45 \mathrm{~mA} \cdot \mathrm{cm}^{-2}$ was reported with a $\mathrm{V}_{\mathrm{OC}}$ of $238 \mathrm{mV}$, fill factor of 0.36 and PCE of $2.10 \%$ respectively [67]. This pioneering work on $\mathrm{FASnI}_{3}$ based perovskite provided a solid reason to explore and further optimize the performance of these devices for environment friendly and stable tin based PSCs. The real push towards a stable and highly efficient FA based tin halide perovskite came from Shin et al. [68] in 2016, when they fabricated a 100 day stable encapsulated perovskite device with a PCE of $4.8 \%$ using $\mathrm{SnF}_{2}$-Pyrazine complex. To achieve this outstanding performance Shin and group deposited the perovskite film using both non solvent dripping process and solvent engineering technique [68].

They demonstrated that $\mathrm{SnF}_{2}$ incorporated perovskite films made with only DMF as a solvent showed a very poor surface coverage and morphology (Figure 4a). The results were the same even for non-solvent dripping process (Figure $4 \mathrm{~b}$ ). But when solvent engineering was applied and films were grown from a mixture of DMF and DMSO in 4:1 volume respectively, a very smooth and uniform film was obtained (Figure 4c). However excess $\mathrm{SnF}_{2}$ in the $\mathrm{FASnI}_{3}$ films caused aggregation on top of film and few plate like aggregates were found on surface. These aggregates disappeared when pyrazine was also introduced along with DMF and DMSO in the solvent mixture (Figure 4d). This proved that pyrazine significantly improved the surface morphology by separation of phases induced by excess $\mathrm{SnF}_{2}$. The surface of films prepared with $\mathrm{SnF}_{2}$ addition oxidized $100 \%$ in air during fabrication process. However, $\mathrm{Sn}^{4+}$ content decreased in underneath layers. When pyrazine was added to films the oxidation decreased by $4-15 \%$ in each layer. When PSCs were fabricated using these optimized perovskite films a JSC of $23.7 \mathrm{~mA} \cdot \mathrm{cm}^{-2}, \mathrm{~V}_{\mathrm{OC}}$ of $320 \mathrm{mV}$, FF of 0.63 and PCE of $4.8 \%$ was recorded for the best performing device. These devices showed exceptional reproducibility and long term stability of 100 days in ambient conditions when encapsulated [68].

In addition to the same concept of solvent engineering and $\mathrm{SnF}_{2}$ addition Zhao and group [69] modified perovskite formation by addition of diethyl ether dripping. This modification allowed them to achieve uniform provskite films with full surface coverage. The conventional n-i-p structure was also 
replaced by p-i-n inverted architecture (ITO/PEDOT:PSS/FASnI $3 / \mathrm{C}_{60} / \mathrm{BCP} / \mathrm{Ag}$ ) to avoid using salt-doped hole selective layers (HSLs), known to damage $\mathrm{FASnI}_{3}$ perovskite [51,70]. Anti-solvent dripping is reported to enhance the quality of perovskite films [48] with toluene and chlorobenzene being the most popular choices. However, Zhao and group [69] observed that while using chlorobenzene or toluene to prepare $\mathrm{FASnI}_{3}$ layers pin holes emerged in the surface of films because of rapid crystallization, reducing the quality of perovskites. When diethyl ether was used instead of chrolobenzene and toluene a comparatively slow crystallization rate was observed resulting in a pin hole free and smooth surface.

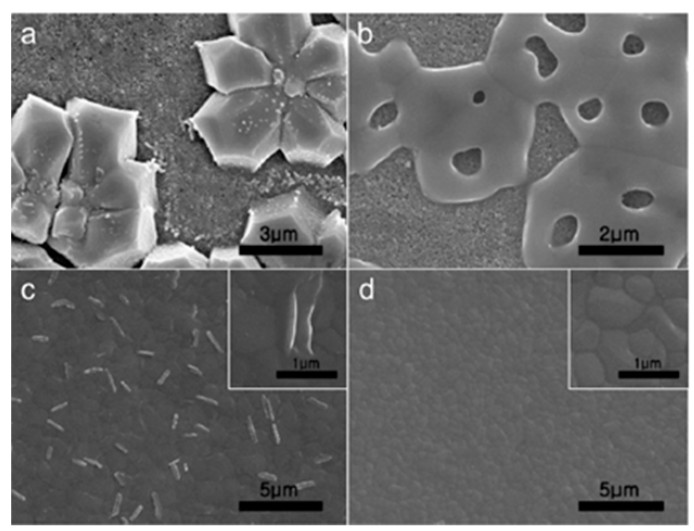

Figure 4. Images of $\mathrm{FASnI}_{3}$ perovskite films produced using DMF as a solvent as seen under SEM; (a) without any nonsolvent dripping treatment; (b) with nonsolvent dripping. Images of $\mathrm{FASnI}_{3}$ perovskite films produced using mixture of DMF and DMSO as solvent with nonsolvent dripping; (c) in the absence of pyrazine and (d) in the presence of pyrazine. Adapted with permission from [68]. Copyright (C) 2016, American Chemical Society.

A cross sectional view of inverted p-i-n PSC fabricated using these pin hole free, high quality $\mathrm{FASnI}_{3}$ perovskites as seen under SEM is shown in Figure 5a. Where $\mathrm{C}_{60}$ and PEDOT:PSS acts as ESL and HSL respectively. The conduction band (CB) minima of $\mathrm{FASnI}_{3}$ is well matched with the lowest unoccupied molecular orbital (LUMO) of $\mathrm{C}_{60}$ facilitating effective transfer of generated electrons from perovskite to $\mathrm{Ag}$. The holes were blocked as the $\mathrm{FASnI}_{3}$ has a valence band (VB) maxima above the highest occupied molecular orbital (HOMO) of $\mathrm{C}_{60}$ resulting in suppressing charge carrier recombination's at the interface. The best device provided a PCE of $6.22 \%$ with $\mathrm{JSC}_{\mathrm{SC}}$ of $22.07 \mathrm{~mA} \cdot \mathrm{cm}^{-2}$, $\mathrm{V}_{\mathrm{OC}}$ of $465 \mathrm{mV}$ and $\mathrm{FF}$ of $60.67 \%$ under forward scan. A very small J-V hysteresis was observed due to invert device architecture. These fabricated devices showed good stability as a cell with PCE of $5.80 \%$ had only $5.86 \%$ decrease in performance even after $45 \mathrm{~min}$. When kept in dark and inert environment devices were stable for 30 days. Zeng et al. [71] also used a similar approach with additional mixing of poly $(\alpha$-methylstyrene) (PAMS) in diethyl ether dripping.
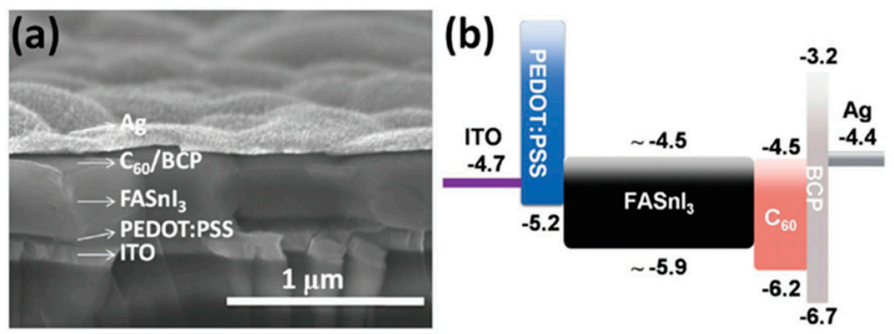

Figure 5. (a) A cross-sectional view of the fabricated device having $10 \mathrm{~mol} \% \mathrm{SnF}_{2}$ additives as seen under SEM; (b) Energy level diagram. Adapted with permission from [69]. Copyright (C) 2016, WILEY-VCH Verlag GmbH \& Co. KGaA, Weinheim. 
In an attempt to improve the PCE of $\mathrm{FASnI}_{3}$ based devices Kanatzidis and group suggested a thin layer of $\mathrm{ZnS}$ to be coated on top of mesoporous $\mathrm{TiO}_{2}$ [72]. This cascade structure significantly reduced the interfacial recombination and enhanced the electron transfer capability. The best cell provided a PCE of $5.27 \%$ with $\mathrm{V}_{\mathrm{OC}}$ of $380 \mathrm{mV}$, a short circuit current density of $23.09 \mathrm{~mA} \cdot \mathrm{cm}^{-2}$ and a FF of $60.01 \%$. Kanatzidis and coworkers also fabricated a flexible $\mathrm{FASnI}_{3}$ based perovskite with a PCE of $3.12 \%$ employing multichannel inter diffusion technique [73]. Perovskite films were prepared by spin coating mixture of FAI and PEDOT:PSS followed by annealing. $\mathrm{SnI}_{2}$ film was then evaporated to have high quality, homogeneous $\mathrm{FASnI}_{3}$ films. This fabrication technique allowed them to have a flexible PSC paving the way for commercializing of Sn based PSCs.

In the quest of achieving high PCE and considerable stability for lead free FA based tin PSCs Chueh et al. [74] used sequential deposition route. To form defect free homogeneous $\mathrm{FASnI}_{3}$ films the reaction rate between $\mathrm{FAI}$ and $\mathrm{SnI}_{2}$ was controlled. In the first step of deposition tri-methylamine (TMA) was incorporated in Sn solution to form $\mathrm{SnY}_{2}$-TMA $\left(\mathrm{Y}=\mathrm{I}^{-}, \mathrm{F}^{-}\right)$complexes [75] followed by intercalating with FAI to produce $\mathrm{FASnI}_{3}$. This method allowed Jen and group to realize PCE of $4.34 \%$ and $7.09 \%$ for conventional n-i-p and inverted p-i-n PSCs, respectively [74]. When tested for stability the inverted device comparatively showed better stability than conventional device. In ambient air with $50 \%$ relative humidity the un-encapsulated devices degraded within the first $24 \mathrm{~h}$. However, when stored in inert environment both devices retained more than $80 \%$ of their performance for 20 days. Figure 6 relates the PCE of devices with respect to storage time in different environments.
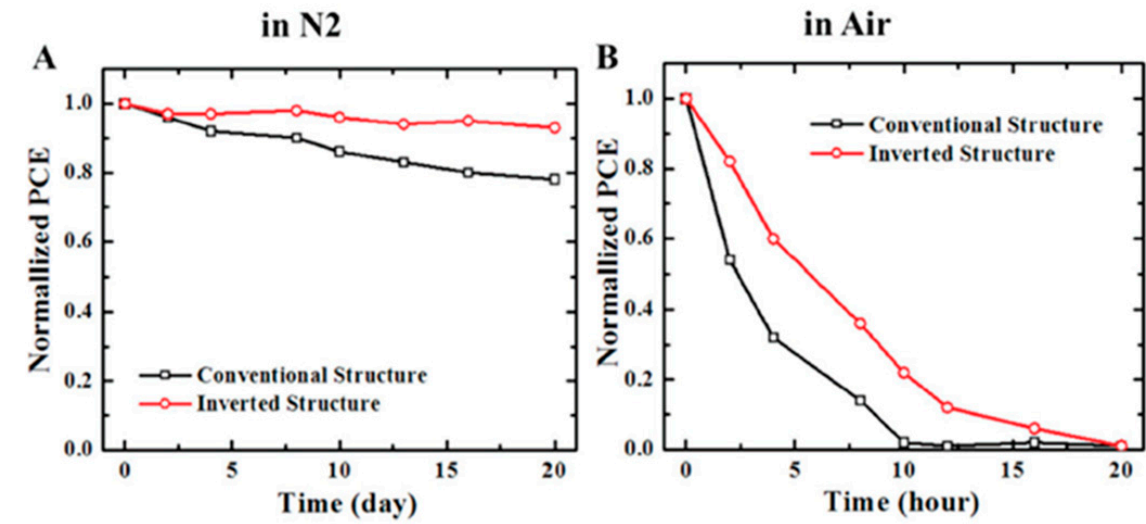

Figure 6. Room temperature stability tests of PSCs both in n-i-p and p-i-n architectures based on FASnI $_{3}+\mathrm{SnF}_{2}+\mathrm{TMA}$ : (A) stored in $\mathrm{N}_{2}$ environment and (B) stored in ambient condition ( $50 \%$ relative humidity). Adapted with permission from [74]. Copyright (C) 2017, WILEY-VCH Verlag GmbH \& Co. KGaA, Weinheim.

As tin based perovskite is relatively new compared to $\mathrm{Pb}$ based perovskites, so many techniques that have already been proved useful for $\mathrm{Pb}$ based perovskties were applied to its $\mathrm{Sn}$ counterparts. It was well established with $\mathrm{Pb}$ perovskite lattice that introduction of $\mathrm{Br}$ atom in perovskite structure changed the shape from tetragonal to cubic. It also affected band gap and significantly improved the stability of these PSCs [76,77]. To enhance the stability of FASn halide based perovskite devices Lyu et al. [78] applied band gap engineering method to fabricate a considerably stable $\mathrm{FASnI}_{2} \mathrm{Br}$ perovskite with a band gap of $1.68 \mathrm{eV}$. When devices were fabricated from these perovskite films employing p-i-n architecture and with $\mathrm{C}_{60}$ as electron transport layer (ETL), a maximum PCE of $1.72 \%$ was recorded. When PCBM was used as ETL the efficiency dropped to $1.43 \%$ mainly because of a lower $\mathrm{V}_{\mathrm{OC}}$. However, the stability of un-encapsulated devices in nitrogen glove box increased from few hours to $30 \mathrm{~h}$. This stability although is not enough, but the fact that it was recorded for un-encapsulated devices make it appealing. Applying proper encapsulation it can be significantly enhanced.

Using the same idea Shin et al. [79] incorporated $\mathrm{Br}$ atoms in $\mathrm{FASnI}_{3}$ perovskite structure. The doping concentration of bromine was kept from 0 to $33 \mathrm{~mol} \%$. To investigate the effect of bromine 
addition in crystal structure of $\mathrm{FASnI}_{3}$ perovskites, films with and without bromine addition were prepared and their absorption spectra was measured for about $100 \mathrm{~h}$ while being exposed to air. The absorption of pure $\mathrm{FASnI}_{3}$ films at $500 \mathrm{~nm}$ reduced to almost zero when exposed to air for 100 $\mathrm{h}$ while films with bromine maintained almost $40 \%$ of its initial absorption for the same time when tested under same conditions. This experiment further verified notion that addition of bromine not only shifts the band gap but also decrease $\mathrm{Sn}^{2+}$ oxidation, making films more stable in air.

The $\mathrm{C}-\mathrm{V}$ measurements revealed that films produced with $25 \mathrm{~mol} \% \mathrm{Br}$ doped $\mathrm{FASnI}_{3}$ have 3 order of magnitude less carrier density compared to film produced without any $\mathrm{Br}$ doping. This significant decrease of carrier density proved the initial assumption of $\mathrm{Br}$ doping reducing $\mathrm{Sn}^{2+}$ oxidation. A maximum PCE of $5.5 \%$ was obtained for $\mathrm{Br}$ doped device with a JSC of $19.8 \mathrm{~mA} \cdot \mathrm{cm}^{-2}, \mathrm{~V}_{\mathrm{OC}}$ of $0.414 \mathrm{~V}$ and FF of $66.9 \%$. When encapsulated these devices showed outstanding stability in ambient air, by retaining almost $100 \%$ of their initial performance for $600 \mathrm{~h}$ under continuous 1 Sun irradiation. Even after $1000 \mathrm{~h}$ only $17 \%$ reduction in the initial performance was observed for these remarkably stable $\mathrm{Br}$ doped $\mathrm{FASnI}_{3}$ based PSCs. This considerably high efficiency along with remarkable stability was a great step towards lead free perovskite solar cells.

To further improve the PCE of FASnI 3 based devices Bian and group came up with a low cost solution of tin source purification [80]. Any commercial $\mathrm{SnX} \mathrm{X}_{2}$ source contains $\mathrm{Sn}^{4+}$, even those with $99 \%$ purity contain a significant concentration of oxidized $\mathrm{Sn}^{4+}$ resulting in poor performance and reproducibility issues. To solve this, Bian and coworkers added $\mathrm{Sn}$ powder to $\mathrm{SnI}_{2}$. Tin powder reacts with $\mathrm{Sn}^{4+}$ and reduce it to $\mathrm{Sn}^{2+}$ state $\left(\mathrm{Sn}^{4+}+\mathrm{Sn}>>>>2 \mathrm{Sn}^{2+}\right)$ [80]. A maximum PCE of $6.75 \%$ was achieved for inverted $\mathrm{p}-\mathrm{i}-\mathrm{n}$ architecture when annealing temperature and reaction time was optimized. However, the real breakthrough for record efficiency in $\mathrm{FASnI}_{3}$ based devices was achieved in 2019 when Wu et al. [81] reported a 10.1\% efficient device. To obtain a pin hole free film and control the grain boundaries $\mathrm{Wu}$ et al. [81] introduced $\pi$-conjugated Lewis base molecules during crystallization of $\mathrm{FASnI}_{3}$ perovskite films.

The precursor solution for the films were prepared mixing $0.1 \%-1 \%$ in molar ratio, 2-cyano-3-[5-[4-(diphenylamino)phenyl]-2-thienyl]-propenoicacid (CDTA) in DMSO. During film fabrication this additive formed a stable intermediate phase and optimized the crystallization process of perovskite film by significantly slowing down the crystal formation. This method resulted in pin hole free and smooth $\mathrm{FASnI}_{3}$ perovskite films with a larger carrier lifetime of $3.87 \mathrm{~ns}$ compared to pristine $\mathrm{FASnI}_{3}$ film with a carrier lifetime of 2.09 ns. Perovskite devices were fabricated using these films employing ITO/PEDOT:PSS/FASnI $3 / \mathrm{C}_{60} / \mathrm{BCP} / \mathrm{Ag}$ architecture. The champion device with an active area of $0.09 \mathrm{~cm}^{2}$ yielded record efficiency of $10.17 \%$ when $0.2 \%$ molar ratio of CDTA was used. The CDTA treatment of the perovskite films enhanced the $\mathrm{V}_{\mathrm{OC}}$ to $0.63 \mathrm{~V}$ and FF to $74.7 \%$. When tested for stability, the encapsulated device retained $90 \%$ of its initial performance even after $1000 \mathrm{~h}$ under continuous light soaking.

Recently Chen et al. [82] introduced [poly(ethylene-co-vinyl acetate) a unique polymer, as anti-solvent during spin coating $\mathrm{FASnI}_{3}$ perovskite film. The $\mathrm{C}=\mathrm{O}$ groups present in EVA had a very strong Lewis acid-base complexation with the uncoordinated tin atoms present in the perovskite film. This resulted in a considerably improved grain size, optimized orientation and significant decrease in surface defects of perovskite films. PSCs fabricated by this method gave a PCE of $7.72 \%$, incorporating self-encapsulation properties. When tested for stability the un-encapsulated devices retained almost $62.4 \%$ of their initial efficiency even after $48 \mathrm{hr}$ storage in ambient conditions with $60 \%$ relative humidity [82]. Such high efficiency along with self-encapsulation properties is a promising sign for future of highly efficient and stable lead free perovskite solar cells. Table 3 summarizes the performance of best FA tin halide (s) based devices reported until 2020 while, Table 4 includes the stability profiles of FA tin halide (s) reported until 2020. 
Table 3. Performance of best FA tin halide (s) based devices reported until 2020

\begin{tabular}{|c|c|c|c|c|c|c|c|}
\hline Year & Device Architecture & $\begin{array}{l}\text { Perovskite Film Fabrication } \\
\text { Technique/Perovskite Film }\end{array}$ & $\begin{array}{c}\mathrm{JSC} \\
\left(\mathrm{mA} \cdot \mathrm{cm}^{-2}\right)\end{array}$ & $\begin{array}{l}\mathrm{V}_{\mathrm{OC}} \\
\text { (V) }\end{array}$ & FF & $\begin{array}{l}\mathrm{EFF} \\
(\%)\end{array}$ & Ref. \\
\hline 2015 & $\mathrm{FTO} / \mathrm{c}-\mathrm{TiO}_{2} / \mathrm{mp}-\mathrm{TiO}_{2}$-Perovskite/spiro-OMeTAD/Au & Spin Coating + Annealing/FASnI $3+\mathrm{SnF}_{2}$ & 24.45 & 0.238 & 0.36 & 2.10 & [67] \\
\hline 2016 & ITO/PEDOT:PSS/Perovskite/C $60 / \mathrm{Ca} / \mathrm{Al}$ & $\begin{array}{l}\text { Spin Coating using DMF as solvent }+ \text { chlorobenzene } \\
\text { dripping }+ \text { Annealing/FASnI }{ }_{2} \mathrm{Br} \\
\end{array}$ & 6.82 & 0.467 & 0.543 & 1.72 & [78] \\
\hline 2016 & 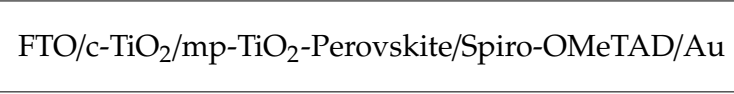 & $\begin{array}{l}\text { Spin Coating using DMF+DMSO as solvent }+ \\
\text { Annealing/FASnI }{ }_{3}+\mathrm{SnF}_{2}+\text { Pyrazine }\end{array}$ & 23.7 & 0.32 & 0.63 & 4.8 & [68] \\
\hline 2016 & ITO/PEDOT:PSS/Perovskite/C $60 / \mathrm{BCP} / \mathrm{Ag}$ & $\begin{array}{l}\text { Spin Coating using DMF+DMSO as solvent }+ \text { diethyl } \\
\text { ether dripping }+ \text { Annealing/FASnI } 3+\mathrm{SnF}_{2}\end{array}$ & 22.07 & 0.465 & 0.606 & 6.22 & [69] \\
\hline 2016 & $\mathrm{FTO} / \mathrm{c}-\mathrm{TiO}_{2} / \mathrm{mp}-\mathrm{TiO}_{2}-\mathrm{ZnS}$-Perovskite/PTAA/Au & $\begin{array}{c}\text { Spin Coating using DMF+DMSO as solvent }+ \text { diethyl } \\
\text { ether dripping + Annealing/FASnI } 3+\mathrm{SnF}_{2}\end{array}$ & 23.09 & 0.380 & 0.601 & 5.27 & {$[72]$} \\
\hline 2017 & ITO/PEDOT:PSS/PP-Perovskite/C 60 / BCP/Ag & $\begin{array}{c}\text { Spin Coating FAI:PEDOT:PSS using water as solvent + } \\
\text { Annealing + Evaporation of } \mathrm{SnI}_{2} / \mathrm{FASnI}_{3}\end{array}$ & 17.78 & 0.33 & 0.679 & 3.98 & [73] \\
\hline 2017 & $\mathrm{FTO} / \mathrm{c}-\mathrm{TiO}_{2} / \mathrm{mp}-\mathrm{TiO}_{2}$-Perovskite /spiro-OMeTAD/Au & $\begin{array}{c}\text { Spin Coating using DMF+DMSO as } \\
\text { solvent/FASnI } \mathrm{Fr}_{3-\mathrm{x}} \mathrm{Br}_{\mathrm{x}}+\mathrm{SnF}_{2}+ \\
\text { Pyrazine }\end{array}$ & 19.8 & 0.414 & 0.669 & 5.5 & [79] \\
\hline 2018 & ITO/PEDOT:PSS/Perovskite/C $60: 1 \mathrm{wt} \% \mathrm{TBAI} / \mathrm{Ag}$ & Sequential Deposition Route/FASnI $3+\mathrm{SnF}_{2}+\mathrm{TMA}$ & 22.45 & 0.47 & 0.678 & 7.09 & [74] \\
\hline 2018 & ITO/PEDOT:PSS/Perovskite/ $\mathrm{C}_{60} / \mathrm{BCP} / \mathrm{Ag}$. & $\begin{array}{l}\text { Adding Sn powder in precursor solution }+ \text { Spin Coating } \\
\text { using DMSO as solvent }+ \text { Annealing/FASnI }{ }_{3}+\mathrm{SnF}_{2}\end{array}$ & 17.5 & 0.58 & 0.663 & 6.75 & {$[80]$} \\
\hline 2019 & $\begin{array}{l}\text { ITO/PEDOT:PSS/Perovskite/ } \\
\text { PCBM/BCP/Ag }\end{array}$ & $\begin{array}{l}\text { Spin Coating using DMF+DMSO as solvent }+ \text { diethyl } \\
\text { ether blended with PAMS dripping }+ \text { Annealing/FASnI } 3\end{array}$ & 17.64 & 0.314 & 0.410 & 2.28 & [71] \\
\hline 2019 & $\begin{array}{l}\text { ITO/PEDOT:PSS/Perovskite/C } 60 \\
\text { /BCP/Ag }\end{array}$ & $\begin{array}{l}\text { Adding CDTA in precursor solution + Spin Coating } \\
\text { using DMSO as solvent+ CB dripping + Annealing/ } \\
\text { FASnI }_{3}+\mathrm{CDTA}+\mathrm{SnF}_{2}\end{array}$ & 21.22 & 0.63 & 0.747 & 10.17 & [81] \\
\hline 2020 & $\begin{array}{l}\text { ITO/PEDOT:PSS/Perovskite/ } \\
\text { PCBM/PEI/Ag }\end{array}$ & Spin Coating in Nitrogen environment/FASnI 3 & 15.36 & 0.64 & 0.56 & 5.51 & {$[62]$} \\
\hline 2020 & ITO/PEDOT:PSS/perovskite $/ \mathrm{PC}_{61} \mathrm{BM} / \mathrm{BCP} / \mathrm{Ag}$ & Spin Coating + EVA in CB as dripping/FASnI ${ }_{3}$-EVA & 22.80 & 0.523 & 0.646 & 7.72 & [82] \\
\hline
\end{tabular}


Table 4. Stability of FA tin halide(s) based perovskites.

\begin{tabular}{|c|c|c|c|c|}
\hline Year & Device Architecture & Testing Environment & Stability & Ref. \\
\hline 2016 & ITO/PEDOT:PSS/ FASnI ${ }_{2} \mathrm{Br} / \mathrm{C}_{60} / \mathrm{Ca} / \mathrm{Al}$ & $\begin{array}{l}\text { Un-encapsulated devices were } \\
\text { stored in nitrogen environment }\end{array}$ & $\begin{array}{l}\text { Retained over } 60 \% \text { of their initial } \\
\text { efficiency for more than } 30 \mathrm{~h}\end{array}$ & [78] \\
\hline 2016 & $\begin{array}{l}\text { ITO/PEDOT:PSS/FASnI }{ }_{3}+ \\
\mathrm{SnF}_{2} / \mathrm{C}_{60} / \mathrm{BCP} / \mathrm{Ag}\end{array}$ & $\begin{array}{l}\text { Encapsulated devices stored in } \\
\text { dark under inert environment }\end{array}$ & $\begin{array}{c}\text { Retained almost } 85 \% \text { efficiency for } \\
720 \mathrm{~h}\end{array}$ & [69] \\
\hline 2016 & $\begin{array}{c}\mathrm{FTO} / \mathrm{c}-\mathrm{TiO}_{2} / \mathrm{mp}-\mathrm{TiO} 2-\mathrm{FASnI}_{3}+\mathrm{SnF}_{2}+ \\
\text { Pyrazine/Spiro-OMeTAD/Au }\end{array}$ & $\begin{array}{l}\text { Encapsulated devices stored in } \\
\text { dark under ambient conditions }\end{array}$ & $\begin{array}{l}\text { Retained almost } 98 \% \text { of their initial } \\
\text { efficiencies for } 2400 \mathrm{~h}\end{array}$ & [68] \\
\hline 2017 & $\begin{array}{c}\mathrm{FTO} / \mathrm{c}-\mathrm{TiO}_{2} / \mathrm{mp}-\mathrm{TiO}_{2}-\mathrm{FASnI}_{3-\mathrm{x}} \mathrm{Br}_{\mathrm{x}}+\mathrm{SnF}_{2}+ \\
\text { Pyrazine /spiro-OMeTAD/Au }\end{array}$ & $\begin{array}{l}\text { Encapsulated devices under } \\
\text { continuous } 1 \text { Sun irradiation in } \\
\text { ambient environment }\end{array}$ & $\begin{array}{l}\text { Retained almost } 83 \% \text { of initial } \\
\text { performance after } 1000 \mathrm{~h}\end{array}$ & [79] \\
\hline 2018 & $\begin{array}{l}\text { ITO/PEDOT:PSS/FASnI }{ }_{3}+\mathrm{SnF}_{2}+ \\
\text { TMA } / \mathrm{C}_{60}: 1 \mathrm{wt} \% \mathrm{TBAI} / \mathrm{Ag}\end{array}$ & $\begin{array}{l}\text { Encapsulated devices stored in } \\
\text { ambient conditions }\end{array}$ & $\begin{array}{l}\text { Retained almost } 80 \% \text { of initial } \\
\text { performance for } 420 \mathrm{~h}\end{array}$ & [74] \\
\hline 2019 & $\begin{array}{c}\text { ITO/PEDOT:PSS/FASnI } 3+\text { CDTA + } \\
\mathrm{SnF}_{2} / \mathrm{C}_{60} / \mathrm{BCP} / \mathrm{Ag}\end{array}$ & $\begin{array}{l}\text { Encapsulated devices under } \\
\text { continuous } 1 \text { Sun irradiation }\end{array}$ & $\begin{array}{l}\text { Retained almost } 90 \% \text { of its initial } \\
\text { efficiency for } 1000 \mathrm{~h}\end{array}$ & {$[81]$} \\
\hline 2020 & $\begin{array}{l}\text { ITO/PEDOT:PSS/FASnI }{ }_{3} \text {-EVA } \\
\text { /PC }{ }_{61} \mathrm{BM} / \mathrm{BCP} / \mathrm{Ag}\end{array}$ & $\begin{array}{l}\text { Un-encapsulated devices stored } \\
\text { in ambient conditions with RH } \\
\text { of } 60 \%\end{array}$ & $\begin{array}{l}\text { Retained } 62.4 \% \text { of their initial } \\
\text { efficiencies for } 48 \mathrm{~h}\end{array}$ & [82] \\
\hline
\end{tabular}




\section{Cesium Tin Halides (CsSnX $\left.\mathrm{X}_{3}, \mathrm{X}=\mathrm{I}, \mathrm{Br}, \mathrm{Cl}\right)$}

Kanatzidis and coworkers were the very first to demonstrate effective use of $\mathrm{CsSnI}_{3}$ in all solid state DSSC as a hole transport material [83]. The commonly used corrosive redox electrolyte was replaced with $\mathrm{CsSnI}_{3}$ to realize efficiencies up to $10.2 \%$ in the DSSCs. The first use of $\mathrm{CsSnI}_{3}$ as light harvesting material was reported by Wang et al. [84] in 2012, when a simple configuration of ITO/CsSnI $3 / \mathrm{Au} / \mathrm{Ti}$ produced a PCE of $0.9 \%$. To produce the perovskite film $\mathrm{SnCl}_{2} / \mathrm{CsI}$ stack was deposited by e-beam deposition and thermal evaporation of $\mathrm{CsI}$ and $\mathrm{SnCl}_{2}$, respectively. Followed by annealing at $175^{\circ} \mathrm{C}$ for $1 \mathrm{~min}$. This process created a single phased, dense and black colored polycrystalline perovskite film with a grain size of $300 \mathrm{~nm}$. The Schottky solar cell based on these films provided a $\mathrm{V}_{\mathrm{OC}}$ of $0.42 \mathrm{~V}$, with a JSC of $4.80 \mathrm{~mA} \cdot \mathrm{cm}^{-2}$, FF of $22 \%$ and PCE of $0.9 \%$.

Kumar et al., were also among the very first researchers who reported the use of $\mathrm{CsSnI}_{3}$ in perovskite solar cells [85]. With a band gap close to ideal $(1.3 \mathrm{eV})$ [83] and higher theoretical limit of achievable JSC $\left(34.3 \mathrm{~mA} \cdot \mathrm{cm}^{-2}\right)$ than its lead based counterparts $\left(25.9 \mathrm{~mA} \cdot \mathrm{cm}^{-2}\right)$ [86], this material was expected to yield extraordinary efficiencies. However, theoretical calculations revealed that although the material is a semiconductor, it exhibit metallic characteristics with a very high hole mobility arising from intrinsic defects associated with Sn-cation vacancies [87]. To control this metallic conductivity Kumar et al., added $\mathrm{SnF}_{2}$ to $\mathrm{CsSnI}_{3}$. Perovskite films were prepared by Stichometric mixing of $\mathrm{SnI}_{2}$, $\mathrm{SnF}_{2}$ and $\mathrm{CsI}$ in proper solvents followed by spin coating and thermal annealing $\left(70^{\circ} \mathrm{C}\right)$. Perovskite solar cells employing conventional $n$-i-p architecture $\left(\mathrm{FTO} / \mathrm{c}-\mathrm{TiO}_{2} / \mathrm{mp}-\mathrm{TiO}_{\mathrm{s}}-\mathrm{CsSnI}_{3}+\mathrm{SnF}_{2} / \mathrm{HTM} / \mathrm{Au}\right)$ were fabricated using $4^{\prime}$, 4- 4,-tris (N,N-phenyl-3-methylamino) triphenylamine (m-MTDATA) as hole transport material.

To compare performance and effect of $\mathrm{SnF}_{2}$ on $\mathrm{Sn}$ vacancies, $\mathrm{CsSnI}_{3}$ pervoskite films with 0,5 , 10, 20 and $40 \mathrm{~mol} \%$ of $\mathrm{SnF}_{2}$ were used. Devices without any $\mathrm{SnF}_{2}$ doping were not functioning at all, while devices with $\mathrm{SnF}_{2}$ doping were properly functioning with the best efficiency of $2.02 \%$ recorded for device with $20 \mathrm{~mol} \% \mathrm{SnF}_{2}$ doping. These results were further explained by measuring the carrier densities of perovskite films. A very high carrier density of $10^{19} \mathrm{~cm}^{-3}$ was recorded for pure $\mathrm{CsSnI}_{3}$ with holes as majority charge carriers. This p-type conductivity was caused by Sn-vacancies. With increasing $\mathrm{mol} \%$ of $\mathrm{SnF}_{2}$ the carrier densities tend to decrease. This proves that $\mathrm{SnF}_{2}$ doping can significantly suppress Sn vacancies. Surprisingly, when stored in glove box these devices were stable for more than $250 \mathrm{~h}$. While these devices show some stability, a very low open circuit voltage hinders the performance of these devices. With an astonishing JSC of $22.70 \mathrm{~mA} \cdot \mathrm{cm}^{-2}$ obtained for the best performing device a very low $\mathrm{V}_{\mathrm{OC}}$ of $0.24 \mathrm{~V}$ was recorded.

In an attempt to increase the $\mathrm{V}_{\mathrm{OC}}$ of $\mathrm{CsSnI}_{3}$ based perovskite devices the same group incorporated $\mathrm{Br}$ in $\mathrm{CsSnI}_{3}$ perovskite structure [88]. As the bromine content was increased, the crystal structure of $\mathrm{CsSnI}_{3}$ showed a phase transition from orthorhombic for $\mathrm{CsSnI}_{3}$ to cubic for $\mathrm{CsSnIBr}_{2}$ and $\mathrm{CsSnBr}_{3}$ respectively. Also the optical bandgap of material changed from $1.27 \mathrm{eV}$ for pure $\mathrm{CsSnI}_{3}$ to $1.37 \mathrm{eV}$ for $\mathrm{CsSnI}_{2} \mathrm{Br}$. For $\mathrm{CsSnIBr}_{2}$ and $\mathrm{CsSnBr}_{3}$ the optical bandgap of $1.65 \mathrm{eV}$ and $1.75 \mathrm{eV}$ was recorded respectively. The increasing bromine content also induced a change in the color of perovskite films from black to light brown, resulting in reduced light harvesting but simultaneously increasing the $\mathrm{V}_{\mathrm{OC}}$. Bromine doping also resulted for lowering charge carrier densities by one order of magnitude for $\mathrm{CsSnI}_{2} \mathrm{Br}\left(1.42 \times 10^{17} \mathrm{~cm}^{-3}\right)$ and 2 order of magnitude for $\mathrm{CsSnIBr}_{2}\left(6.32 \times 10^{15} \mathrm{~cm}^{-3}\right)$ compared to pure $\mathrm{CsSnI}_{3}$ films $\left(5.28 \times 10^{18} \mathrm{~cm}^{-3}\right)$ [88]. Overall the reduced charge carrier densities along with increase in the bandgap made it possible to achieve a maximum $\mathrm{V}_{\mathrm{OC}}$ of $0.41 \mathrm{~V}$ for $\mathrm{CsSnBr}_{3}$ based devices. However, this increase in the $\mathrm{V}_{\mathrm{OC}}$ came at the expense of $\mathrm{J}_{\mathrm{SC}}$, and a very meager $\mathrm{J}_{\mathrm{SC}}$ of 3.99 $\mathrm{mA} \cdot \mathrm{cm}^{-2}$ was recorded with a low PCE of $0.95 \%$.

Remarkably Marshall and coworkers achieved a $\mathrm{V}_{\mathrm{OC}}$ of $0.55 \mathrm{~V}$ using inverted $\mathrm{p}-\mathrm{i}-\mathrm{n}$ architecture (ITO|CuI|CsSnI 3 |fullerene|BCP|Al) with indene- $\mathrm{C}_{60}$ bis-adduct (ICBA) as electron transport layer [89]. A $50 \mathrm{~nm}$ perovskite film prepared by spin coating $8 \mathrm{wt} \% \mathrm{CsSnI}_{3}$ in DMF was used as light harvester. To minimize charge carrier recombination's and enhance device stability the $\mathrm{CsSnI}_{3}$ films were prepared using $10 \mathrm{~mol} \%$ excess $\mathrm{SnI}_{2}$. A highest efficiency of $2.76 \%$ was recorded for device incorporating these 
perovskite films and using ICBA as ETL. The excess $\mathrm{SnI}_{2}$ played a major role in deciding different performance parameters of fabricated devices. Firstly the excess $\mathrm{SnI}_{2}$ provided a $\mathrm{Sn}$ rich source during perovskite formation which is known to suppress $\mathrm{Sn}$ vacancies and hence reduce background carrier density. Secondly it facilitated charge carriers transfer to $\mathrm{CuI}$ because of its favorable band alignment, reducing recombination losses. Most importantly the use of excess $\mathrm{SnI}_{2}$ significantly improved device stability. When un-encapsulated devices fabricated without any excess $\mathrm{SnI}_{2}$ lost almost $70 \%$ of their initial efficiency within 10 days while being stored in nitrogen glove box, surprisingly devices fabricated with $10 \mathrm{~mol} \%$ excess $\mathrm{SnI}_{2}$ retained $90 \%$ of their performance for the same period of time. The FF and $\mathrm{V}_{\text {oc }}$ of these devices remained stable even when exposed to air for $14 \mathrm{~h}$.

The same approach was employed by Kanatzidi and coworkers to report one of the highest efficiencies of $4.81 \%$, among all $\mathrm{CsSnX}_{3}$ perovskite films based devices [90]. Perovskite films were produced from $\mathrm{CsI} / \mathrm{SnI}_{2}$ solutions in DMF and DMSO with different molar ratios starting from 0.1 reaching up to 1. As discussed in previous sections Kanatzidis and group used reducing vapor atmosphere as the films were produced in hydrazine environment to suppress $\mathrm{Sn}^{2+}$ oxidation during film formation. In conventional $n-i-p$ architecture the best performance was recorded from devices incorporating films made with 0.4 molar ratio of $\mathrm{CsI} / \mathrm{SnI}_{2}$, having $\mathrm{TiO}_{2}$ as ETL and PTAA doped with tetrakis(pentafluorophenyl)borate (TPFB) as HTL. When molar ratio was increased from 0.4 , devices gave a low $\mathrm{V}_{\mathrm{OC}}$ corresponding to high conductivities, while devices with molar ratio less than 0.4 gave poor $\mathrm{J}_{\mathrm{SC}}$ due to lack of $\mathrm{CSSnI}_{3}$ phase. A strong hydrazine environment was created in the glove box dropping $800 \mu \mathrm{L}$ on glass substrate while spinning it to have the PCE of $4.81 \%$ with $\mathrm{J}_{\mathrm{SC}}$ of 25.71 $\mathrm{mA} \cdot \mathrm{cm}^{-2}, \mathrm{~V}_{\mathrm{OC}}$ of $381.66 \mathrm{mV}$ and $\mathrm{FF}$ of $49.05 \%$.

Marshall and group went on to investigate effectiveness of $\mathrm{SnCl}_{2}$ addition, while preparing $\mathrm{CsSnI}_{3}$ perovskites [91]. While devices prepared with $10 \mathrm{~mol} \%$ of $\mathrm{SnCl}_{2}$ presence during perovskite fabrication show no considerable effect on stability with respect to devices prepared with $10 \mathrm{~mol} \%$ excess $\mathrm{SnI}_{2}$, the efficiency jumped from $2.76 \%$ (as reported by the same group earlier) to $3.56 \%$. Instead of incorporating $\mathrm{Cl}$ in the crystal lattice, the $\mathrm{SnCl}_{2}$ formed a thin layer covering the perovskite crystallite surface. This resulted in a sacrificial oxidation of $\mathrm{SnCl}_{2}$ layer when exposed to air, hence saving $\mathrm{CsSnI}_{3}$ from oxidation. The elevated efficiencies using $\mathrm{SnCl}_{2}$ can be attributed to lowering device performance parameters sensitivity to pin hole defects in the perovskite films. Because of its small size and lower mass the excess $\mathrm{SnCl}_{2}$ present at the surface of the $\mathrm{CsSnI}_{3}$ crystallites diffuse into fullerene layer causing its moderate n-doping. This resulted in forming a Schottky barrier limiting leakage current at $\mathrm{ITO} /$ Fullerene junction at the site of pinholes in the $\mathrm{CsSnI}_{3}$ films.

Cahen and group reported an optimization strategy for $\mathrm{CsSnBr}_{3}$ based devices by selecting different electron transport materials (ETM) and hole transport materials (HTM) layers for conventional n-i-p architecture based PSCs [92]. Devices were fabricated using $\mathrm{TiO}_{2}$ and $\mathrm{Al}_{2} \mathrm{O}_{3}$ as ETM while PTAA, CBP and Spiro-MeOTAD were chosen as HTMs. By using $\mathrm{TiO}_{2}$ as ETM, spiro-MeOTAD as HTM and $20 \mathrm{~mol} \% \mathrm{SnF}_{2}$ doping, optimized PCE of $2.1 \%$ was achieved with a JSC of $9.1 \mathrm{~mA} \cdot \mathrm{cm}^{-2}$, a $\mathrm{V}_{\mathrm{OC}}$ of $0.42 \mathrm{~V}$ and a FF of $57 \%$. All other combinations of HTM and ETM produced unsatisfactory results. The band alignment diagram of optimized device comparing effect of $\mathrm{SnF}_{2}$ addition in $\mathrm{CsSnBr}_{3}$ is given in Figure 7. When work function and ionization potential (valence band maximum, EVBM) of pristine $\mathrm{CsSnBr}_{3}$ was compared to $\mathrm{CsSnBr}_{3}$ doped with $20 \mathrm{~mol} \%$ of $\mathrm{SnF}_{2}$, the role of $\mathrm{SnF}_{2}$ doping was revealed as it decreased work function $\left(\mathrm{W}_{\mathrm{F}}\right)$ and the ionization potential of $\mathrm{CsSnBr}_{3}$ as shown in Figure 7. This decrease in $\mathrm{EVBM}$ of $\mathrm{CsSnBr}_{3}$ resulted in reducing the voltage loss by bringing it close to HOMO of spiro-MeOTAD.

Moghe and group fabricated $\mathrm{CsSnBr}_{3}$ based PCSs using thermal deposition [93] to achieve $50 \mathrm{~min}$ stable devices under continuous 1 sun irradiation and ambient conditions without any encapsulation. Planar heterojunction architecture was selected for device fabrication with $\mathrm{CsSnBr}_{3}: \mathrm{SnF}_{2}$ sandwiched between $\mathrm{MoO}_{3}$ and $\mathrm{C}_{60}$. Figure 8 a gives the band alignment diagram of fabricate devices. $\mathrm{SnF}_{2}$ dopant was incorporated in the devices with different concentrations of $0 \%, 2.5 \%, 5 \%$ and $7.5 \%$. The position of $\mathrm{SnF}_{2}$ vapor deposited layer was also varied as shown in Figure 8. The best efficiency of $0.50 \%$ was 
obtained for devices having $2.5 \mathrm{~mol}^{\circ}$ of $\mathrm{SnF}_{2}$ doping and $\mathrm{SnF}_{2}$ layer sandwiched between $\mathrm{CsBr}$ and $\mathrm{SnBr}_{2}$. While these devices are expected to have considerable stability when properly encapsulated, the low PCE limit its application on commercial scale. Kanatzidi's group further optimized the $\mathrm{CsSnBr}_{3}$ perovskite layer by using hydrazine vapor atmosphere to grow $\mathrm{CsSnBr}_{3}$ films [50]. This technique along its effects on perovskite layer has already been discussed in previous sections. Using reducing vapor atmosphere during $\mathrm{CsSnBr}_{3}$ film growth they were able to suppress tin vacancies and reduce $\mathrm{Sn}^{+}$oxidation. A maximum PCE of $3.04 \%$ was recorded for $\mathrm{CsSnBr}_{3}$ based devices.

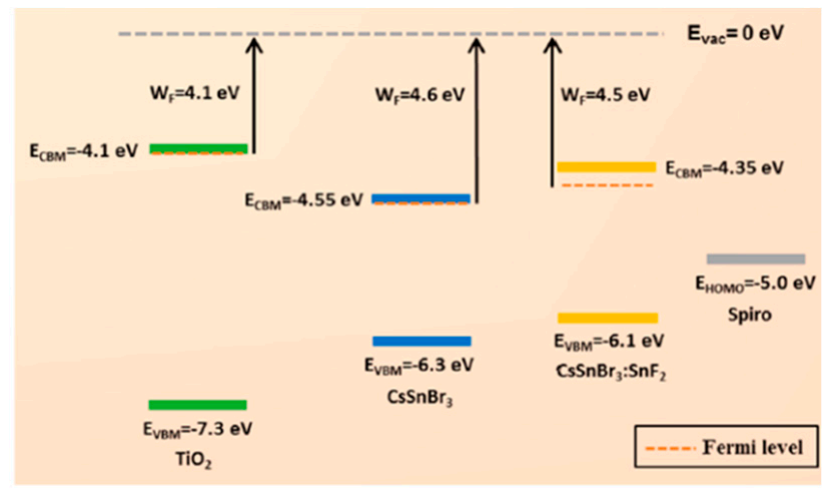

Figure 7. VBM energies from UPS measurements and CBM energies calculated using the UPS measurements and the optical band gap, i.e., neglecting the exciton binding energy, and the Fermi level (from UPS data) of dense $\mathrm{TiO}_{2}$, pristine $\mathrm{CsSnBr}_{3}$, and $\mathrm{CsSnBr}_{3}$ (with $20 \mathrm{~mol} \% \mathrm{SnF}_{2}$ ). Adapted with permission from [92]. Copyright (C) 2016, American Chemical Society.

(a)
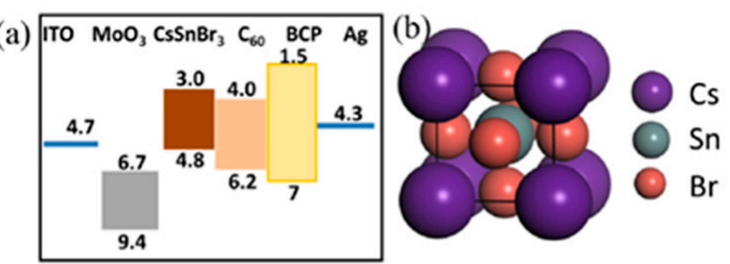

(c)
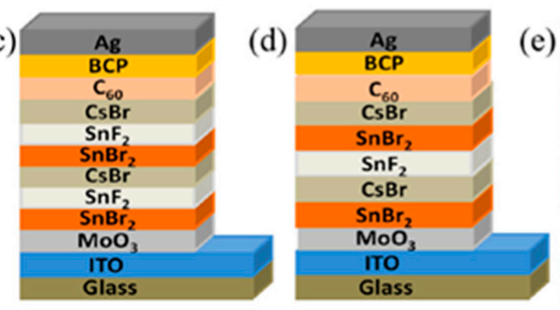

(e)

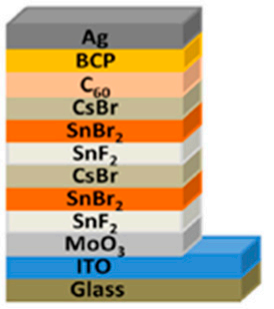

Figure 8. (a) Band alignment diagram of the planar $\mathrm{CsSnBr}_{3}$ structure; (b) Crystal structure of $\mathrm{CsSnBr}_{3}$; (c) $\mathrm{SnF}_{2}$ layers splitting $\mathrm{SnBr}_{2}-\mathrm{CsBr}$ layers in configuration 1(C1); (d) Single $\mathrm{SnF}_{2}$ layer is inserted in configuration 2(C2), and (e) $\mathrm{SnF}_{2}$ is inserted as split layer before $\mathrm{SnBr}_{2}$ in configuration 3(C3). Adapted with permission from [93]. Copyright (C) 2016, Elsevier Limited.

In a similar attempt of enhancing the performance of $\mathrm{CsSnX}_{3}$ based devices, Kanatzidi's group explored the possible effects of adding Piperazine to precursor solution of $\mathrm{CsSnI}_{3}$ perovskite films [94]. Adding piperazine significantly suppressed the self-doping of the perovskite films and increased surface coverage while simultaneously reducing the crystallization of excess $\mathrm{SnI}_{2}$. Perovskite films were spin coated keeping ratio of $\mathrm{CsI} / \mathrm{SnI}_{2}$ as 0.4 . The molar ratio of piperazine to tin was changed from 0 to $25 \%$ by adding $2 \mathrm{M}$ of piperazine solution to $\mathrm{CsSnI}_{3}$ solution. Films were annealed at $90{ }^{\circ} \mathrm{C}$ for $25 \mathrm{~min}$. Addition of piperazine significantly improved the film coverage by suppressing excess 
$\mathrm{SnI}_{2}$ crystallization. Figure 9 reveals the morphologies of perovskite films prepared from 0, 10 and 20 $\mathrm{mol} \%$ of piperazine addition as seen under scanning electron microscope (SEM).

a)

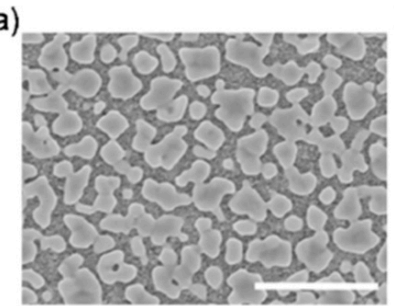

c)

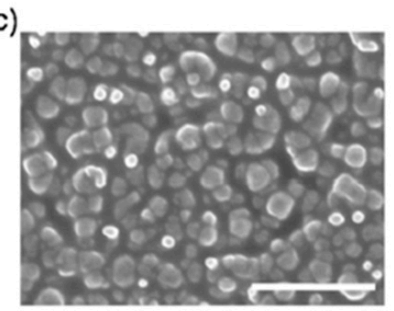

b)

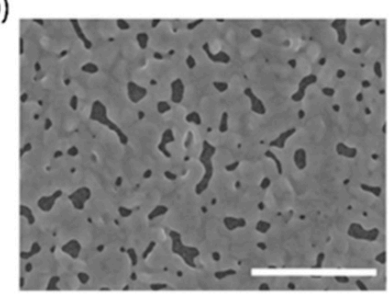

d) $10^{1}-0.4 \mathrm{cssn}$,

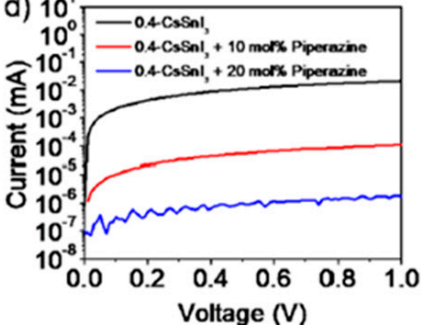

Figure 9. $0.4-\mathrm{CsSnI}_{3}$ perovskite films on top of meso- $\mathrm{TiO}_{2}$ substrates as seen under SEM. When prepared with molar ratios of piperazine: (a) $0 \mathrm{~mol} \%$; (b) $10 \mathrm{~mol} \%$; and (c) $20 \mathrm{~mol} \%$. Scale bar represent length of $2 \mu \mathrm{m}$; (d) Semilog plot of the I-V characteristics for each condition. The measurements were performed using the four point probe technique. Adapted with permission from [94]. Copyright (C) 2018, American Chemical Society.

When no piperazine was added, the excess $\mathrm{SnI}_{2}$ crystallized resulting in poor surface coverage. However, with piperazine addition the surface coverage enhanced as can be seen in Figure 9b,c. Addition of piperazine significantly increased the resistance of films as can be seen in Figure 9d. With $20 \mathrm{~mol} \%$ of piperazine with resistance of perovskite films increased almost 4 orders of magnitude compared to resistance of pristine $\mathrm{CsSnI}_{3}$ films. An optimized device was fabricated using $10 \mathrm{~mol} \%$ of $\mathrm{SnF}_{2}$ doping and $15 \mathrm{~mol} \%$ of piperazine addition to achieve a maximum PCE of $3.83 \%$ with a JSC of $20.63 \mathrm{~mA} \cdot \mathrm{cm}^{-2}, \mathrm{~V}_{\mathrm{OC}}$ of $0.338 \mathrm{~V}$ and a FF of $54.18 \%$. Although, the efficiency increased significantly the stability of these devices still remained considerably low.

In $2016 \mathrm{Li}$ et al., reported 77 day stable $\mathrm{CsSnIBr}_{2}$ films based devices [95]. This extraordinary stability was achieved by adding hypophosphorous acid (HPA) to precursor solution of $\mathrm{CsSnIBr}_{2}$ perovskite films. Addition of HPA in precursor solution made tiny clusters of $\mathrm{CsSn}_{3}-\mathrm{HPA}_{\mathrm{y}}(\mathrm{X}=$ $\mathrm{Br}, \mathrm{I})$. These tiny clusters promoted growth of perovskite crystals by removing the redundant $\mathrm{SnF}_{2}$, hence suppressing phase separation. When films were tested for conductivity, samples prepared with HPA had one order of magnitude less conductivity then those prepared without any HPA addition. Moreover, the charge carrier density reduced by one order of magnitude for films prepared with HPA addition $\left(1.5 \times 10^{15} \mathrm{~cm}^{-3}\right)$ compared to film prepared without any HPA addition $(1.6 \times$ $10^{16} \mathrm{~cm}^{-3}$ ). Overall addition of HPA proved effective in reducing trap densities and Sn vacancies in $\mathrm{CsSnIBr}_{2}$ films. The best device was fabricated with $0.5 \mu \mathrm{L} \mathrm{mL}{ }^{-1}$ concentration of HPA acid, presenting efficiency of $3.02 \%$ with a $\mathrm{J}_{\mathrm{SC}}$ of $17.4 \mathrm{~mA} \cdot \mathrm{cm}^{-2}$, a $\mathrm{V}_{\mathrm{OC}}$ of $0.31 \mathrm{~V}$ and Fill factor of $56 \%$. When encapsulated these devices retained almost all of their initial performance for a time period of 77 days in ambient conditions. This extraordinary stability with moderate efficiency demonstrated the effective use of $\mathrm{CsSnIBr}_{2}$ perovskite layer in lead free stable perovskite devices, paving the way for its commercial applications.

Sun and coworkers reported 3.31\% efficient perovskite device based on a coarse grain B- $\gamma-\mathrm{CsSnI}_{3}$ perovskite film [96]. A single step spin coating technique was employed to produce the perovskite films from the precursor solution, followed by $2 \mathrm{~min}$ annealing at $100{ }^{\circ} \mathrm{C}, 150{ }^{\circ} \mathrm{C}, 200{ }^{\circ} \mathrm{C}, 250{ }^{\circ} \mathrm{C}$ and $300^{\circ} \mathrm{C}$. The grain size showed an increasing trend with increase in annealing temperature as can be 
observed in Figure 10. Grain size averaged $50 \mathrm{~nm}$ for films without any temperature treatment. For films annealed at $100{ }^{\circ} \mathrm{C}$ average grain size of $100 \mathrm{~nm}$ was reported, which further increased to $350 \mathrm{~nm}$ for $150{ }^{\circ} \mathrm{C}$ annealing temperature. Figure $10 \mathrm{G}$ represents the annealing temperature vs. average grain size.

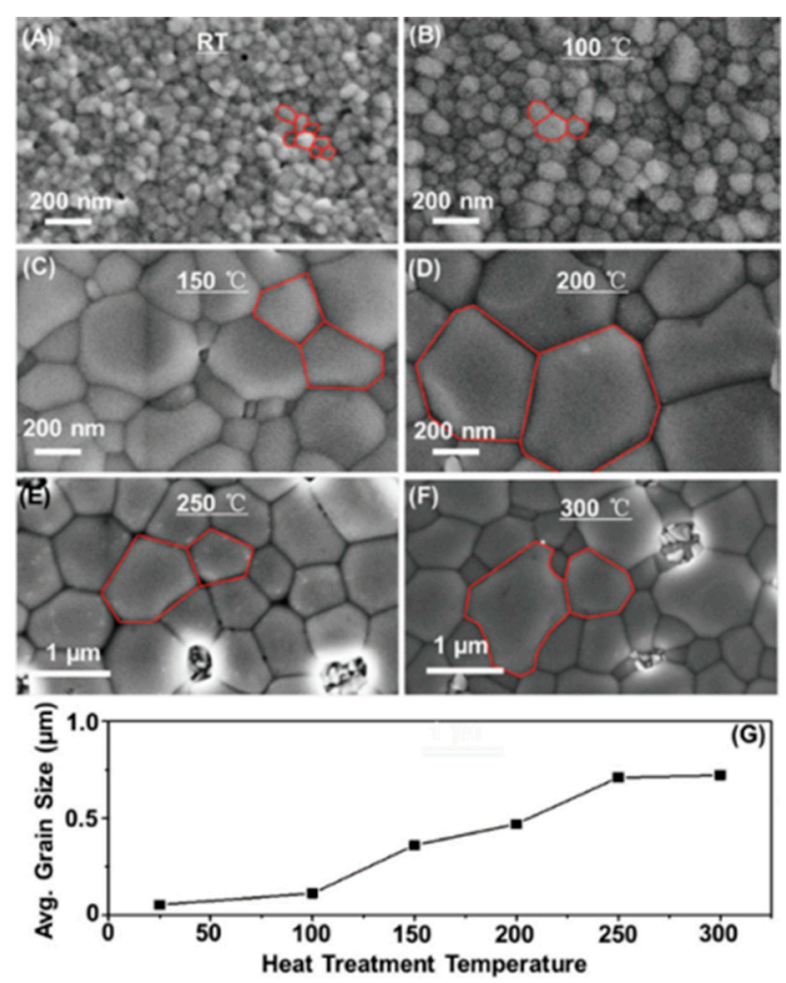

Figure 10. Top view of the B- $\gamma-\mathrm{CsSnI}_{3}$ perovskite films as seen under SEM. (A) as-deposited; (B) annealed at $100{ }^{\circ} \mathrm{C}$ for $2 \mathrm{~min}$; (C) annealed at $150{ }^{\circ} \mathrm{C}$ for $2 \mathrm{~min}$; (D) annealed at $200{ }^{\circ} \mathrm{C}$ for $2 \mathrm{~min}$; (E) annealed at $250{ }^{\circ} \mathrm{C}$ for $2 \mathrm{~min}$ and (F) annealed at $300{ }^{\circ} \mathrm{C}$ for $2 \mathrm{~min}$; (G) Average grain size of the B- $\gamma-\mathrm{CsSnI}_{3}$ thin films show increasing trend as the annealing temperature is increased. Adapted with permission from [96]. Copyright (C) 2016, WILEY-VCH Verlag GmbH \& Co. KGaA, Weinheim.

It was confirmed from both theoretical and experimental calculations that as annealing temperature increased number of $\mathrm{Sn}$ vacancies also increased. Devices with different architectures were fabricated and tested for photovoltaic parameters. Devices having $\mathrm{TiO}_{2}$ as ETL and Spiro-OMeTAD as HTL in conventional n-i-p architecture showed almost no performance when incorporated with B- $\gamma$-CsSnI 3 annealed at $100{ }^{\circ} \mathrm{C}$ as perovskite layer. When $\mathrm{TiO}_{2}$ was replaced by $\mathrm{Al}_{2} \mathrm{O}_{3}$ as ETL in the same architecture, a very meager efficiency of $0.32 \%$ was achieved. A low crystallinity, perovskite making non ideal interfaces with scaffold material and presence of impurities, such as $\mathrm{Y}_{-} \mathrm{CsSnI}_{3}$ and $\mathrm{Cs}_{2} \mathrm{SnI}_{6}$ were identified as causes of poor performance. To address these issues an inverted $\mathrm{p}-\mathrm{i}-\mathrm{n}$ architecture was used with a compact p-type nickel oxide $\left(\mathrm{NiO}_{\mathrm{x}}\right)$ as $\mathrm{HTL}, \mathrm{PCBM}$ as ETL and the perovskite layer was annealed at $150{ }^{\circ} \mathrm{C}$. This device gave an outstanding efficiency of $3.31 \%$ with a JSC of $10.21 \mathrm{~mA} \cdot \mathrm{cm}^{-2}$, $\mathrm{V}_{\mathrm{OC}}$ of $0.52 \mathrm{~V}$ and a FF of $62.5 \%$.

During the past few years many unique attempts were also reported to elevate the efficiency and enhance the stability of inorganic $\mathrm{Sn}$ based perovskite solar cells. Chen and group reported $\mathrm{CsSnX}_{3}$ based quantum rods to achieve a champion cell efficiency of $12.96 \%$ [97]. Quantum rods of $\mathrm{CsSnI}_{3}, \mathrm{CsSnBr}_{3}$ and $\mathrm{CsSnCl}_{3}$ were synthesized respectively by solvothermal method as described in literature [97]. These high quality rods had lengths of several tens of nanometers with a diameter of $5 \mathrm{~nm}$. The image of these rods as seen under transmission electron microscope (TEM) along with its elemental mapping from TEM energy-dispersive X-ray spectroscopy (EDS) is shown in Figure 11. 
PSCs were fabricated in planar p-i-n heterojucntion architecture using these $\mathrm{CsSnX}_{3}$ quantum rods as perovksite layers. The best PCE of $12.96 \%$ was obtained for devices based on $\mathrm{CsSnI}_{3}$ quantum rods, whereas devices based on $\mathrm{CsSnBr}_{3}$ and $\mathrm{CsSnCl}_{3}$ quantum rods yielded efficiencies of $9.66 \%$ and $10.46 \%$ respectively. When tested for stability, devices fabricated with $\mathrm{CsSnI}_{3}$ quantum rods remained stable for more than $240 \mathrm{~h}$.
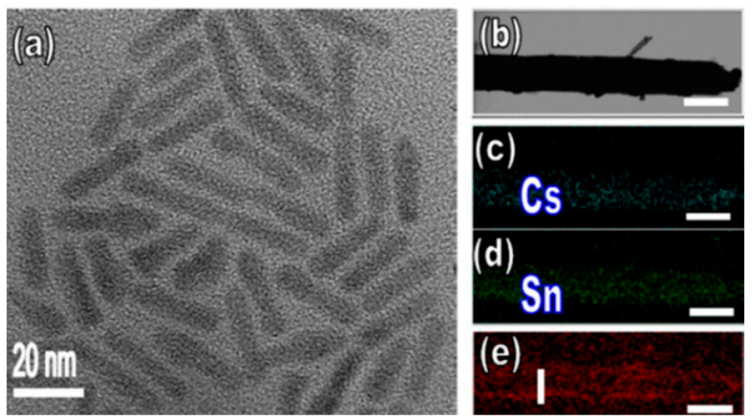

Figure 11. (a) $\mathrm{CsSnI}_{3}$ Perovskite QRs as seen under TEM. (b-e) Selected zoom-in TEM images of several QRs: (b) A single $\mathrm{CsSnI}_{3}$ perovskite QR as seen under TEM with corresponding energy dispersive spectroscopy (EDS) elemental mapping images, confirming that (c) Cs, (d) Sn, and (e) I are sequentially and uniformly spread over the entire surface of the $\mathrm{CsSnI}_{3}$ QRs. The scale bars are $5 \mathrm{~nm}$. Adapted with permission from [97]. Copyright (C) 2016, American Chemical Society.

Quan and coworkers reported $0 \mathrm{D} \mathrm{Cs}_{4} \mathrm{SnX}_{6}$ nanocrystals having 21\% Photoluminescence quantum yield (PLQY) [98] but with no considerable stability. In an attempt to enhance the air stability of perovskites Guo et al. [99] synthesized cubic nanocages of $\mathrm{CsSnBr}_{3}$. When treated with perfluorooctanoic acid (PFOA), perovskite film of these $\mathrm{CsSnBr}_{3}$ nanocages showed stability for over $24 \mathrm{~h}$ while being in ambient air. However in these unique approaches Kanatzidis and group were the first to report a considerably stable device based on $\mathrm{Cs}_{2} \mathrm{SnI}_{6}$ [100]. This material had a bandgap of $1.48 \mathrm{eV}$ with a high absorption coefficient. While achieving a modest efficiency of $0.96 \%$ for the best device based on these perovskites, its stability remained outstanding. Un-encapsulated devices were stable for more than one week in ambient conditions which is quite remarkable. Recently Wang and group reported a 3\% efficient $\mathrm{CsSnI}_{3}$ based device by chemically doping cobaltocene $\left(\mathrm{CoCp}_{2}\right)$ into perovskite layer [101]. Doping of $\mathrm{CoCp}_{2}$ into $\mathrm{CsSnI}_{3}$ helped create a reducing environment which resulted in effective suppression of $\mathrm{Sn}^{2+}$ oxidation. This method also considerably enhanced the overall stability of these devices.

Although all the techniques discussed above for $\mathrm{CsSnI}_{3}$ PSCs produced some excellent results, very recently Li et al. [102] reported one of state-of-the-art performance with a PCE of 3.8\% and stability of 180 days. For the very first time vacuum flash-assisted solution processing (VASP) was used to fabricate the high quality $\mathrm{CsSnI}_{3}$ perovskite films. The VASP method involved transferring the already spin coated Sn-based perovskite precursor to a vacuum (60 Pa) for $40 \mathrm{~s}$. Followed by annealing at $60 \mathrm{C}^{\circ}$ for $10 \mathrm{~min}$. The controlled solvent removal method allowed to produce high quality $\mathrm{CsSnI}_{3}$ films with very few pin holes, reduced background charge carrier density and considerably enhanced perovskite stability. Films produced by VASP showed greatly improved stability than that of films produced using single step spin coating (controlled films). UV absorption spectrum revealed that at $450 \mathrm{~nm}$ VASP films retained 95\% of their initial absorption even after 100 min exposure to air, while the controlled film retained only $85.5 \%$ absorption. The VASP PSCs yielded a PCE of $2 \%$ which increased to $3.8 \%$ upon storing in glove box for 3 months. The controlled PSC produced PCE of $1.1 \%$ and almost lost all of its performance within the first month of storage. As can be seen from Table 5 the performance of $\mathrm{CsSnX}_{3}$ based devices has considerably progressed even in ambient conditions. These elevated efficiencies along with enhanced stability as given in Table 6 prove the importance of these devices in search of environment friendly highly efficient PSCs. 
Table 5. Performance of best Cs tin halide (s) based devices reported until 2020.

\begin{tabular}{|c|c|c|c|c|c|c|c|}
\hline Year & Device Architecture & $\begin{array}{l}\text { Perovskite Film Fabrication } \\
\text { Technique/Perovskite Film }\end{array}$ & $\begin{array}{c}\mathrm{JSC} \\
\left(\mathrm{mA} \cdot \mathrm{cm}^{-2}\right)\end{array}$ & $\begin{array}{l}\mathrm{V}_{\mathrm{OC}} \\
(\mathrm{V})\end{array}$ & FF & $\begin{array}{l}\text { EFF } \\
(\%)\end{array}$ & Ref. \\
\hline 2014 & $\mathrm{FTO} / \mathrm{c}-\mathrm{TiO}_{2} / \mathrm{mp}^{-\mathrm{TiO}_{2}}$-Perovskite/m-MTDATA/Au & $\begin{array}{l}\text { Spin Coating using DMSO as solvent + } \\
\text { Annealing/CsSnI } 3+\mathrm{SnF}_{2}\end{array}$ & 22.70 & 0.24 & 0.37 & 2.02 & {$[85]$} \\
\hline 2015 & $\mathrm{FTO} / \mathrm{c}-\mathrm{TiO}_{2} / \mathrm{mp}-\mathrm{TiO}_{2}$-Perovskite/Spiro-OMeTAD/Au & $\begin{array}{l}\text { Spin Coating using } \mathrm{DMSO} \text { as solvent }+ \\
\text { Annealing/CsSnI }{ }_{2} \mathrm{Br}+\mathrm{SnF}_{2}\end{array}$ & 15.06 & 0.289 & 0.38 & 1.67 & {$[88]$} \\
\hline 2015 & ITO/CuI/Perovskite/ICBA/BCP/Al & $\begin{array}{l}\text { Spin Coating using DMF as solvent }+ \\
/ \text { CsSnI }_{3}+\text { excess } \mathrm{SnI}_{2}\end{array}$ & $12.30 \pm 0.48$ & $0.430 \pm 0.061$ & $0.395 \pm 0.053$ & $2.13 \pm 0.53$ & [89] \\
\hline 2016 & ITO/Perovskite/PC ${ }_{61} \mathrm{BM} / \mathrm{BCP} / \mathrm{Al}$ & $\begin{array}{l}\text { Spin Coating using DMF as solvent + } \\
\text { Annealing/CsSnI }{ }_{3}+\mathrm{SnCl}_{2}\end{array}$ & $9.89 \pm 0.55$ & $0.50 \pm 0.01$ & $0.68 \pm 0.01$ & $3.35 \pm 0.21$ & [91] \\
\hline 2016 & $\begin{array}{c}\mathrm{FTO} / \mathrm{c}-\mathrm{TiO}_{2} / \mathrm{mp}-\mathrm{TiO}_{2}-\text { Perovskite } / \mathrm{Al}_{2} \mathrm{O}_{3} \text {-Perovskite/ } \\
\text { C-Perovskite }\end{array}$ & $\begin{array}{c}\text { Spin Coating using DMSO as solvent }+ \\
\text { Annealing } / \mathrm{CsSnIBr}_{2}+\mathrm{SnF}_{2}+\text { Hypophosphorous } \\
\text { Acid (HPA) }\end{array}$ & $16.7 \pm 0.7$ & $0.33 \pm 0.02$ & $0.53 \pm 0.02$ & $3 \pm 0.2$ & [95] \\
\hline 2016 & $\mathrm{FTO} / \mathrm{c}-\mathrm{TiO}_{2} / \mathrm{mp}-\mathrm{TiO}_{2}$-Perovskite/Spiro-MeOTAD/Au & $\begin{array}{l}\text { Spin Coating using DMSO as a Solvent }+ \\
\text { Annealing/CsSnBr } 3+\mathrm{SnF}_{2}\end{array}$ & 9.1 & 0.42 & 0.57 & 2.17 & [92] \\
\hline 2016 & $\mathrm{ITO} / \mathrm{MoO}_{3} /$ Perovskite/ $\mathrm{C}_{60} / \mathrm{BCP} / \mathrm{Ag}$ & $\begin{array}{l}\text { Vapor Deposition + Anealing/CsSnBr } 3+ \\
\mathrm{SnF}_{2}+\text { Excess } \mathrm{SnBr}_{2}\end{array}$ & $2.1 \pm 0.2$ & $0.45 \pm 0.05$ & $0.52 \pm 0.05$ & $0.50 \pm 0.05$ & [93] \\
\hline 2016 & ITO/NiO $/$ Perovskite/PCBM/Al & $\begin{array}{l}\text { Spin Coating using a mixed polar Solvent + } \\
\text { Annealing/B- } \gamma \text {-CsSnI } \\
\end{array}$ & 10.21 & 0.52 & 0.625 & 3.31 & [96] \\
\hline 2016 & $\begin{array}{l}\text { ITO/mp-TiO }{ }_{2} \text {-Quantum Rods of } \\
\mathrm{CsSnI}_{3} / \text { spiro-OMeTAD/Au }^{-O}\end{array}$ & $\begin{array}{c}\text { Spin Coating using } \mathrm{CsSn}_{3} \text { perovskites } \\
(160 \mathrm{mg} / \mathrm{mL}) \text { in toluene }+ \text { Annealing/QRs of } \mathrm{CsSnI}_{3}\end{array}$ & 23.2 & 0.86 & 0.65 & 12.96 & [97] \\
\hline 2017 & $\begin{array}{c}\mathrm{FTO} / \mathrm{c}-\mathrm{TiO}_{2} / \mathrm{mp}^{-\mathrm{TiO}_{2}} \text {-perovskite/perovskite capping } \\
\text { layer } \\
\text { /PTAA/Au }\end{array}$ & $\begin{array}{l}\text { Spin Coating in Hydrazine environment using } \\
\text { DMSO as Solvent } / \mathrm{CsSnBr}_{3}\end{array}$ & 13.96 & 0.366 & 0.593 & 3.04 & {$[50]$} \\
\hline 2017 & 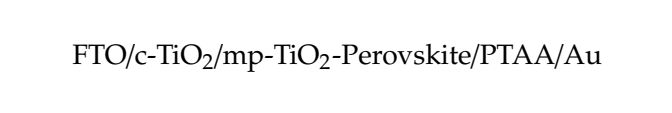 & $\begin{array}{c}\text { Spin Coating using DMF + DMSO as solvent }+ \\
\text { Annealing + Hydraizne environment/ } \mathrm{CsSnI}_{3}+ \\
\text { Excess } \mathrm{SnI}_{2}\end{array}$ & 25.71 & 0.381 & 0.49 & 4.81 & {$[90]$} \\
\hline 2017 & $\mathrm{FTO} / \mathrm{c}-\mathrm{TiO}_{2} / \mathrm{Cs}_{2} \mathrm{SnI}_{6} / \mathrm{P} 3 \mathrm{HT} / \mathrm{Ag}$ & $\begin{array}{l}\text { Vapor deposition of CsI,SnI }+ \text { Solid State } \\
\text { Reaction + Oxidation } / \mathrm{Cs}_{2} \mathrm{SnI}_{6}\end{array}$ & 5.41 & 0.51 & 0.35, & 0.96 & [100] \\
\hline 2018 & $\mathrm{FTO} / \mathrm{c}-\mathrm{TiO}_{2} / \mathrm{mp}^{-\mathrm{TiO}_{2}}$-Perovskite /PTAA/Au & $\begin{array}{c}\text { Spin Coating using DMF+DMSO as } \\
\text { solvent/CsSnI }{ }_{3}+\text { Excess } \mathrm{SnI}_{2}+\mathrm{SnF}_{2}+\text { Piperazine }\end{array}$ & 20.63 & 0.338 & 0.541 & 3.83 & [94] \\
\hline 2020 & $\begin{array}{l}\mathrm{Mp}-\mathrm{TiO}_{2} / \mathrm{CoCp}_{2}-\mathrm{CsSnI}_{3} / \mathrm{Al}_{2} \mathrm{O}_{3} / \mathrm{NiO} / \\
\text { carbon framework }\end{array}$ & $\begin{array}{l}\text { Drop Casting using DMSO as solvent + } \\
\text { Annealing/CoCp }{ }_{2}-\mathrm{CsSnI}_{3}\end{array}$ & 18.24 & 0.36 & 0.46 & 3 & [101] \\
\hline 2020 & ITO/Perovskite/ $\mathrm{C}_{60} / \mathrm{BCP} / \mathrm{Ag}$ & $\begin{array}{l}\text { Vacuum flash-assisted solution processing } \\
\text { (VASP)/CsSnI } 3\end{array}$ & 16.5 & 0.41 & 0.55 & 3.8 & [102] \\
\hline
\end{tabular}


Table 6. Stability of Cs tin halide(s) based perovskites.

\begin{tabular}{|c|c|c|c|c|}
\hline Year & Device Architecture & Testing Environment & Stability & Ref. \\
\hline 2014 & $\begin{array}{c}\mathrm{FTO} / \mathrm{c}-\mathrm{TiO}_{2} / \mathrm{mp}_{-}-\mathrm{TiO}_{2}-\mathrm{CsSnI}_{3}+ \\
\mathrm{SnF}_{2} / \mathrm{m}-\mathrm{MTDATA} / \mathrm{Au}\end{array}$ & Devices stored in inert environment & $\begin{array}{l}\text { Showed no significant loss of } \\
\text { performance for almost } 250 \mathrm{~h}\end{array}$ & [85] \\
\hline 2015 & $\begin{array}{l}\mathrm{ITO} / \mathrm{CuI} / \mathrm{CsSnI} \mathrm{I}_{3}+\text { excess } \\
\mathrm{SnI}_{2} / \mathrm{ICBA} / \mathrm{BCP} / \mathrm{Al}\end{array}$ & $\begin{array}{l}\text { Un-encapsulated devices tested } \\
\text { under } 1 \text { Sun constant illumination in } \\
\text { ambient conditions }\end{array}$ & $\begin{array}{l}\text { Retained } 70 \% \text { of their initial } \\
\text { efficiencies for } 16 \mathrm{~h}\end{array}$ & [89] \\
\hline 2016 & $\begin{array}{c}\mathrm{ITO} / \mathrm{MoO}_{3} / \mathrm{CsSnBr}_{3}+ \\
\mathrm{SnF}_{2}+\text { Excess } \mathrm{SnBr}_{2} / \mathrm{C}_{60} / \mathrm{BCP} / \mathrm{Ag}\end{array}$ & $\begin{array}{l}\text { Un-encapsulated devices tested } \\
\text { under } 1 \text { Sun illumination in ambient } \\
\text { conditions }\end{array}$ & $\begin{array}{l}\text { Devices remained stable for } \\
\qquad 50 \mathrm{~min}\end{array}$ & [93] \\
\hline 2016 & 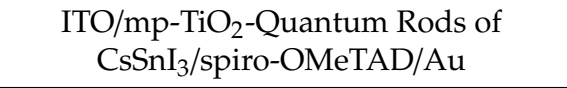 & 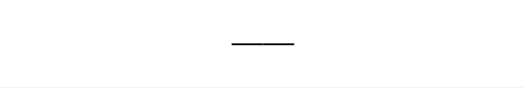 & $\begin{array}{l}\text { Sealed Devices remained stable } \\
\text { for } 240 \mathrm{~h}\end{array}$ & [97] \\
\hline 2016 & 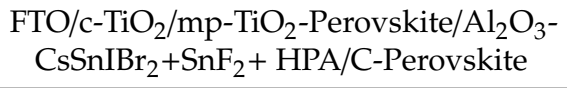 & $\begin{array}{l}\text { Encapsulated devices stored under } \\
\text { ambient condition }\end{array}$ & $\begin{array}{l}\text { Retained almost all of their } \\
\text { initial efficiencies for } 1848 \mathrm{~h}\end{array}$ & [95] \\
\hline 2017 & Cubic nanocages of $\mathrm{CsSnBr}_{3}$ & Ambient conditions & $24 \mathrm{~h}$ stable & [99] \\
\hline 2020 & ITO/VASP-CsSnI $3 / \mathrm{C}_{60} / \mathrm{BCP} / \mathrm{Ag}$ & Stored in inert environment & $\begin{array}{c}\text { Increased its PCE from } 2 \% \text { to } \\
3.8 \% \text { after } 2160 \mathrm{~h}\end{array}$ & [102] \\
\hline
\end{tabular}


Over the years a steady progress has been made in elevating the efficiency and enhancing air stability of this single cation (MA, FA, Cs) based Sn perovskites. However, the challenge of commercialization has pushed the scientific and research community to come up with unique ideas. A new trend of combining two or more cations in a single perovskite has emerged, as it offers numerous possibilities of enhancing device performance and stability. This idea proved very successful in lead based perovskites [103-106], simultaneously gaining the attention of groups working on Sn based perovskites. The coming section summarize all work done in this regard based on Sn based perovskite, keeping in view the objective that high efficiency and long term stability should go hand to hand.

\section{Mix-Cations (MC) Tin Halides $\left(\mathrm{MCSn}_{3}, \mathrm{X}=\mathrm{I}, \mathrm{Br}, \mathrm{Cl}\right)$}

Liu and coworkers were the first to report a mixed cation $(\mathrm{FA})_{x}(\mathrm{MA})_{1-\mathrm{x}} \mathrm{SnI}_{3}$ perovskite in 2017 [107]. By employing an inverted $\mathrm{p}-\mathrm{i}-\mathrm{n}$ architecture for device fabrication and by optimizing the ratio of both cations within the perovskite layer, a maximum PCE of $8.12 \%$ was achieved. By changing the volume ratio $\mathrm{x}$ : (1-x) of $\mathrm{FASnI}_{3}$ and $\mathrm{MASnI}_{3}$ precursor solutions, different mixed cations perovskite layers were obtained with ratios of FA and MA as 0:100, 25:75, 50:50, 75:25 and 100:0 respectively. Perovskite films were realized by a one-step spin coating technique with chlorobenzene and $\mathrm{SnF}_{2}$ addition to precursor solution made in DMSO. Bandgap of these films as calculated from photo luminescence (PL) spectra showed an increasing trend with the increase of FA content in films. For the films with FA:MA as 25:75 a bandgap of $1.28 \mathrm{eV}$ was recorded, while for films with FA:MA as 50:50 and 75:25, bandgaps of 1.30 $\mathrm{eV}$ and $1.33 \mathrm{eV}$ was recorded respectively. The morphological study of these mixed cation perovskite films revealed that films having lower FA content had few pin holes and low coverage, whereas films with higher FA content, $(\mathrm{FA})_{0.75}(\mathrm{MA})_{0.25} \mathrm{SnI}_{3}$ and $\mathrm{FASnI}_{3}$ was pin hole free and had complete coverage.

When devices were fabricated incorporating these mixed cations perovskite films a low average PCE of $3.61 \% \pm 0.32 \%$ was obtained for $\mathrm{MASnI}_{3}$ films. Moreover, with increasing FA content an increase in FF and $\mathrm{V}_{\mathrm{OC}}$ was observed, with the best average PCE of $7.48 \% \pm 0.52 \%$ recorded for devices based on (FA) $)_{0.75}(\mathrm{MA})_{0.25} \mathrm{SnI}_{3}$ perovskite films. The best device based on (FA) $)_{0.75}(\mathrm{MA})_{0.25} \mathrm{SnI}_{3}$ perovskite films gave maximum efficiency of $8.12 \%$ with a $\mathrm{J}_{\mathrm{SC}}$ of $21.2 \mathrm{~mA} \cdot \mathrm{cm}^{-2}$, a $\mathrm{V}_{\mathrm{OC}}$ of $0.61 \mathrm{~V}$ and a FF of $62.7 \%$. This outstanding performance was attributed to the pin hole free and complete coverage of $(\mathrm{FA})_{0.75}(\mathrm{MA})_{0.25} \mathrm{SnI}_{3}$ perovskite film. This combination of cations in perovskite significantly reduced the carrier recombination rate as was proved from transient state PL spectra and electrochemical impedance spectroscopy (EIS) of these films. (FA) $0.75(\mathrm{MA})_{0.25} \mathrm{SnI}_{3}$ had the highest PL lifetime of $3.07 \pm$ $0.1 \mathrm{~ns}$ compared to other mixed cations perovskite films. At high applied voltages the value of $\mathrm{R}_{\text {rec }}$ recorded from EIS was also the largest for this combination among all perovskite films proving the effectiveness of reducing carrier recombination rate through cation mixing. These devices had a very high reproducibility with considerable stability. Under inert environment these PSCs retained $80 \%$ of their initial efficiency for more than $400 \mathrm{~h}$.

To further improve coverage of $(\mathrm{FA})_{0.75}(\mathrm{MA})_{0.25} \mathrm{SnI}_{3}$ perovskite films and increase the crystallite size Ozaki et al. [108] reported a hot antisolvent treatment (HAT) along with annealing in DMSO vapors. Pin hole free films with complete coverage were obtained when antisolvent was preheated to $65^{\circ} \mathrm{C}$ before dripping (in this case chlorobenzene). A large density of perovskite nucleation sites were formed in the case of preheated antisolvent dripping technique, resulting in a pin hole free full coverage films. Whereas, films without HAT resulted in poor coverage, and had pin holes after annealing. When films were annealed in a mild DMSO vapor-enriched environment the quality of perovskite further increased and average crystallite size increased from $237 \mathrm{~nm}$ to $440 \mathrm{~nm}$. Combining both of these optimizing strategies Ozaki et al. [108] were able to achieve a best PCE of 7.2\%.

By employing solvent engineering technique, Yan et al. [109] were able to achieve efficiency of $9.06 \%$. Different anti solvents such as toluene (TL), chlorobenzene (CB) and diethyl ether (DE) were used for perovskite film production. For optimum performance, $\mathrm{SnF}_{2}$ was added to suppress $\mathrm{Sn}^{2+}$ oxidation and mixture of DMF as well as DMSO was used as a solvent in the perovskite precursors. When films were prepared without anti-solvent dripping it affected both, their crystallinity and crystal 
orientation. The preferred orientation for perovskites without anti-solvent dripping was (120), while those prepared with anti-solvent dripping preferred (100) and (200) [109]. A morphological study of $(\mathrm{FA})_{0.75}(\mathrm{MA})_{0.25} \mathrm{SnI}_{3}$ perovskite films prepared with and without anti-solvent dripping revealed that films produced without any anti-solvent treatment resulted in discontinuous films with several flower shaped grains as shown in Figure 12. This discontinuous film is resulted due to low number of nucleation sites. When anti-solvent treatment was applied number of nucleation sites considerably increased and a much smoother full coverage film was formed. As can be seen from Figure 12 with DE as anti-solvent higher number of pin holes are present, the number of pin holes dropped when TL was used. However, the best film having least number of pin holes was produced when $C B$ was used as anti-solvent.
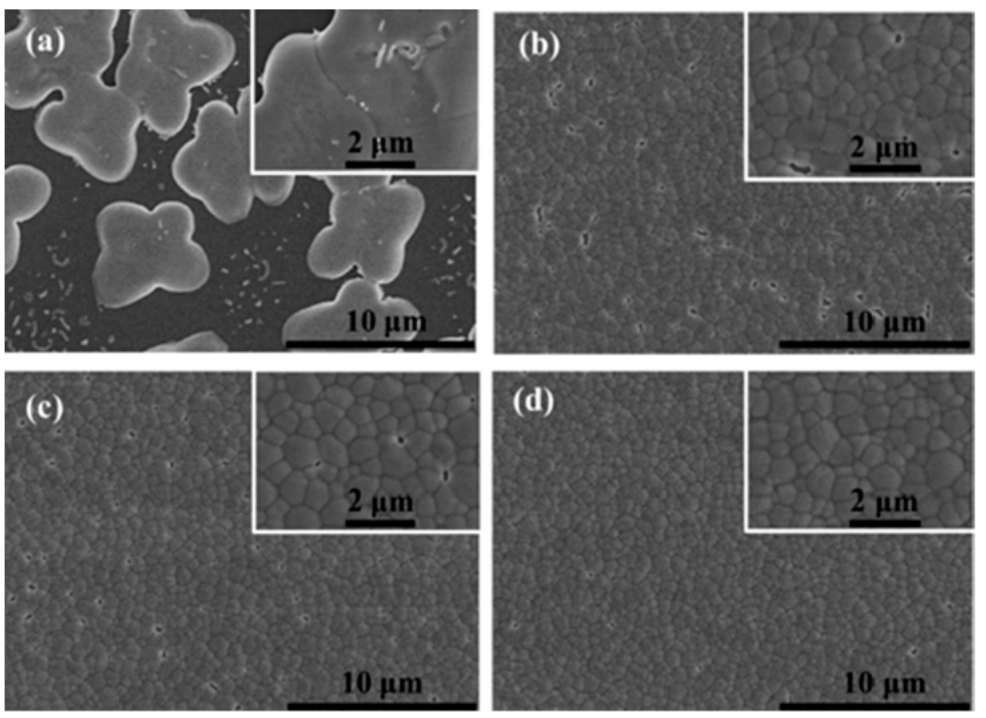

Figure 12. Top-view $(\mathrm{FA})_{0.75}(\mathrm{MA})_{0.25} \mathrm{SnI}_{3}$ films deposited on ITO/PEDOT:PSS substrates as seen under SEM (a) without anti-solvent; (b) with DE; (c) with TL; and (d) with CB. Adapted with permission from [109]. Copyright (C) 2018, American Chemical Society.

Perovskite devices employing $\mathrm{p}-\mathrm{i}-\mathrm{n}$ architecture were fabricated based on these films using PEDOT: PSS as HTL and $\mathrm{C}_{60}$ as ETL. Films dripped by CB yielded the best PCE of $9.06 \%$. Whereas films dripped with TL and DE gave PCE of $7.52 \%$ and $6.29 \%$ respectively. The high efficiency obtained from films dripped with $\mathrm{CB}$ was attributed to low charge carrier recombination rate resulted from pin hole free films with full coverage. At high applied voltages value of $R_{\text {rec }}$ recorded from EIS was also the largest for $\mathrm{CB}$ dripped films based devices proving the effectiveness of reducing carrier recombination rate through CB dripping. When tested for stability, CB dripped perovskite films based encapsulated devices retained almost $75 \%$ of their initial efficiency over a period of 30 days when stored in nitrogen glove box.

Kanatzidi and group applied a different approach to enhance overall performance and improve air stability of lead free Sn based perovskite solar cells. Perovskite devices based on hollow ethylenediammonium $\mathrm{FASnI}_{3}$ (\{en\}FASnI 3 ) were fabricated to achieve a PCE of $7.14 \%$ with enhanced air stability of more than $1000 \mathrm{~h}$ with proper encapsulation [110]. The incorporation of en in perovskite resulted in a novel 3D mixed cation perovskite (\{en\}FASnI $\left.{ }_{3}\right)$, opening the door for tuning the bandgap without using solid solutions. This 3D hollow (\{en\}FASnI $\left.{ }_{3}\right)$ was prepared by mixing stichometric amount of en and FAI in a solution of $\mathrm{SnI}_{2}$, followed by adding it to a mix solvent of hydroiodic acid (HI) and $\mathrm{H}_{3} \mathrm{PO}_{2}$. Initially en/FA ratio was kept at $0 \%, 10 \%$ and $25 \%$ to determine the optimum amount of en loading. The crystal structure of $\{\mathrm{en}\} \mathrm{FASnI}_{3}$ retained the pseudocubic shape of pristine $\mathrm{FASnI}_{3}$ and orthorhombic unit cell with very minor change in the unit cell volume. It was assumed that to 
incorporate large sized en in 3D crystal structure other species, neutral or charged with proportionate size must be removed from crystal resulting in Schottky defects or point defects respectively.

To investigate the exact structure of this new mixed cation perovskite Kanatzidi and coworkers used many experimental techniques and theoretical calculations, all of which confirmed a hollow $3 \mathrm{D}$ structure with missing $\mathrm{SnI}_{2}$ neutral fragments. This resulted in narrowing of both, $\mathrm{VB}$ and $\mathrm{CB}$ hence increasing the bandgap of these $\{\mathrm{en}\} \mathrm{FASnI}_{3}$ perovskites. Removal of $\mathrm{SnI}_{2}$ units from the crystal structure, the observed decrease in energy levels of VB maxima automatically enhanced the stability of devices based on these perovskites as it shifted the absolute work function to lower energies resulting in reduction of oxidation tendency. A bandgap of 1.4, 1.5 and $1.9 \mathrm{eV}$ was reported for perovskite materials with 0,10 and $25 \%$ of en loading, respectively. Films with $0 \%$ en loading showed a carrier lifetime of 0.19 ns whereas a carrier lifetime of 0.46 and 0.68 ns was calculated for 10 and $25 \%$ en loading respectively. Perovskite devices employing n-i-p architecture were fabricated using these \{en\}FASnI 3 perovskties. Device based on pristine $\mathrm{FASnI}_{3}$ yielded a PCE of $1.40 \%$, whereas devices based on 10 and $25 \%$ of en loading gave PCE of $6.94 \%$ and $2.34 \%$, respectively.

The relatively poor performance of pristine $\mathrm{FASnI}_{3}$ based device was attributed to poor coverage and a very high carrier recombination rate. While low efficiency of $2.34 \%$ in devices based on $25 \%$ en loading was caused by a very low $\mathrm{J}_{\mathrm{sc}}$ resulted from a high bandgap of $1.9 \mathrm{eV}$. These results proved the optimum value for en loading to be $10 \%$ where the champion cell achieved a PCE of $7.14 \%$ with a JSC of $22.54 \mathrm{~mA} \cdot \mathrm{cm}^{-2}$, a V $\mathrm{OC}$ of $0.480 \mathrm{~V}$ and a FF of $65.96 \%$ when measured under reverse voltage scan. When tested for stability the encapsulated devices retained $96 \%$ of their initial performance even after $1000 \mathrm{~h}$ which is a very encouraging prospect for the future of highly efficient and stable lead free tin based PSCs. Later Kanatzidis and group extended the same approach to fabricate highly efficient and stable $\{$ en $\} \mathrm{MASnI}_{3}$ and $\{\mathrm{en}\} \mathrm{CsSnI}_{3}$ perovskites [111]. The champion cell achieved a PCE of $6.63 \%$ for $\left\{\right.$ en\} $\mathrm{MASnI}_{3}$ with $15 \%$ of en loading, while the best performance for \{en\} $\mathrm{CsSnI}_{3}$ based solar cell was recorded for $10 \%$ of en loading with a PCE of 3.79\%. This optimum en loading also significantly increased the air stability of both perovskites and PSCs based on them. Very recently Kanatzidis and group demonstrated the effective use of benzodithiophene (BDT)-based small organic molecules as hole transport materials for efficient lead free Sn based PSCs [112]. Efficiency of 7.59\% was achieved for the champion device using these HTMs.

It was observed in the case of lead based perovskite devices that as the dimensionality of perovskite decreased the stability of device increased [113,114]. Keeping this in mind Kanatzidis and group reported $2 \mathrm{D}(\mathrm{BA})_{2}(\mathrm{MA})_{\mathrm{n}-1} \mathrm{Sn}_{\mathrm{n}} \mathrm{I}_{3 \mathrm{n}+1}$ perovskites with enhanced moisture stability [115]. The optical band gaps of these 2D perovskites can be tuned from $1.83 \mathrm{eV}(\mathrm{n}=1)$ to $1.20 \mathrm{eV}(\mathrm{n}=\infty)$, however for solar applications $n=3$ and $n=4$ were selected to have an optimal band gap of 1.50 and $1.42 \mathrm{eV}$ respectively. To improve perovskite film morphology triethylphosphine (TEP) and $\mathrm{SnF}_{2}$ was added to the precursor solution. Devices were fabricated using these perovskite films to test their performance and moisture stability. For value of $n=3$ a maximum PCE of $1.94 \%$ was obtained, while devices with $\mathrm{n}=4$ yielded a PCE of $2.53 \%$. When compared for stability with $\mathrm{MASnI}_{3}$ based devices, the encapsulated devices with $n=4$ retained almost $90 \%$ of their initial efficiency for more than one month while in the same period the encapsulated devices based on $\mathrm{MASnI}_{3}$ completely degraded. This enhanced stability of $2 \mathrm{D}(\mathrm{BA})_{2}(\mathrm{MA})_{n-1} \mathrm{Sn}_{n} \mathrm{I}_{3 \mathrm{n}+1}$ perovskites based solar cell is attributed to the formation of long chains of hydrophobic butyl ammonium in the perovskite resulting in protecting perovskite films.

In 2017 Liao et al. [116] reported a 5.94\% efficient and $100 \mathrm{~h}$ stable $2 \mathrm{D}(\mathrm{PEA})_{2}(\mathrm{FA})_{\mathrm{n}-1} \mathrm{Sn}_{\mathrm{n}} \mathrm{I}_{3 \mathrm{n}+1}$ based perovskite solar cell. Very recently Liu et al. [117] demonstrated that different alkyl chain lengths have significant effects on crystal orientation and phase distribution in 2D perovskite films. Organic cations with short lengths of alkyl chains can increase dimensionality and can produce highly oriented crystal grains [117]. 2D/3D mixed cations $\left(\mathrm{PEA}_{x} \mathrm{FA}_{(1-\mathrm{x})} \mathrm{SnI}_{3}\right)$ Sn based PSC with a PCE of $6.98 \%$ was reported in 2018 by $\mathrm{Xi}$ et al. [118]. Incorporation of large PEA in perovskite structure significantly improved the PCE and stability of the 2D/3D mixed fabricated devices. A two-step fabrication route was used to 
prepare (PEA,FA)SnI ${ }_{3}$ bulk heterojunction perovskites. First PEAI molecules were evaporated to form PEAI/FAI mixture on top of FAI films followed by evaporation of $\mathrm{SnI}_{2}$ forming a 2D/3D perovskite. To find the best combination different amounts of PEAI was evaporated such as 25,50 and $75 \mathrm{mg}$. Devices were fabricated employing p-i-n planar heterojunction architecture with an ultrathin layer of $\mathrm{LiF}(3,5$ and $8 \mathrm{~nm}$ thick) deposited at ITO/PEDOT:PSS interface. This insulating LiF improved the hole extraction at ITO/PEDOT:PSS interface along with lowering the work function of PEDOT:PSS. The best performance was realized with $50 \mathrm{mg}$ of PEAI evaporation along with keeping LiF thickness at $5 \mathrm{~nm}$. The champion device provided a PCE of $6.98 \%$ with a JSC of $20.07 \mathrm{~mA} \cdot \mathrm{cm}^{-2}$, a V $\mathrm{OC}$ of $0.47 \mathrm{~V}$ and a FF of 0.74. Shao et al. [119] reported a $9 \%$ efficient $2 \mathrm{D} / 3 \mathrm{D}$ mixed highly crystalline $\mathrm{FASnI}_{3}$ based perovskite solar cells. The perovskite films were prepared by mixing $0.08 \mathrm{M}$ of 2D layered tin perovskite with 0.92 $\mathrm{M}$ of 3D FASnI 3 along 2-phenylethylammoniumiodide (PEAI).

Marshall and group reported a 3D mixed cation $\mathrm{Cs}_{1-x} \mathrm{Rb}_{x} \mathrm{SnI}_{3}$ perovskite material for solar cell applications. By increasing the value of $x$ open circuit voltage can be significantly increased in this type of perovskite material. However they observed that as the number of $\mathrm{Rb}$ atoms substituting $\mathrm{Cs}$ increased the stability of the perovskite decreased. The champion cell provided a PCE of $2.25 \%$ with $50 \%$ of Cs substituted by $\mathrm{Rb}$ and having $10 \mathrm{~mol} \%$ of excess $\mathrm{SnI}_{2}$ [120]. Ran et al. [121] reported a $2000 \mathrm{~h}$ stable perovskite device when stored in nitrogen filled glove box with a PCE of $6.08 \%$ by successfully doping $\mathrm{Cs}$ in $\mathrm{FASnI}_{3}$ perovskite. Incorporating Cs into $\mathrm{FASnI}_{3}$ improved the geometric symmetry of the crystal by inducing contraction of corner sharing $\mathrm{SnI}_{6}$ octahedra. It also significantly enhanced the stability of perovskite by reducing $\mathrm{Sn}^{2+}$ oxidation tendency. Compared to pristine $\mathrm{FASnI}_{3}$, absorption edge in UV-Vis spectra and PL spectra of $\mathrm{Cs}_{x} \mathrm{FA}_{1-x} \mathrm{SnI}_{3}$ films were considerably red shifted. This red shift is attributed to reduction of band gap resulted from the contraction of crystal lattice due to incorporation of Cs. Details of optimization can be read from the published report [121], where the best PCE of $6.08 \%$ is reported for device based on perovskite film having $8 \%$ of CsI doping. This enhanced efficiency is attributed to reduction of hole trap density, increase of carrier motilities and reduction in bulk resistance for $\mathrm{Cs}_{x} \mathrm{FA}_{1-x} \mathrm{SnI}_{3}$ films compared to pristine $\mathrm{FASnI}_{3}$ films. The $8 \%$ doped CSI device showed an outstanding stability of $2000 \mathrm{~h}$ in nitrogen filled glove box by maintaining $90 \%$ of its initial performance in that time period. Compared with pristine $\mathrm{MASnI}_{3}$ and $\mathrm{FASnI}_{3}$ based devices Cs doped device had considerably improved stability both in nitrogen and in air.

Jokar et al. [122] reported addition of butylammonium iodide (BAI) and ethylenediammonium diiodide $\left(\mathrm{EDAI}_{2}\right)$ as additives in $\mathrm{FASnI}_{3}$ based perovskite to achieve power efficiencies of $5.5 \%$ and $7.4 \%$ respectively. Addition of $\mathrm{BAI}$ in the $\mathrm{FASnI}_{3}$ perovskite provided the benefit of lowering dimensionality of perovskite from 3D to a hybrid 2D/3D structure. Although this hybrid structure possessed advantages such as superior crystallinity and preferred crystallographic orientation, the surface was not pin hole free as was resulted from the slow nucleation and too rapid crystal growth rate. When BAI was replaced by di-ammonium cations a dense pin hole free perovskite film was produced as a result of the presence of two ammonium groups which increased interactions with Sn perovskite and ultimately controlling the crystal growth rate. These mixed cations perovskites were less likely to oxidize as compared to pristine $\mathrm{FASnI}_{3}$ perovskites. Since, forming a compact layer and preventing water molecules to diffuse in the perovskite BAI successfully retarded the oxidation while in case of $\mathrm{EDAI}_{2}$ the enhanced stability is attributed to it being a good reducing agent. Almost $90 \%$ of the initial efficiency was maintained by the encapsulated devices based on FASnI $_{3}$-BAI $15 \%$ for over $2000 \mathrm{~h}$ under inert environment. For devices based on $\mathrm{FASnI}_{3}-\mathrm{EDAI}_{2} 1 \%$ the efficiency gradually increased from its initial value of $6.3 \%$ to its maximum value of $8.9 \%$ after storing in nitrogen for $1462 \mathrm{~h}$. This increase in performance is attributed to $\mathrm{EDAI}_{2}$ slowly passivating the surface and gradually adjusting the crystal structure to its optimal phase near $1500 \mathrm{~h}$ [122]. Recently Weber et al. [123] reported a 4.63\% efficient mixed cation perovskite device by mixing three different cations along with introducing bromide in the perovskite lattice. $\mathrm{MA}_{0.75} \mathrm{FA}_{0.15} \mathrm{PEA}_{0.1} \mathrm{Sn}\left(\mathrm{Br}_{x} \mathrm{I}_{1-x}\right)_{3}$ was used as perovskite layer having an optical bandgap of $1.29 \mathrm{eV}$. 
It was in 2019 when Jokar et al. [124] reported one of the most efficient and highly stable Sn based perovskite solar cell with a PCE of $8.5 \%$ recorded for fresh device. This extraordinary efficiency was achieved by incorporating a non-polar organic cation guanidinium $\left(\mathrm{CH}_{6} \mathrm{~N}_{3}{ }^{+}, \mathrm{GA}\right)$ in the perovskite crystal of $\mathrm{FASnI}_{3}$ while simultaneously adding ethylenediammonium diiodide $\left(\mathrm{EDAI}_{2}\right)$ and $\mathrm{SnF}_{2}$ to perovskite. Besides being a non-polar, Guanidinium has a size slightly larger (278 pm) than that of $\mathrm{FA}^{+}$ (253 pm) [125]. When used in Sn based perovskite the $\mathrm{GASnI}_{3}$ is reported to adopt a hexagonal shape with a bandgap of 1.9 and $2.1 \mathrm{eV}$ for its 3D hexagonal and its 2D monoclinic structures respectively [126]. Perovskite films were prepared from precursor solutions of GAI and FAI with varying ratios and mixing them with equimolar $\mathrm{SnI}_{2}$ solution. For enhancing performance and stability of perovskites, $\mathrm{SnF}_{2}$ and $\mathrm{EDAI}_{2}$ were also added in the mixture to obtain the final perovskite films of $\mathrm{GA}_{x} \mathrm{FA}_{1-x-2 y} \mathrm{SnI}_{3-y} \mathrm{EDAI}_{2}$. As reported earlier by the same group incorporating trace amounts of $\mathrm{EADI}_{2}$ in $\mathrm{FASnI}_{3}$ perovskite produced pin hole free, uniform and dense perovskite films simultaneously reducing tendency of $\mathrm{Sn}^{2+}$ oxidation hence increasing stability [122]. As the ratio of GAI:FAI increased the size of perovskite crystal also increased resulted from the larger size of the GA. Incorporation of GA into the perovskite crystal also caused expansion of unit cell hence, increasing the lattice parameters. Increasing GAI proportion from 0 to 30, the absorption band edges of E1Gx perovskites correspondingly shifted towards smaller wavelengths. Whereas, bandgap energies increased from $1.44 \mathrm{eV}$ for $\mathrm{x}=0$ to $1.53 \mathrm{eV}$ for $\mathrm{x}=30$.

The optimal performance was recorded for device based on $20 \%$ GAI and 1\% $\mathrm{EDAI}_{2}$, represented as E1G20 this device yielded a champion PCE of $8.5 \%$ (8.3\% certified). The efficiency continuously increased and reached $9.6 \%$ after $2000 \mathrm{~h}$ storage in nitrogen filled glove box. To test the champion device for stability, performance of device under three different test conditions were analyzed. For comparison device based on pristine $\mathrm{FASnI}_{3}$ and device based on perovskite having only $\mathrm{EADI}_{2}$ mixed in $\mathrm{FASnI}_{3}$ (E1) was also tested under same conditions. As can be seen from Figure 13a the encapsulated E1G20 device remained stable for more than one $h$ with negligible loss of PCE in air $(\mathrm{RH}=50 \%)$ under continuous 1 Sun AM1.5G illumination. While under the same conditions encapsulated E1 device only sustained its maximum performance for $300 \mathrm{~s}$ and deteriorated quickly afterwards. When unencapsulated devices were stored in air $(\mathrm{RH}=60 \%)$ devices based on pristine $\mathrm{FASnI}_{3}$ lost their performance within two h, whereas E1G20 devices retained $80 \%$ of their initial performance for $96 \mathrm{~h}$. The performance of E1G20 device was completely loss free for $170 \mathrm{~h}$ when was stored in air under $20 \%$ relative humidity as shown in Figure 13b. The same device when stored in nitrogen glove box for over $2000 \mathrm{~h}$ its PCE gradually increased with time from $7.3 \%$ to a maximum of $9.6 \%$. Figure $13 \mathrm{~d}$ represent the certified efficiency for E1G20 device.

Fu et al. [127] used a similar strategy of adding $\mathrm{NH}_{2} \mathrm{GACl}$ to the perovskite film to passivate defects and decrease $\mathrm{Sn}^{2+}$ oxidation. Addition of $\mathrm{NH}_{2} \mathrm{GACl}$ in the perovskite also helped optimize the energy levels of the perovskite and favorably adjusted it to the charge transport layers that resulted in faster charge carrier dynamics. Devices fabricated from $\mathrm{NH}_{2} \mathrm{GACl}$ doped perovskites yielded a maximum PCE of $7.30 \%$ and were stable for more than 30 days when stored in nitrogen glove box. Very recently Kanatzidis and group reported a $9.61 \%$ efficient device by introducing 3-phenyl-2-propen-1-amine (PPA) in $\mathrm{FASnI}_{3}$ perovskite [128]. The incorporation of these conjugated organic cations in the perovskite lattice resulted in larger grain sizes, reduced density of traps, enhanced charge extraction and increased overall structural stability of the perovskite film. Performance was optimized when the concentration of PPAI was kept at $15 \%$. The champion cell yielded a $\mathrm{V}_{\mathrm{OC}}$ of $0.56 \mathrm{~V}, \mathrm{~J}_{\mathrm{SC}}$ of $23.34 \mathrm{~mA} \cdot \mathrm{cm}^{-2}, \mathrm{FF}$ of $73.5 \%$ and a PCE of $9.61 \%$ by reverse scan. Kanatzidis and group also demonstrated the large scale fabrication keeping the active area at $1 \mathrm{~cm}^{2}$ to achieve a maximum PCE of $7.08 \%$. When these devices were tested for stability it was revealed that the un-encapsulated $15 \%$ PPAI devices retained almost $92 \%$ of their initial performance even after 60 days, while being kept in nitrogen glove box. Song and group reported an $8.07 \%$ efficient device using a technique of secondary crystallization for improved film quality and remarkably reduced $\mathrm{Sn}^{2+}$ oxidation [129]. 
When stored in Nitrogen glove box, the un-encapsulated device retained $87 \%$ of its initial efficiency even after $1000 \mathrm{~h}$.

(a)

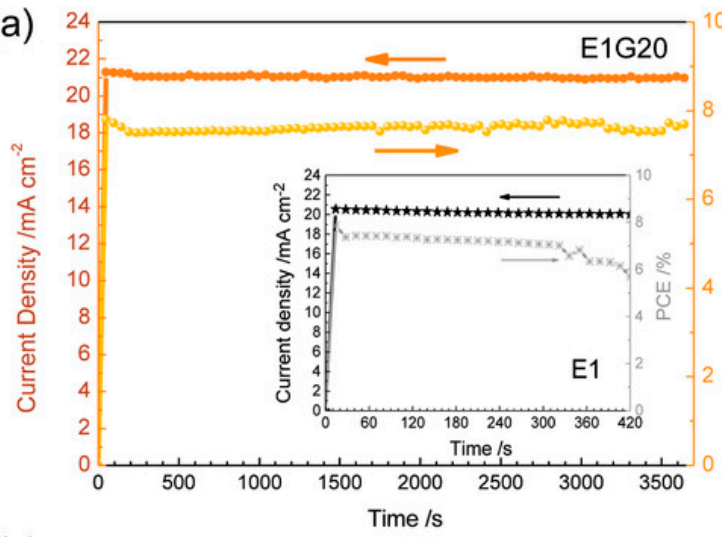

(c)

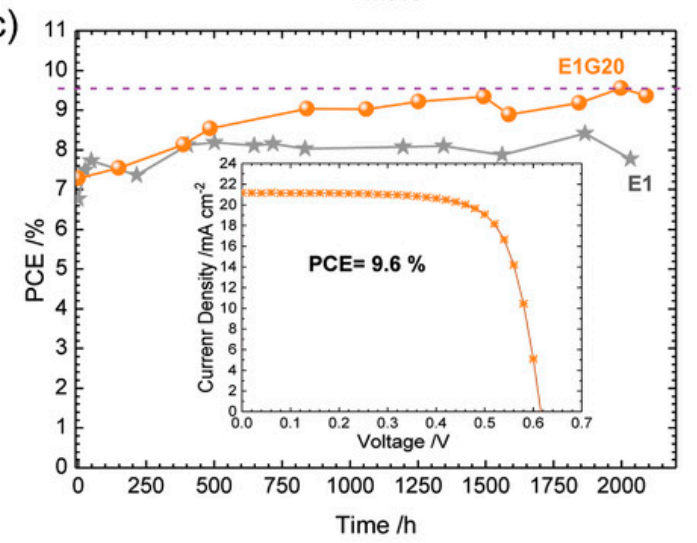

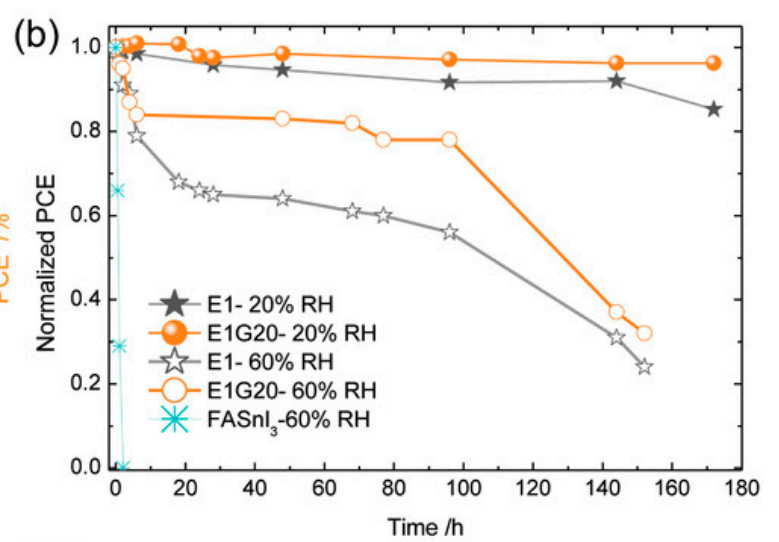

(d)

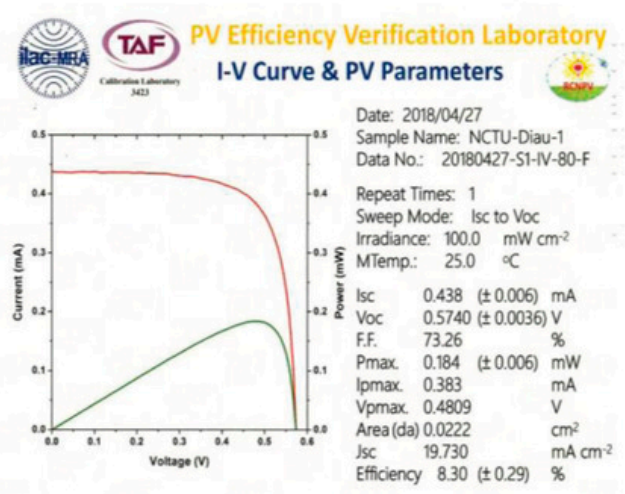

Figure 13. (a) Stabilized PCE and JSC of E1G20 and E1 (shown in the inset) devices taken at the position of maximum power under 1 sun irradiation from AM1.5G solar simulator for $3600 \mathrm{~s}$; PCE of both devices E1 and E1G20 as a function of storage period in two environments: (b) un-encapsulated devices in ambient air with $\mathrm{RH}=20 \%$ and $60 \%$, (c) Nitrogen glove box, and (d) certified efficiency $8.30 \%$ for the E1G20 device in an ISO-approved PV Efficiency Verification Laboratory in Taiwan. Adapted with permission from [124]. Copyright (C) 2018, WILEY-VCH Verlag GmbH \& Co. KGaA, Weinheim.

Han et al. [130] reported a $10.81 \%$ efficient device by controlling $\mathrm{FASnI}_{3}$ nucleation at solution-air interface. A tailor made organic cation, pentafluorophen-oxyethylammonium iodide (FOEI) was introduced in the perovskite lattice, which reduced the surface energy of solution-air surface and enhanced the crystallization intensity of perovskite films by 20-fold. PSCs fabricated from these films provided a long term stability of $500 \mathrm{~h}$ under continuous 1 sun illumination. A unique blend of Sn triple-halide amorphous layer and Cs-formamidinium tin iodide polycrystals was reported by Liu et al. [131] very recently to achieve PCE of over $10 \%$ with a $1000 \mathrm{~h}$ stability. An amorphous-polycrystalline perovskite film composed of a Sn triple-halide amorphous layer and $\mathrm{CsFASnI}_{3}$ polycrystals was fabricated. The resulted structure proved very efficient in blocking moisture and oxygen resulting in elevated efficiency and enhanced stability. The champion device provided a PCE of $10.4 \%$ with a $\mathrm{V}_{\mathrm{OC}}$ of $0.64 \mathrm{~V}$, a J $\mathrm{J}_{\mathrm{SC}}$ of $21.6 \mathrm{~mA} \cdot \mathrm{cm}^{-2}$, and FF of $75.2 \%$. The encapsulated device maintained over $95 \%$ of its initial PCE for more than $1000 \mathrm{~h}$. Jiang et al. [132] reported an unprecedented $\mathrm{V}_{\mathrm{OC}}$ of $0.94 \mathrm{~V}$ for $\mathrm{PEA}_{\mathrm{x}} \mathrm{FA}_{1-\mathrm{x}} \mathrm{SnI}_{3}$ based PSC, using indene- $\mathrm{C}_{60}$ bisadduct (ICBA) as ETL. The introduction of ICBA as ETL instead of commonly used PCBM considerably suppressed the iodide remote doping resulting in a higher $\mathrm{V}_{\mathrm{OC}}$ and PCE. Champion device showed a PCE of $12.4 \%$ with shelf life of more than $3800 \mathrm{~h}$. 
Use of $\mathrm{PEA}^{+}$or $\mathrm{EADI}_{2}$ is desirable to reduce trap density and enhance perovskite stability by improving crystal grain and orientation. However, doping optimized amount of Ge into the perovskite matrix is the latest focus of research $[133,134]$. The ab initio density functional theory (DFT) simulations performed on mixed elements $\mathrm{Ca} /(\mathrm{Ge}, \mathrm{Sn})$ and $\mathrm{Sr} /(\mathrm{Ge}, \mathrm{Sn})$ perovskites revealed that they have higher stability than $\mathrm{Pb}$ based perovskite deives [135]. Hayase and group introduced $\mathrm{Ge}$ in the perovskite lattice to significantly reduce trap density and suppress $\mathrm{Sn}$ vacancies. When $7.5 \% \mathrm{~mol}$ of Ge was added, the total trap density of the perovskite was doubly reduced to $4.14 \times 10^{20} \mathrm{~cm}^{-3}$ and PCE of $7.45 \%$ was realized [136]. Because of the double positive effects of both $\mathrm{PEA}^{+}$and $\mathrm{Ge}^{+}$on the stability of the perovskite, the un-encapsulated device retained $70 \%$ of its PCE for $3 \mathrm{~h}$ under continuous 1 Sun illumination in ambient conditions.

To further increase the stability of mixed perovsite devices Chen et al. [134] replaced FA with Cs. Devices fabricated with $\mathrm{CsSn}_{0.5} \mathrm{Ge}_{0.5} \mathrm{I}_{3}$ perovskties yielded a PCE of $7.11 \%$. This perovskite had remarkable stability because of a stable native-oxide layer that formed on its surface when the perovskite got exposed to air. This stable native-oxide layer had completely encapsulated the surface of the perovskite which resulted in more than $500 \mathrm{~h}$ operational stability under continuous 1 Sun illumination in inert environment [134]. Although remarkably stable, these devices showed low PCE as compared to organic cation based perovskites. Very recently Hayase and group reported the most efficient Sn based PSC with a PCE of more than 13\% [137]. To achieve such an outstanding PCE they used two different strategies of efficiency enhancement simultaneously. First of which involved the addition of metals to suppress Sn oxidation, while the second involved the addition of A cite cations to control perovskite crystallization. An optimized concentration of EAI was added to the perovskite lattice to favorably align energy bands between the perovskite and charge transport layers. To remove any iodide deficiency in the film $\mathrm{GeI}_{2}$ doping was performed, which combined with EAI addition reduced the trap density of the perovskite by 1 order of magnitude. In addition by controlling the amount of EAI in the perovskite lattice the tolerance factor close to 1 was achieved. This proved that this method can be successfully used to produce considerably stable crystal structures.

When devices were fabricated from $\mathrm{GeI}_{2}$ doped perovskite employing $\mathrm{p}-\mathrm{i}-\mathrm{n}$ architecture (FTO/PEDOT:PSS/GeI ${ }_{2}$ doped Sn-perovskite/ $\mathrm{C}_{60} / \mathrm{BCP} / \mathrm{Ag} / \mathrm{Au}$ ), PCE of $13.24 \%$ was achieved with a JSC of $20.32 \mathrm{~mA} \cdot \mathrm{cm}^{-2}$, a V $\mathrm{OC}$ of $0.84 \mathrm{~V}$ and a FF of $78 \%$ [137]. This is the highest value of PCE reported for $\mathrm{Sn}$ based perovskites till date. Table 7 show the progress in performance mixed cation devices has made so far. Tables 7 and 8 prove the importance of these devices in search of environment friendly highly efficient PSCs. 
Table 7. Performance of best Mixed tin halide (s) based devices reported until 2020.

\begin{tabular}{|c|c|c|c|c|c|c|c|}
\hline Year & Device Architecture & Perovskite Film Fabrication Technique/Perovskite Film & $\begin{array}{c}\mathrm{JSC} \\
\left(\mathrm{mA} \cdot \mathrm{cm}^{-2}\right)\end{array}$ & $\begin{array}{l}\mathrm{V}_{\text {OC }} \\
(\mathrm{V})\end{array}$ & FF & $\begin{array}{l}\text { EFF } \\
(\%)\end{array}$ & Ref. \\
\hline 2017 & ITO/PEDOT:PSS/Perovskite/C $60 / \mathrm{BCP} / \mathrm{Ag}$ & $\begin{array}{l}\text { Spin Coating using DMSO as solvent }+ \\
\text { Annealing/(FA) })_{x}(\mathrm{MA})_{1-x} \mathrm{SnI}_{3}+\mathrm{SnF}_{2}\end{array}$ & 21.2 & 0.61 & 0.627 & 8.12 & [107] \\
\hline 2017 & $\mathrm{FTO} / \mathrm{c}-\mathrm{TiO}_{2} / \mathrm{mp}^{-\mathrm{TiO}_{2}}$-Perovskite/PTAA/Au & $\begin{array}{l}\text { Spin Coating using DMF }+\mathrm{DMSO}_{\text {as solvent }+ \text { Annealing }} \\
\qquad /\{\mathrm{en}\} \mathrm{FASnI}_{3}+\mathrm{SnF}_{2}\end{array}$ & 22.54 & 0.480 & 65.96 & 7.14 & [110] \\
\hline 2017 & $\mathrm{FTO} / \mathrm{c}-\mathrm{TiO}_{2} / \mathrm{mp}-\mathrm{TiO}_{2}$-Perovskite/PTAA/Au & $\begin{array}{l}\text { Spin Coating using DMF + DMSO as solvent + Annealing } \\
\qquad /\{e n\} \mathrm{MASnI}_{3}+\mathrm{SnF}_{2}\end{array}$ & 24.28 & 0.428 & 0.6372 & 6.63 & [111] \\
\hline 2017 & 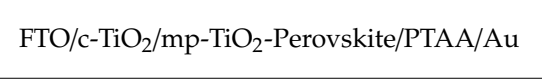 & $\begin{array}{l}\text { Spin Coating using DMF }+\mathrm{DMSO}_{\text {as solvent }+ \text { Annealing }} \\
\qquad /\{\mathrm{en}\} \mathrm{CsSnI}{ }_{3}+\mathrm{SnF}_{2}\end{array}$ & 25.07 & 0.280 & 0.5382 & 3.79 & [111] \\
\hline 2017 & 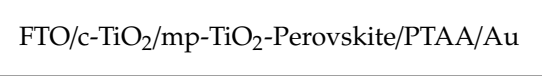 & $\begin{array}{c}\text { Spin coating using DMSO as solvent/(BA) }{ }_{2}(\mathrm{MA})_{3} \mathrm{Sn}_{4} \mathrm{I}_{13}+\mathrm{SnF}_{2}+ \\
\text { triethylphosphine (TEP) }\end{array}$ & 24.1 & 0.229 & 0.457 & 2.53 & [115] \\
\hline 2017 & ITO/NiO $/$ Perovskite/PCBM/Al & $\begin{array}{l}\text { Spin Coating using DMF + DMSO as solvent } \\
\quad /(\mathrm{PEA})_{2}(\mathrm{FA})_{\mathrm{n}-1} \mathrm{Sn}_{\mathrm{n}} \mathrm{I}_{3 \mathrm{n}+1}+\mathrm{SnF}_{2}\end{array}$ & 14.44 & 0.59 & 0.69 & 5.94 & [116] \\
\hline 2018 & ITO/LiF/PEDOT:PSS/Perovskite/C $60 / \mathrm{BCP} / \mathrm{Ag}$ & $\begin{array}{c}\text { Multichannel interdiffusion } \\
\text { two-step film fabrication protocol/(PEA,FA)SnI } 3\end{array}$ & 20.07 & 0.47 & 0.74 & 6.98 & [118] \\
\hline 2018 & ITO/PEDOT:PSS/Perovskite/ $\mathrm{C}_{60} / \mathrm{BCP} / \mathrm{Al}$ & $\begin{array}{l}\text { Spin Coating using DMF + DMSO as solvent }+ \text { Anti solvent } \\
\text { dripping + Annealing/(PEA })_{2}(\mathrm{FA})_{\mathrm{n}-1} \mathrm{Sn}_{\mathrm{n}} \mathrm{I}_{3 \mathrm{n}+1}\end{array}$ & 24.1 & 0.525 & 0.71 & 9 & [119] \\
\hline 2018 & ITO/PEDOT:PSS/Perovskite/C $60 / \mathrm{BCP} / \mathrm{Ag}$ & $\begin{array}{l}\text { Spin Coating using DMSO as solvent+ Hot antisolvent } \\
\text { treatment+Annealing in DMSO vapor atmoshpere/ } \\
(\mathrm{FA})_{x}(\mathrm{MA})_{1-x} \mathrm{SnI}_{3}+\mathrm{SnF}_{2}\end{array}$ & 19.4 & 0.55 & 0.67 & 7.2 & [110] \\
\hline 2018 & ITO/PEDOT:PSS/Perovskite/ $\mathrm{C}_{60} / \mathrm{BCP} / \mathrm{Al}$ & $\begin{array}{l}\text { Spin Coating using DMF }+ \text { DMSO as solvent + Antisolvent } \\
\text { dripping / } \mathrm{FA}_{0.75} \mathrm{MA}_{0.25} \mathrm{SnI}_{3}+\mathrm{SnF}_{2}\end{array}$ & 24.3 & 0.55 & 0.673 & 9.06 & [109] \\
\hline 2018 & ITO/Perovskite/PC 61 BM/BCP/Al & Spin Coating using DMF as solvent $/ \mathrm{Cs}_{\mathrm{x}} \mathrm{Rb}_{1-\mathrm{x}} \mathrm{SnI}_{3}+$ Excess $\mathrm{SnI}_{2}$ & $8.11 \pm 0.53$ & $0.48 \pm 0.04$ & $0.46 \pm 0.05$ & $1.81 \pm 0.30$ & [120] \\
\hline 2018 & ITO/PEDOT:PSS/Perovskite/ $\mathrm{C}_{60} / \mathrm{BCP} / \mathrm{Ag}$ & Spin Coating + Annealing $/ \mathrm{Cs}_{\mathrm{x}} \mathrm{FA}_{1-\mathrm{x}} \mathrm{FASnI}_{3}$ & 20.70 & 0.44 & 0.668 & 6.08 & [121] \\
\hline 2018 & ITO/PEDOT:PSS/Perovskite/C 60 /BCP/Ag & $\begin{array}{l}\text { Spin Coating using DMSO as solvent }+ \text { Antisolvent } \\
\text { dripping/FASnI } 3-y \mathrm{EDAI}_{2}+\mathrm{SnF}_{2}\end{array}$ & 21.3 & 0.538 & 0.718 & 8.9 & [122] \\
\hline 2019 & $\mathrm{FTO} / \mathrm{mp}^{-\mathrm{TiO}_{2}}$-Perovskite/BDT-4D/Au & $\begin{array}{l}\text { Spin Coating using DMF + DMSO as solvent + Annealing } \\
\qquad /\left\{\text { en\}FASnI } 3+\mathrm{SnF}_{2}\right.\end{array}$ & 22.41 & 0.497 & 0.682 & 7.59 & [112] \\
\hline 2019 & ITO/PEDOT:PSS/Perovskite/PC 60 BM/Al & $\begin{array}{l}\text { Spin Coating using DMF + DMSO as solvent + Antisolvent } \\
\text { dripping/ } \mathrm{MA}_{0.75} \mathrm{FA}_{0.15} \mathrm{PEA}_{0.1} \mathrm{Sn}\left(\mathrm{Br}_{0.25} \mathrm{I}_{0.75}\right)_{3}\end{array}$ & 16.45 & 0.49 & 0.633 & 4.63 & [123] \\
\hline 2019 & ITO/PEDOT:PSS/Perovskite/C 60 /BCP/Ag. & $-/ \mathrm{GA}_{x} \mathrm{FA}_{1-x-2 y} \mathrm{SnI}_{3}-y \mathrm{EDAI}_{2}+\mathrm{SnF}_{2}$ & 21.2 & 0.619 & 0.729 & 9.6 & [124] \\
\hline 2019 & ITO/PEDOT:PSS/Perovskite/C $60 / \mathrm{BCP} / \mathrm{Ag}$ & $\begin{array}{c}\text { Spin Coating using DMSO as solvent }+ \text { Antisolvent dripping }+ \\
\text { Annealing/ } \mathrm{PPA}_{x} \mathrm{FA}_{1-\mathrm{x}} \mathrm{SnI}_{3}\end{array}$ & 23.34 & 0.56 & 0.735 & 9.61 & [128] \\
\hline
\end{tabular}


Table 7. Cont.

\begin{tabular}{|c|c|c|c|c|c|c|c|}
\hline Year & Device Architecture & Perovskite Film Fabrication Technique/Perovskite Film & $\begin{array}{c}\mathrm{JSC} \\
\left(\mathrm{mA} \cdot \mathrm{cm}^{-2}\right)\end{array}$ & $\begin{array}{l}\mathrm{V}_{\mathrm{OC}} \\
\text { (V) }\end{array}$ & FF & $\begin{array}{l}\mathrm{EFF} \\
(\%)\end{array}$ & Ref. \\
\hline 2020 & ITO/PEDOT:PSS/ Perovskite/PCBM+PEI/Ag & $\begin{array}{l}\text { Spin Coating using DMSO + DMF as solvent }+ \text { Antisolvent } \\
\text { dripping + Annealing/ } \mathrm{NH}_{2} \mathrm{GACl}+\mathrm{FASnI}_{3}+\mathrm{SnF}_{2}\end{array}$ & $19.30 \pm 0.35$ & $0.54 \pm 0.02$ & $0.681 \pm 0.084$ & $7.10 \pm 0.2$ & [127] \\
\hline 2020 & $\mathrm{FTO} / \mathrm{c}-\mathrm{TiO}_{2} / \mathrm{mp}-\mathrm{TiO}_{2} /$ perovskite$/ \mathrm{PTAA} / \mathrm{Au}$ & $\mathrm{BA}_{2}(\mathrm{FA})_{\mathrm{n}-1} \mathrm{Sn}_{\mathrm{n}} \mathrm{I}_{3 \mathrm{n}+1}$ & 22.02 & 0.439 & 0.433 & 4.12 & [117] \\
\hline 2020 & ITO/PEDOT:PSS/Perovskite/C $60 / \mathrm{BCP} / \mathrm{Ag}$ & $\begin{array}{l}\text { Secondary crystallization growth (SCG) technique/ } \\
\qquad \mathrm{FA}_{0.75} \mathrm{MA}_{0.25} \mathrm{SnI}_{2.75} \mathrm{Br}_{0.25}\end{array}$ & 22.3 & 0.52 & 0.695 & 8.07 & [129] \\
\hline 2020 & ITO/PEDOT:PSS/Perovskite/C $60 / \mathrm{BCP} / \mathrm{Ag}$ & $\begin{array}{l}\text { Spin Coating using DMSO as solvent + Antisolvent dripping of CB } \\
+ \text { Annealing/FASnI } 3 \text {-FOEI }\end{array}$ & 21.59 & 0.67 & 0.75 & 10.81 & [130] \\
\hline 2020 & $\begin{array}{l}\text { ITO/PEDOT:PSS/Perovskite/ } \\
\text { PCBM/BCP/Ag }\end{array}$ & $\begin{array}{l}\text { Spin Coating using DMSO as solvent + Antisolvent dripping of CB } \\
+ \text { Annealing/CsFASnI } 3\end{array}$ & 21.6 & 0.64 & 0.752 & 10.4 & [131] \\
\hline 2020 & ITO/PEDOT/Perovskite/ICBA/BCP/Ag & $\begin{array}{l}\text { Spin Coating using DMSO + DMF as solvent }+ \text { Antisolvent } \\
\text { dripping of toluene }+ \text { Annealing/ } \mathrm{PEA}_{x} \mathrm{FA}_{1-\mathrm{x}} \mathrm{SnI}_{3}+\mathrm{SCN}\end{array}$ & 17.4 & 0.94 & 0.75 & 12.4 & [132] \\
\hline 2020 & FTO/PEDOT:PSS/Perovskite/ $\mathrm{C}_{60} / \mathrm{BCP} / \mathrm{Ag} / \mathrm{Au}$ & $\begin{array}{l}\text { Spin Coating using DMSO + DMF as solvent }+ \text { Antisolvent } \\
\text { dripping of } \mathrm{CB}+\text { Annealing/FA } \mathrm{FA}_{0.92} \mathrm{PEA}_{0.08} \mathrm{Sn}_{\mathrm{x}} \mathrm{Ge}_{1-\mathrm{x}} \mathrm{I}_{3}\end{array}$ & 21.92 & 0.46 & 0.73 & 7.45 & [136] \\
\hline 2020 & FTO/PEDOT:PSS/perovskite/C $60 / \mathrm{BCP} / \mathrm{Ag} / \mathrm{Au}$. & $\mathrm{GeI}_{2}$ doped $\left(\mathrm{FA}_{0.9} \mathrm{EA}_{0.1}\right)_{0.98} \mathrm{EDA}_{0.01} \mathrm{SnI}_{3}$ & 20.32 & 0.84 & 0.78 & 13.24 & [137] \\
\hline
\end{tabular}


Table 8. Stability of Mixed Cation tin halide(s) based perovskites.

\begin{tabular}{|c|c|c|c|c|}
\hline Year & Device Architecture & Testing Environment & Stability & Ref. \\
\hline 2017 & $\begin{array}{c}\mathrm{FTO} / \mathrm{c}-\mathrm{TiO}_{2} / \mathrm{mp}_{-}-\mathrm{TiO}_{2}-(\mathrm{BA})_{2}(\mathrm{MA})_{3} \mathrm{Sn}_{4} \mathrm{I}_{13}+\mathrm{SnF}_{2}+ \\
\text { triethylphosphine (TEP)/PTAA/Au }\end{array}$ & Encapsulated devices under inert environment & $\begin{array}{c}\text { Retained almost } 90 \% \text { of initial efficiency after } \\
720 \mathrm{~h}\end{array}$ & [115] \\
\hline 2017 & ITO/PEDOT:PSS/(FA) $)_{x}(\mathrm{MA})_{1-x} \mathrm{SnI}_{3}+\mathrm{SnF}_{2} / \mathrm{C}_{60} / \mathrm{BCP} / \mathrm{Ag}$ & Encapsulated devices stored in inert environment & $\begin{array}{l}\text { Retained almost } 80 \% \text { of initial efficiency after } \\
400 \mathrm{~h}\end{array}$ & [107] \\
\hline 2017 & $\mathrm{FTO} / \mathrm{c}-\mathrm{TiO}_{2} / \mathrm{mp}^{-\mathrm{TiO}_{2}-}-\{\mathrm{en}\} \mathrm{FASnI}_{3}+\mathrm{SnF}_{2} / \mathrm{PTAA} / \mathrm{Au}$ & Encapsulated devices when stored & $\begin{array}{l}\text { Retained almost all of their initial } \\
\text { performance after } 1000 \mathrm{~h}\end{array}$ & [110] \\
\hline 2018 & ITO/PEDOT:PSS/FA $0.75 \mathrm{MA}_{0.25} \mathrm{SnI}_{3}+\mathrm{SnF}_{2} / \mathrm{C}_{60} / \mathrm{BCP} / \mathrm{Al}$ & Encapsulated devices stored in inert environment & $\begin{array}{l}\text { Retained almost } 75 \% \text { of their initial } \\
\text { efficiencies after } 720 \mathrm{~h}\end{array}$ & [109] \\
\hline 2018 & ITO/PEDOT:PSS/Cs $\mathrm{FA}_{1-\mathrm{x}} \mathrm{FASnI}_{3} / \mathrm{C}_{60} / \mathrm{BCP} / \mathrm{Ag}$ & Encapsulated devices stored in inert environment & Remained stable for almost $2000 \mathrm{~h}$ & [121] \\
\hline 2018 & ITO/PEDOT:PSS/FASnI $3-y \mathrm{EDAI}_{2}+\mathrm{SnF}_{2} / \mathrm{C}_{60} / \mathrm{BCP} / \mathrm{Ag}$ & Encapsulated devices & $\begin{array}{l}\text { Retained } 90 \% \text { of their initial efficiencies upto } \\
\qquad 2000 \mathrm{~h}\end{array}$ & [122] \\
\hline 2019 & $\begin{array}{c}\text { ITO/PEDOT:PSS/ } \mathrm{GA}_{x} \mathrm{FA}_{1-x-2 y} \mathrm{SnI}_{3}-y \mathrm{EDAI}_{2}+\mathrm{SnF}_{2} / \mathrm{C}_{60} \\
\text { /BCP/Ag. }\end{array}$ & $\begin{array}{c}\text { Encapsulated device under } 1 \text { Sun illumination in } \\
\text { ambient condition (RH }=50 \%) \\
\text { Un-encapsulated device stored in ambient } \\
\text { condition }(\mathrm{RH}=60 \%) \\
\text { Un-encapsulated device stored in ambient } \\
\text { condition }(\mathrm{RH}=20 \%) \text { Un-encapsulated device } \\
\text { stored in inert environment }\end{array}$ & $\begin{array}{c}\text { Efficiency remained stable for } 1 \mathrm{~h} \\
\text { Retained } 80 \% \text { of its initial PCE after } 96 \mathrm{~h} \\
\text { Retained } 100 \% \text { of its initial PCE after } 170 \mathrm{~h} \\
\text { PCE increased from } 7.3 \% \text { to } 9.6 \% \text { after } 2000 \mathrm{~h}\end{array}$ & [124] \\
\hline 2019 & ITO/PEDOT:PSS/ $\mathrm{PPA}_{\mathrm{x}} \mathrm{FA}_{1-\mathrm{x}} \mathrm{SnI}_{3} / \mathrm{C}_{60} / \mathrm{BCP} / \mathrm{Ag}$ & $\begin{array}{c}\text { Un-encapsulated device stored in inert } \\
\text { environment }\end{array}$ & Retained $90 \%$ of its initial PCE after $1440 \mathrm{~h}$ & [128] \\
\hline 2020 & ITO/PEDOT:PSS/NH ${ }_{2} \mathrm{GACl}+\mathrm{FASnI}_{3} / \mathrm{PCBM}+\mathrm{PEI} / \mathrm{Ag}$ & $\begin{array}{c}\text { Un-encapsulated device stored in inert } \\
\text { environment }\end{array}$ & Retained $90 \%$ of its initial PCE after $720 \mathrm{~h}$ & [127] \\
\hline 2020 & $\mathrm{FTO} / \mathrm{c}-\mathrm{TiO}_{2} / \mathrm{mp}-\mathrm{TiO}_{2} / \mathrm{BA}_{2}(\mathrm{FA})_{\mathrm{n}-1} \mathrm{Sn}_{\mathrm{n}} \mathrm{I}_{3 \mathrm{n}+1} / \mathrm{PTAA} / \mathrm{Au}$ & $\begin{array}{l}\text { Un-encapsulated device stored in inert } \\
\text { environment }\end{array}$ & Retained $80 \%$ of its initial PCE after $336 \mathrm{~h}$ & [117] \\
\hline 2020 & $\begin{array}{c}\text { ITO/PEDOT:PSS/FA }{ }_{0.75} \mathrm{MA}_{0.25} \mathrm{SnI}_{2.75} \mathrm{Br}_{0.25} / \mathrm{C}_{60} / \\
\text { BCP/Ag }\end{array}$ & $\begin{array}{c}\text { Un-encapsulated devices stored in inert } \\
\text { environment }\end{array}$ & Retained $87 \%$ of their initial PCEs after $1000 \mathrm{~h}$ & [129] \\
\hline 2020 & ITO/PEDOT:PSS/ FASnI ${ }_{3}$-FOEI / $\mathrm{C}_{60} / \mathrm{BCP} / \mathrm{Ag}$ & Under continuous 1 Sun irradiation & Remained Stable for $500 \mathrm{~h}$ & [130] \\
\hline 2020 & $\begin{array}{l}\text { ITO/PEDOT:PSS/CsFASnI } 3 / \\
\text { PCBM/BCP/Ag }\end{array}$ & $\begin{array}{c}\text { Encapsulated device operation at simulated } \\
\text { illumination of AM } 1.5 \mathrm{G}\end{array}$ & Retained $95 \%$ of its initial PCE after $1000 \mathrm{~h}$ & [131] \\
\hline 2020 & ITO/PEDOT / $\mathrm{PEA}_{\mathrm{x}} \mathrm{FA}_{1-\mathrm{x}} \mathrm{SnI}_{3}+\mathrm{SCN} / \mathrm{ICBA} / \mathrm{BCP} / \mathrm{Ag}$ & Encapsulated device stored in shelf & Retained $90 \%$ of its initial PCE for $3800 \mathrm{~h}$ & [132] \\
\hline 2020 & FTO/PEDOT:PSS/FA $0.92 \mathrm{PEA}_{0.08} \mathrm{Sn}_{\mathrm{x}} \mathrm{Ge}_{1-\mathrm{x}} \mathrm{I}_{3} / \mathrm{C}_{60} / \mathrm{BCP} / \mathrm{Ag} / \mathrm{Au}$ & $\begin{array}{c}\text { Un-encapsulated devices continuous operation at } \\
\text { simulated illumination of AM } 1.5 \mathrm{G} \text { in ambient } \\
\text { conditions }\end{array}$ & Retained $70 \%$ of their initial PCEs for $3 \mathrm{~h}$ & [136]. \\
\hline 2020 & FTO/PCBM/CsSn $0.5 \mathrm{Ge}_{0.5} \mathrm{I}_{3}$-Native oxide/Spiro-OMeTAD/Au & $\begin{array}{l}\text { Un-encapsulated devices continuous operation at } \\
\text { simulated illumination of AM } 1.5 \mathrm{G} \text { in inert } \\
\text { conditions }\end{array}$ & $\begin{array}{l}\text { Retained more than } 90 \% \text { of their initial PCEs } \\
\text { for } 500 \mathrm{~h}\end{array}$ & [134] \\
\hline
\end{tabular}




\section{Conclusions and Outlook}

In this comprehensive Review, we have summarized all the efforts made on enhancing the performance and stability of Sn based PSCs from the very first report in 2014 to reports published in 2020. Performance and stability of Sn based PSCs is largely depended on perovskite film quality, device architecture and fabrication technique. Optimizing film deposition technique, interface modification and cation substitution have attracted much attention in recent years. Band gap engineering and solvent engineering proved effective in elevating overall PCE and stability of PSCs. Although still lagging in both efficiency and stability when compared to conventional $\mathrm{Pb}$ based perovskites, the $\mathrm{Sn}$ based counterparts are progressing ever so rapidly. With excellent optical and electrical properties and recent demonstration of efficiency exceeding $13 \%$ the prospect of these perovskites playing a leading role in the future PV market cannot be ruled out. PCE can be significantly improved from the current highest reported efficiencies of $7.78 \%$ [60], 10.17\% [81], $4.81 \%$ [37,90] and 13.24\% for MASnX 3 , FASnX 3 , $\mathrm{CsSnI}_{3}$ and $\mathrm{MCSnX}_{3}$, respectively. As the theoretical maximum PCE calculated for $\mathrm{MASnX}_{3}, \mathrm{FASnX}_{3}$ and $\mathrm{CsSnI}_{3}$ based PSCs is $19.9 \%, 26.9 \%$, and $25.6 \%$ respectively [37]. Based on our thorough analysis, we will provide suggestions on ways to further elevate the PCE and improve stability of tin-based PSCs. Moreover, focusing the commercial applications of Sn based PSCs in building integrated photovoltaics (BIPVs), suggestions to enhance transparency of PSCs are also provided.

- Minimizing oxygen exposure. One of the major reasons for low performance is $\mathrm{Sn}^{2+}$ oxidation. Reducing oxygen exposure during film growth by using techniques such as reducing vapor atmosphere [50] and vacuum growth [129] can significantly improve both efficiency and stability by minimizing p-type doping and enhancing film quality.

- Controlling perovskite crystallization. To reduce density of trap states and optimize charge carrier dynamics different strategies can be used such as introduction of [poly(ethylene-co-vinyl acetate) [82], pentafluorophen-oxyethylammonium iodide (FOEI) [130] or triethylphosphine (TEP) [115] in the perovskite matrix.

- Purification of Sn sources to prevent oxidation. Any commercial SnX $X_{2}$ source contains $\mathrm{Sn}^{4+}$, even those with $99 \%$ purity contain a significant concentration of oxidized $\mathrm{Sn}^{4+}$ resulting in poor performance and reproducibility issues [80]. Addition of tin powder can solve this problem by reacting with $\mathrm{Sn}^{4+}$ and reducing it to $\mathrm{Sn}^{2+}$ state.

- Inverted p-i-n architecture should be preferred. Better quality of perovskite film can be formed on HTLs by avoiding using salt-doped hole selective layers (HSLs), known to damage Sn perovskite [51,70]. Also p-i-n architecture can favorably align the energy levels of HTL and ETL with perovskite than when used in conventional n-i-p configuration.

- Increasing $\mathrm{V}_{\mathrm{OC}}$ by optimizing energy levels. While, the short circuit current $\left(\mathrm{J}_{S C}\right)$ of the PSCs is approaching the theoretical limit, the open circuit voltage $\left(\mathrm{V}_{\mathrm{OC}}\right)$ emerges as a major limiting factor for overall performance of Sn based PSCs. $V_{O C}$ is reduced greatly due to the existence of severe recombination and mismatched energy levels in the device. New techniques of bandgap engineering must be explored along trying more suitable materials as HTL and ETL. For example, Jiang et al. [132] used indene- $\mathrm{C}_{60}$ bisadduct (ICBA) as ETL instead of commonly used PCBM which considerably suppressed the iodide remote doping resulting in a record $\mathrm{V}_{\mathrm{OC}}$ of $0.94 \mathrm{~V}$ and PCE of $12.4 \%$ with shelf life of more than $3800 \mathrm{~h}$.

- Regulating the A site cation to achieve a tolerance factor of nearly 1. An inverse relation exists between tolerance factor and lattice strain of perovskite crystal. Optimizing A site cation with proper substitution is vital to achieve high performance and stability. Regulating A cite cation can make the tolerance factor as close to one as possible, resulting in a stable perovskite structure. For example Nishimura et al. [137] partially substituted formamidinium cation with ethylammonium cation to achieve tolerance factor of 0.9985 , achieving record PCE exceeding $13 \%$.

- Doping Ge in Sn based PSCs. Ge is known to passivate traps and stabilize the mixed 2D/3D perovskite lattice by simultaneously suppressing defect/trap states and $\mathrm{Sn}^{2+}$ oxidation $[133,134]$. 
The addition of an optimum amount of Ge to develop efficient and stable tin-based PSCs should be an efficient approach. $\mathrm{Ge}^{2+}$ oxidizes into $\mathrm{Ge}^{4+}$ resulting in a thin $\mathrm{GeO}_{4}$ protecting layer encapsulating tin perovskite crystals. The highest PCE of $13.24 \%$ reported for Sn based PSCs is achieved doping Ge in the perovskite lattice [137].

- Enhancing transparency using bandgap engineering. Halides $(\mathrm{Cl}, \mathrm{Br}, \mathrm{I})$ play a major role in determining the bandgap of the perovskite. As the halide radii decrease, the bandgap of perovskite increases, allowing more light in the visible region to pass through the perovskite film. For example, the optical bandgap changed from $1.27 \mathrm{eV}$ for pure $\mathrm{CsSnI}_{3}$ to $1.37 \mathrm{eV}$ for $\mathrm{CsSnI}_{2} \mathrm{Br}$, and from $1.65 \mathrm{eV}$ for $\mathrm{CsSnIBr}_{2}$ to $1.75 \mathrm{eV}$ for $\mathrm{CsSnBr}_{3}$. The increasing bromine content also induced a change in the color of perovskite films from black to light brown, increasing transparency [88].

- Use of transparent contact. Currently most of the fabricated devices use relatively thick $(\sim 70 \mathrm{~nm}$ or more) metal film as back contact which makes the design opaque. However, a fully semitransparent PSC can be achieved by using 2D structures, transparent conducting oxides (TCOs), graphene electrodes and metal nanowires etc.

Recent progress in the field confirms that Sn based PSCs has great potential for commercialization with very optimistic future prospects. Starting with a PCE of $5.73 \%$ and a shelf life of $12 \mathrm{~h}$, within few years the PCE has exceeded 13\% and stability reached $3800 \mathrm{~h}$. With further research and resources directed in this field these nontoxic PSCs will be a major trend of the future.

Author Contributions: Writing-Original Draft Preparation, S.A.A.S., and Z.G.; Data Curation, M.H.S., K.K., K.G., F.S., J.S., A.K.T. and Y.G.; Writing-Review \&Editing, Z.G. All authors have read and agreed to the published version of the manuscript.

Funding: This research was supported by Dongguan University of Technology.

Acknowledgments: The authors acknowledge the financial support provided by Dongguan University of Technology to carry out this extensive research work.

Conflicts of Interest: The authors declare no conflict of interest.

\section{References}

1. Green, M.A.; Hishikawa, Y.; Dunlop, E.D.; Levi, D.H.; Hohl-Ebinger, J.; Yoshita, M.; Ho-Baillie, A.W.Y. Solar cell efficiency tables (Version 53). Prog. Photovolt. Res. Appl. 2019, 27, 3-12. [CrossRef]

2. Lin, J.-T.; Hu, Y.-K.; Hou, C.-H.; Liao, C.-C.; Chuang, W.-T.; Chiu, C.-W.; Tsai, M.-K.; Shyue, J.-J.; Chou, P.-T. Superior Stability and Emission Quantum Yield (23\% $\pm 3 \%)$ of Single-Layer 2D Tin Perovskite TEA2SnI4 via Thiocyanate Passivation. Small 2020, 16, 2000903. [CrossRef] [PubMed]

3. Gao, W.; Li, P.; Chen, J.; Ran, C.; Wu, Z. Interface Engineering in Tin Perovskite Solar Cells. Adv. Mater. Interfaces 2019, 6, 1901322. [CrossRef]

4. Mali, S.S.; Shim, C.S.; Hong, C.K. Highly porous Zinc Stannate $\left(\mathrm{Zn}_{2} \mathrm{SnO}_{4}\right)$ nanofibers scaffold photoelectrodes for efficient methyl ammonium halide perovskite solar cells. Sci. Rep. 2015, 5, 11424. [CrossRef] [PubMed]

5. Mali, S.S.; Shim, C.S.; Hong, C.K. Highly stable and efficient solid-state solar cells based on methylammonium lead bromide $\left(\mathrm{CH}_{3} \mathrm{NH}_{3} \mathrm{PbBr}_{3}\right)$ perovskite quantum dots. NPG Asia Mater. 2015, 7, e208. [CrossRef]

6. Xie, F.; Chen, C.-C.; Wu, Y.; Li, X.; Cai, M.; Liu, X.; Yang, X.; Han, L. Vertical recrystallization for highly efficient and stable formamidinium-based inverted-structure perovskite solar cells. Energy Environ. Sci. 2017, 10, 1942-1949. [CrossRef]

7. Liu, T.; Zhou, Y.; Li, Z.; Zhang, L.; Ju, M.G.; Luo, D.; Yang, Y.; Yang, M.; Kim, D.H.; Yang, W. Stable Formamidinium-Based Perovskite Solar Cells via In Situ Grain Encapsulation. Adv. Energy Mater. 2018, 8, 1800232. [CrossRef]

8. Zhou, W.; Zhao, Y.; Zhou, X.; Fu, R.; Li, Q.; Zhao, Y.; Liu, K.; Yu, D.; Zhao, Q. Light-independent ionic transport in inorganic perovskite and ultrastable Cs-based perovskite solar cells. J. Phys. Chem. Lett. 2017, 8 , 4122-4128. [CrossRef]

9. $\quad$ Liang, J.; Wang, C.; Wang, Y.; Xu, Z.; Lu, Z.; Ma, Y.; Zhu, H.; Hu, Y.; Xiao, C.; Yi, X. All-inorganic perovskite solar cells. J. Am. Chem. Soc. 2016, 138, 15829-15832. [CrossRef] 
10. Qin, P.; Tanaka, S.; Ito, S.; Tetreault, N.; Manabe, K.; Nishino, H.; Nazeeruddin, M.K.; Grätzel, M. Inorganic hole conductor-based lead halide perovskite solar cells with $12.4 \%$ conversion efficiency. Nat. Commun. 2014, 5, 3834. [CrossRef]

11. Krishnamoorthy, T.; Ding, H.; Yan, C.; Leong, W.L.; Baikie, T.; Zhang, Z.; Sherburne, M.; Li, S.; Asta, M.; Mathews, N. Lead-free germanium iodide perovskite materials for photovoltaic applications. J. Mater. Chem. A 2015, 3, 23829-23832. [CrossRef]

12. Asghar, M.; Zhang, J.; Wang, H.; Lund, P. Device stability of perovskite solar cells-A review. Renew. Sustain. Energy Rev. 2017, 77, 131-146. [CrossRef]

13. Chondroudis, K.; Mitzi, D.B. Electroluminescence from an organic- inorganic perovskite incorporating a quaterthiophene dye within lead halide perovskite layers. Chem. Mater. 1999, 11, 3028-3030. [CrossRef]

14. Mitzi, D.B.; Chondroudis, K.; Kagan, C.R. Organic-inorganic electronics. IBM J. Res. Dev. 2001, 45, $29-45$. [CrossRef]

15. Kojima, A.; Teshima, K.; Shirai, Y.; Miyasaka, T. Organometal halide perovskites as visible-light sensitizers for photovoltaic cells. J. Am. Chem. Soc. 2009, 131, 6050-6051. [CrossRef] [PubMed]

16. Im, J.-H.; Lee, C.-R.; Lee, J.-W.; Park, S.-W.; Park, N.-G. 6.5\% efficient perovskite quantum-dot-sensitized solar cell. Nanoscale 2011, 3, 4088-4093. [CrossRef]

17. Kim, H.-S.; Lee, C.-R.; Im, J.-H.; Lee, K.-B.; Moehl, T.; Marchioro, A.; Moon, S.-J.; Humphry-Baker, R.; Yum, J.-H.; Moser, J.E. Lead iodide perovskite sensitized all-solid-state submicron thin film mesoscopic solar cell with efficiency exceeding 9\%. Sci. Rep. 2012, 2, 591. [CrossRef]

18. Zhu, X. The Perovskite Fever and Beyond; ACS Publications: Washington, DC, USA, 2016.

19. Heo, J.H.; Im, S.H.; Noh, J.H.; Mandal, T.N.; Lim, C.-S.; Chang, J.A.; Lee, Y.H.; Kim, H.-j.; Sarkar, A.; Nazeeruddin, M.K. Efficient inorganic-organic hybrid heterojunction solar cells containing perovskite compound and polymeric hole conductors. Nat. Photonics 2013, 7, 486. [CrossRef]

20. Zhou, H.; Chen, Q.; Li, G.; Luo, S.; Song, T.-b.; Duan, H.-S.; Hong, Z.; You, J.; Liu, Y.; Yang, Y. Interface engineering of highly efficient perovskite solar cells. Science 2014, 345, 542-546. [CrossRef]

21. Park, J.H.; Seo, J.; Park, S.; Shin, S.S.; Kim, Y.C.; Jeon, N.J.; Shin, H.W.; Ahn, T.K.; Noh, J.H.; Yoon, S.C. Efficient $\mathrm{CH} 3 \mathrm{NH} 3 \mathrm{PbI} 3$ perovskite solar cells employing nanostructured p-type $\mathrm{NiO}$ electrode formed by a pulsed laser deposition. Adv. Mater. 2015, 27, 4013-4019. [CrossRef]

22. Dong, Q.; Yuan, Y.; Shao, Y.; Fang, Y.; Wang, Q.; Huang, J. Abnormal crystal growth in $\mathrm{CH}_{3} \mathrm{NH}_{3} \mathrm{PbI}_{3-\mathrm{x}} \mathrm{Cl}_{x}$ using a multi-cycle solution coating process. Energy Environ. Sci. 2015, 8, 2464-2470. [CrossRef]

23. Carnie, M.J.; Charbonneau, C.; Davies, M.L.; Troughton, J.; Watson, T.M.; Wojciechowski, K.; Snaith, H.; Worsley, D.A. A one-step low temperature processing route for organolead halide perovskite solar cells. Chem. Commun. 2013, 49, 7893-7895. [CrossRef] [PubMed]

24. Zhao, Y.; Zhu, K. Solution Chem. engineering toward high-efficiency perovskite solar cells. J. Phys. Chem. Lett. 2014, 5, 4175-4186. [CrossRef] [PubMed]

25. Hao, F.; Stoumpos, C.C.; Liu, Z.; Chang, R.P.; Kanatzidis, M.G. Controllable perovskite crystallization at a gas-solid interface for hole conductor-free solar cells with steady power conversion efficiency over $10 \%$. J. Am. Chem. Soc. 2014, 136, 16411-16419. [CrossRef]

26. Zhao, D.; Ke, W.; Grice, C.R.; Cimaroli, A.J.; Tan, X.; Yang, M.; Collins, R.W.; Zhang, H.; Zhu, K.; Yan, Y. Annealing-free efficient vacuum-deposited planar perovskite solar cells with evaporated fullerenes as electron-selective layers. Nano Energy 2016, 19, 88-97. [CrossRef]

27. Li, J.; Munir, R.; Fan, Y.; Niu, T.; Liu, Y.; Zhong, Y.; Yang, Z.; Tian, Y.; Liu, B.; Sun, J. Phase Transition Control for High-Performance Blade-Coated Perovskite Solar Cells. Joule 2018, 2, 1313-1330. [CrossRef]

28. Gribkova, O.L.; Kabanova, V.A.; Tameev, A.R.; Nekrasov, A.A. Ink-Jet Printing of Polyaniline Layers for Perovskite Solar Cells. Tech. Phys. Lett. 2019, 45, 858-861. [CrossRef]

29. Barrows, A.T.; Pearson, A.J.; Kwak, C.K.; Dunbar, A.D.; Buckley, A.R.; Lidzey, D.G. Efficient planar heterojunction mixed-halide perovskite solar cells deposited via spray-deposition. Energy Environ. Sci. 2014, 7, 2944-2950. [CrossRef]

30. Rong, Y.; Ming, Y.; Ji, W.; Li, D.; Mei, A.; Hu, Y.; Han, H. Toward Industrial-Scale Production of Perovskite Solar Cells: Screen Printing, Slot-Die Coating, and Emerging Techniques. J. Phys. Chem. Lett. 2018, 9, 2707-2713. [CrossRef] 
31. Song, Z.; Watthage, S.C.; Phillips, A.B.; Heben, M.J. Pathways toward high-performance perovskite solar cells: Review of recent advances in organo-metal halide perovskites for photovoltaic applications. J. Photonics Energy 2016, 6, 022001. [CrossRef]

32. Green, M.A.; Dunlop, E.D.; Hohlebinger, J.; Yoshita, M.; Kopidakis, N.; Hobaillie, A. Solar cell efficiency tables (Version 55). Prog. Photovolt. 2020, 28, 3-15. [CrossRef]

33. Saliba, M.; Correa-Baena, J.-P.; Wolff, C.M.; Stolterfoht, M.; Phung, N.; Albrecht, S.; Neher, D.; Abate, A. How to Make over 20\% Efficient Perovskite Solar Cells in Regular (n-i-p) and Inverted (p-i-n) Architectures. Chem. Mater. 2018, 30, 4193-4201. [CrossRef]

34. Abate, A. Perovskite solar cells go lead free. Joule 2017, 1, 659-664. [CrossRef]

35. Kopacic, I.; Friesenbichler, B.; Hoefler, S.F.; Kunert, B.; Plank, H.; Rath, T.; Trimmel, G. Enhanced Performance of Germanium Halide Perovskite Solar Cells through Compositional Engineering. ACS Appl. Energy Mater. 2018, 1, 343-347. [CrossRef]

36. Stoumpos, C.C.; Frazer, L.; Clark, D.J.; Kim, Y.S.; Rhim, S.H.; Freeman, A.J.; Ketterson, J.B.; Jang, J.I.; Kanatzidis, M.G. Hybrid Germanium Iodide Perovskite Semiconductors: Active Lone Pairs, Structural Distortions, Direct and Indirect Energy Gaps, and Strong Nonlinear Optical Properties. J. Am. Chem. Soc. 2015, 137, 6804-6819. [CrossRef]

37. Qian, J.; Xu, B.; Tian, W. A comprehensive theoretical study of halide perovskites ABX3. Org. Electron. 2016, 37, 61-73. [CrossRef]

38. Cortecchia, D.; Dewi, H.A.; Yin, J.; Bruno, A.; Chen, S.; Baikie, T.; Boix, P.P.; Grätzel, M.; Mhaisalkar, S.; Soci, C.; et al. Lead-Free MA2CuClxBr4-x Hybrid Perovskites. Inorg. Chem. 2016, 55, 1044-1052. [CrossRef]

39. Stoumpos, C.C.; Malliakas, C.D.; Kanatzidis, M.G. Semiconducting tin and lead iodide perovskites with organic cations: Phase transitions, high mobilities, and near-infrared photoluminescent properties. Inorg. Chem. 2013, 52, 9019-9038. [CrossRef]

40. Abdelaziz, S.; Zekry, A.; Shaker, A.; Abouelatta, M. Investigating the performance of formamidinium tin-based perovskite solar cell by SCAPS device simulation. Opt. Mater. 2020, 101, 109738. [CrossRef]

41. Takahashi, Y.; Hasegawa, H.; Takahashi, Y.; Inabe, T. Hall mobility in tin iodide perovskite CH3NH3SnI3: Evidence for a doped semiconductor. J. Solid State Chem. 2013, 205, 39-43. [CrossRef]

42. Noel, N.K.; Stranks, S.D.; Abate, A.; Wehrenfennig, C.; Guarnera, S.; Haghighirad, A.-A.; Sadhanala, A.; Eperon, G.E.; Pathak, S.K.; Johnston, M.B. Lead-free organic-inorganic tin halide perovskites for photovoltaic applications. Energy Environ. Sci. 2014, 7, 3061-3068. [CrossRef]

43. Stranks, S.D.; Eperon, G.E.; Grancini, G.; Menelaou, C.; Alcocer, M.J.; Leijtens, T.; Herz, L.M.; Petrozza, A.; Snaith, H.J. Electron-hole diffusion lengths exceeding 1 micrometer in an organometal trihalide perovskite absorber. Science 2013, 342, 341-344. [CrossRef] [PubMed]

44. Hao, F.; Stoumpos, C.C.; Cao, D.H.; Chang, R.P.; Kanatzidis, M.G. Lead-free solid-state organic-inorganic halide perovskite solar cells. Nat. Photonics 2014, 8, 489. [CrossRef]

45. Hao, F.; Stoumpos, C.C.; Guo, P.; Zhou, N.; Marks, T.J.; Chang, R.P.; Kanatzidis, M.G. Solvent-mediated crystallization of $\mathrm{CH} 3 \mathrm{NH} 3 \mathrm{SnI} 3$ films for heterojunction depleted perovskite solar cells. J. Am. Chem. Soc. 2015, 137, 11445-11452. [CrossRef] [PubMed]

46. Burschka, J.; Pellet, N.; Moon, S.-J.; Humphry-Baker, R.; Gao, P.; Nazeeruddin, M.K.; Grätzel, M. Sequential deposition as a route to high-performance perovskite-sensitized solar cells. Nature 2013, 499, 316. [CrossRef]

47. Zhang, S.; Audebert, P.; Wei, Y.; Al Choueiry, A.; Lanty, G.; Bréhier, A.; Galmiche, L.; Clavier, G.; Boissiere, C.; Lauret, J.-S. Preparations and characterizations of luminescent two dimensional organic-inorganic perovskite semiconductors. Materials 2010, 3, 3385-3406. [CrossRef]

48. Jeon, N.J.; Noh, J.H.; Kim, Y.C.; Yang, W.S.; Ryu, S.; Seok, S.I. Solvent engineering for high-performance inorganic-organic hybrid perovskite solar cells. Nat. Mater. 2014, 13, 897. [CrossRef]

49. Greul, E.; Docampo, P.; Bein, T. Synthesis of Hybrid Tin Halide Perovskite Solar Cells with Less Hazardous Solvents: Methanol and 1, 4-Dioxane. Z. Für Anorg. Und Allg. Chem. 2017, 643, 1704-1711. [CrossRef]

50. Song, T.-B.; Yokoyama, T.; Stoumpos, C.C.; Logsdon, J.; Cao, D.H.; Wasielewski, M.R.; Aramaki, S.; Kanatzidis, M.G. Importance of reducing vapor atmosphere in the fabrication of tin-based perovskite solar cells. J. Am. Chem. Soc. 2017, 139, 836-842. [CrossRef]

51. Yokoyama, T.; Cao, D.H.; Stoumpos, C.C.; Song, T.-B.; Sato, Y.; Aramaki, S.; Kanatzidis, M.G. Overcoming short-circuit in lead-free $\mathrm{CH}_{3} \mathrm{NH}_{3} \mathrm{SnI}_{3}$ perovskite solar cells via kinetically controlled gas-solid reaction film fabrication process. J. Phys. Chem. Lett. 2016, 7, 776-782. [CrossRef] 
52. Yokoyama, T.; Song, T.-B.; Cao, D.H.; Stoumpos, C.C.; Aramaki, S.; Kanatzidis, M.G. The origin of lower hole carrier concentration in methylammonium tin halide films grown by a vapor-assisted solution process. ACS Energy Lett. 2016, 2, 22-28. [CrossRef]

53. Weiss, M.; Horn, J.; Richter, C.; Schlettwein, D. Preparation and characterization of methylammonium tin iodide layers as photovoltaic absorbers. Phys. Status Solidi 2016, 213, 975-981. [CrossRef]

54. Hoshi, H.; Shigeeda, N.; Dai, T. Improved oxidation stability of tin iodide cubic perovskite treated by 5-ammonium valeric acid iodide. Mater. Lett. 2016, 183, 391-393. [CrossRef]

55. Fujihara, T.; Terakawa, S.; Matsushima, T.; Qin, C.; Yahiro, M.; Adachi, C. Fabrication of high coverage MASnI 3 perovskite films for stable, planar heterojunction solar cells. J. Mater. Chem. C 2017, 5, 1121-1127. [CrossRef]

56. Zhou, Y.; Zhang, T.; Li, C.; Liang, Z.; Gong, L.; Chen, J.; Xie, W.; Xu, J.; Liu, P. Rapid growth of high quality perovskite crystal by solvent mixing. CrystEngComm 2016, 18, 1184-1189. [CrossRef]

57. Handa, T.; Yamada, T.; Kubota, H.; Ise, S.; Miyamoto, Y.; Kanemitsu, Y. Photocarrier recombination and injection dynamics in long-term stable lead-free $\mathrm{CH}_{3} \mathrm{NH}_{3} \mathrm{SnI}_{3}$ perovskite thin films and solar cells. J. Phys. Chem. C 2017, 121, 16158-16165. [CrossRef]

58. Ma, L.; Hao, F.; Stoumpos, C.C.; Phelan, B.T.; Wasielewski, M.R.; Kanatzidis, M.G. Carrier diffusion lengths of over $500 \mathrm{~nm}$ in lead-free perovskite $\mathrm{CH}_{3} \mathrm{NH}_{3} \mathrm{SnI}_{3}$ films. J. Am. Chem. Soc. 2016, 138, 14750-14755. [CrossRef]

59. Tsai, C.M.; Mohanta, N.; Wang, C.Y.; Lin, Y.P.; Yang, Y.W.; Wang, C.L.; Hung, C.H.; Diau, E.W.G. Formation of Stable Tin Perovskites Co-crystallized with Three Halides for Carbon-Based Mesoscopic Lead-Free Perovskite Solar Cells. Angew. Chem. Int. Ed. 2017, 56, 13819-13823. [CrossRef]

60. Wang, P.; Li, F.; Jiang, K.; Zhang, Y.; Fan, H.; Zhang, Y.; Miao, Y.; Huang, J.; Gao, C.; Zhou, X. Ion Exchange/Insertion Reactions for Fabrication of Efficient Methylammonium Tin Iodide Perovskite Solar Cells. Adv. Sci. 2020, 1903047. [CrossRef]

61. Yu, Y.; Zhao, D.; Grice, C.R.; Meng, W.; Wang, C.; Liao, W.; Cimaroli, A.J.; Zhang, H.; Zhu, K.; Yan, Y. Thermally evaporated methylammonium tin triiodide thin films for lead-free perovskite solar cell fabrication. RSC Adv. 2016, 6, 90248-90254. [CrossRef]

62. Peng, L.; Xie, W. Theoretical and experimental investigations on the bulk photovoltaic effect in lead-free perovskites MASnI3 and FASnI3. RSC Adv. 2020, 10, 14679-14688. [CrossRef]

63. Wang, F.; Ma, J.; Xie, F.; Li, L.; Chen, J.; Fan, J.; Zhao, N. Organic Cation-Dependent Degradation Mechanism of Organotin Halide Perovskites. Adv. Funct. Mater. 2016, 26, 3417-3423. [CrossRef]

64. Shi, T.; Zhang, H.-S.; Meng, W.; Teng, Q.; Liu, M.; Yang, X.; Yan, Y.; Yip, H.-L.; Zhao, Y.-J. Effects of organic cations on the defect physics of tin halide perovskites. J. Mater. Chem. A 2017, 5, 15124-15129. [CrossRef]

65. Baikie, T.; Fang, Y.; Kadro, J.M.; Schreyer, M.; Wei, F.; Mhaisalkar, S.G.; Graetzel, M.; White, T.J. Synthesis and crystal Chem. of the hybrid perovskite $\left(\mathrm{CH}_{3} \mathrm{NH}_{3}\right) \mathrm{PbI}_{3}$ for solid-state sensitised solar cell applications. J. Mater. Chem. A 2013, 1, 5628-5641. [CrossRef]

66. Amat, A.; Mosconi, E.; Ronca, E.; Quarti, C.; Umari, P.; Nazeeruddin, M.K.; Graätzel, M.; de Angelis, F. Cation-induced band-gap tuning in organohalide perovskites: Interplay of spin-orbit coupling and octahedra tilting. Nano Lett. 2014, 14, 3608-3616. [CrossRef]

67. Koh, T.M.; Krishnamoorthy, T.; Yantara, N.; Shi, C.; Leong, W.L.; Boix, P.P.; Grimsdale, A.C.; Mhaisalkar, S.G.; Mathews, N. Formamidinium tin-based perovskite with low $\mathrm{E} g$ for photovoltaic applications. J. Mater. Chem. A 2015, 3, 14996-15000. [CrossRef]

68. Lee, S.J.; Shin, S.S.; Kim, Y.C.; Kim, D.; Ahn, T.K.; Noh, J.H.; Seo, J.; Seok, S.I. Fabrication of efficient formamidinium tin iodide perovskite solar cells through SnF2-pyrazine complex. J. Am. Chem. Soc. 2016, 138, 3974-3977. [CrossRef] [PubMed]

69. Liao, W.; Zhao, D.; Yu, Y.; Grice, C.R.; Wang, C.; Cimaroli, A.J.; Schulz, P.; Meng, W.; Zhu, K.; Xiong, R.G. Lead-free inverted planar formamidinium tin triiodide perovskite solar cells achieving power conversion efficiencies up to $6.22 \%$. Adv. Mater. 2016, 28, 9333-9340. [CrossRef] [PubMed]

70. Jung, M.-C.; Raga, S.R.; Qi, Y. Properties and solar cell applications of Pb-free perovskite films formed by vapor deposition. RSC Adv. 2016, 6, 2819-2825. [CrossRef]

71. Zeng, W.; Cui, D.; Li, Z.; Tang, Y.; Yu, X.; Li, Y.; Deng, Y.; Ye, R.; Niu, Q.; Xia, R. Surface optimization by poly $(\alpha$-methylstyrene) as additive in the antisolution to enhance lead-free $\mathrm{Sn}$-based perovskite solar cells. Sol. Energy 2019, 194, 272-278. [CrossRef] 
72. Ke, W.; Stoumpos, C.C.; Logsdon, J.L.; Wasielewski, M.R.; Yan, Y.; Fang, G.; Kanatzidis, M.G. TiO2-ZnS cascade electron transport layer for efficient formamidinium tin iodide perovskite solar cells. J. Am. Chem. Soc. 2016, 138, 14998-15003. [CrossRef] [PubMed]

73. Xi, J.; Wu, Z.; Jiao, B.; Dong, H.; Ran, C.; Piao, C.; Lei, T.; Song, T.B.; Ke, W.; Yokoyama, T. Multichannel Interdiffusion Driven FASnI3 Film Formation Using Aqueous Hybrid Salt/Polymer Solutions toward Flexible Lead-Free Perovskite Solar Cells. Adv. Mater. 2017, 29, 1606964. [CrossRef] [PubMed]

74. Zhu, Z.; Chueh, C.C.; Li, N.; Mao, C.; Jen, A.K.Y. Realizing Efficient Lead-Free Formamidinium Tin Triiodide Perovskite Solar Cells via a Sequential Deposition Route. Adv. Mater. 2018, 30, 1703800. [CrossRef] [PubMed]

75. Hsu, C.; Geanangel, R. Synthesis and studies of trimethylamine adducts with tin (II) halides. Inorg. Chem. 1977, 16, 2529-2534. [CrossRef]

76. Noh, J.H.; Im, S.H.; Heo, J.H.; Mandal, T.N.; Seok, S.I. Chemical management for colorful, efficient, and stable inorganic-organic hybrid nanostructured solar cells. Nano Lett. 2013, 13, 1764-1769. [CrossRef] [PubMed]

77. Eperon, G.E.; Stranks, S.D.; Menelaou, C.; Johnston, M.B.; Herz, L.M.; Snaith, H.J. Formamidinium lead trihalide: A broadly tunable perovskite for efficient planar heterojunction solar cells. Energy Environ. Sci. 2014, 7, 982-988. [CrossRef]

78. Zhang, M.; Lyu, M.; Yun, J.-H.; Noori, M.; Zhou, X.; Cooling, N.A.; Wang, Q.; Yu, H.; Dastoor, P.C.; Wang, L. Low-temperature processed solar cells with formamidinium tin halide perovskite/fullerene heterojunctions. Nano Res. 2016, 9, 1570-1577. [CrossRef]

79. Lee, S.J.; Shin, S.S.; Im, J.; Ahn, T.K.; Noh, J.H.; Jeon, N.J.; Seok, S.I.; Seo, J. Reducing carrier density in formamidinium tin perovskites and its beneficial effects on stability and efficiency of perovskite solar cells. ACS Energy Lett. 2017, 3, 46-53. [CrossRef]

80. Gu, F.; Ye, S.; Zhao, Z.; Rao, H.; Liu, Z.; Bian, Z.; Huang, C. Improving Performance of Lead-Free Formamidinium Tin Triiodide Perovskite Solar Cells by Tin Source Purification. Sol. RRL 2018, 2, 1800136. [CrossRef]

81. Wu, T.; Liu, X.; He, X.; Wang, Y.; Meng, X.; Noda, T.; Yang, X.; Han, L. Efficient and stable tin-based perovskite solar cells by introducing $\pi$-conjugated Lewis base. Sci.China-Chem. 2020, 63, 107-115. [CrossRef]

82. Liu, G.; Liu, C.; Lin, Z.; Yang, J.; Huang, Z.; Tan, L.; Chen, Y. Regulated Crystallization of Efficient and Stable Tin-Based Perovskite Solar Cells via a Self-Sealing Polymer. ACS Appl. Mater. Interfaces 2020, 12, 14049-14056. [CrossRef]

83. Lee, B.; He, J.; Chang, R.P.; Kanatzidis, M.G. All-solid-state dye-sensitized solar cells with high efficiency. Nature 2012, 485, 486.

84. Chen, Z.; Wang, J.J.; Ren, Y.; Yu, C.; Shum, K. Schottky solar cells based on CsSnI3 thin-films. Appl. Phys. Lett. 2012, 101, 093901. [CrossRef]

85. Kumar, M.H.; Dharani, S.; Leong, W.L.; Boix, P.P.; Prabhakar, R.R.; Baikie, T.; Shi, C.; Ding, H.; Ramesh, R.; Asta, M. Lead-free halide perovskite solar cells with high photocurrents realized through vacancy modulation. Adv. Mater. 2014, 26, 7122-7127. [CrossRef]

86. Park, N.-G. Organometal perovskite light absorbers toward a 20\% efficiency low-cost solid-state mesoscopic solar cell. J. Phys. Chem. Lett. 2013, 4, 2423-2429. [CrossRef]

87. Chung, I.; Song, J.-H.; Im, J.; Androulakis, J.; Malliakas, C.D.; Li, H.; Freeman, A.J.; Kenney, J.T.; Kanatzidis, M.G. CsSnI3: Semiconductor or metal? High electrical conductivity and strong near-infrared photoluminescence from a single material. High hole mobility and phase-transitions. J. Am. Chem. Soc. 2012, 134, 8579-8587. [CrossRef] [PubMed]

88. Sabba, D.; Mulmudi, H.K.; Prabhakar, R.R.; Krishnamoorthy, T.; Baikie, T.; Boix, P.P.; Mhaisalkar, S.; Mathews, N. Impact of anionic Br-substitution on open circuit voltage in lead free perovskite (CsSnI3-xBr x) solar cells. J. Phys. Chem. C 2015, 119, 1763-1767. [CrossRef]

89. Marshall, K.P.; Walton, R.I.; Hatton, R.A. Tin perovskite/fullerene planar layer photovoltaics: Improving the efficiency and stability of lead-free devices. J. Mater. Chem. A 2015, 3, 11631-11640. [CrossRef]

90. Song, T.-B.; Yokoyama, T.; Aramaki, S.; Kanatzidis, M.G. Performance enhancement of lead-free tin-based perovskite solar cells with reducing atmosphere-assisted dispersible additive. ACS Energy Lett. 2017, 2, 897-903. [CrossRef]

91. Marshall, K.; Walker, M.; Walton, R.; Hatton, R. Enhanced stability and efficiency in hole-transport-layer-free $\mathrm{CsSnI}_{3}$ perovskite photovoltaics. Nat. Energy 2016, 1, 16178. [CrossRef] 
92. Gupta, S.; Bendikov, T.; Hodes, G.; Cahen, D. CsSnBr 3 , a lead-free halide perovskite for long-term solar cell application: Insights on $\mathrm{SnF}_{2}$ addition. ACS Energy Lett. 2016, 1, 1028-1033. [CrossRef]

93. Moghe, D.; Wang, L.; Traverse, C.J.; Redoute, A.; Sponseller, M.; Brown, P.R.; Bulović, V.; Lunt, R.R. All vapor-deposited lead-free doped $\mathrm{CsSnBr}_{3}$ planar solar cells. Nano Energy 2016, 28, 469-474. [CrossRef]

94. Song, T.-B.; Yokoyama, T.; Logsdon, J.; Wasielewski, M.R.; Aramaki, S.; Kanatzidis, M.G. Piperazine Suppresses Self-Doping in CsSnI3 Perovskite Solar Cells. ACS Appl. Energy Mater. 2018, 1, 4221-4226. [CrossRef]

95. Li, W.; Li, J.; Li, J.; Fan, J.; Mai, Y.; Wang, L. Addictive-assisted construction of all-inorganic CsSnIBr 2 mesoscopic perovskite solar cells with superior thermal stability up to $473 \mathrm{~K}$. J. Mater. Chem. A 2016, 4, 17104-17110. [CrossRef]

96. Wang, N.; Zhou, Y.; Ju, M.G.; Garces, H.F.; Ding, T.; Pang, S.; Zeng, X.C.; Padture, N.P.; Sun, X.W. Heterojunction-Depleted Lead-Free Perovskite Solar Cells with Coarse-Grained B- $\gamma$-CsSnI3 Thin Films. Adv. Energy Mater. 2016, 6, 1601130. [CrossRef]

97. Chen, L.-J.; Lee, C.-R.; Chuang, Y.-J.; Wu, Z.-H.; Chen, C. Synthesis and optical properties of lead-free cesium tin halide perovskite quantum rods with high-performance solar cell application. J. Phys. Chem. Lett. 2016, 7, 5028-5035. [CrossRef]

98. Tan, L.; Wang, W.; Li, Q.; Luo, Z.; Zou, C.; Tang, M.; Zhang, L.; He, J.; Quan, Z. Colloidal syntheses of zero-dimensional Cs $4 \mathrm{SnX} 6(\mathrm{X}=\mathrm{Br}$, I) nanocrystals with high emission efficiencies. Chem. Commun. 2020, 56, 387-390. [CrossRef]

99. Wang, A.; Guo, Y.; Muhammad, F.; Deng, Z. Controlled synthesis of lead-free cesium tin halide perovskite cubic nanocages with high stability. Chem. Mater. 2017, 29, 6493-6501. [CrossRef]

100. Qiu, X.; Cao, B.; Yuan, S.; Chen, X.; Qiu, Z.; Jiang, Y.; Ye, Q.; Wang, H.; Zeng, H.; Liu, J. From unstable CsSnI3 to air-stable Cs2SnI6: A lead-free perovskite solar cell light absorber with bandgap of $1.48 \mathrm{eV}$ and high absorption coefficient. Sol. Energy Mater. Sol. Cells 2017, 159, 227-234. [CrossRef]

101. Zhang, T.; Li, H.; Ban, H.; Sun, Q.; Shen, Y.; Wang, M. Efficient CsSnI3-based inorganic perovskite solar cells based on a mesoscopic metal oxide framework via incorporating a donor element. J. Mater. Chem. 2020, 8 , 4118-4124. [CrossRef]

102. Li, J.; Huang, J.; Zhao, A.; Li, Y.; Wei, M. An inorganic stable Sn-based perovskite film with regulated nucleation for solar cell application. J. Mater. Chem. C 2020, 8, 8840-8845. [CrossRef]

103. Namvar, M.J.; Abbaspour, F.M.H.; Rezaei, R.M.; Behjat, A.; Mirzaei, M. The effect of inserting combined Rubidium-Cesium cation on performance of perovkite solar cell FAMAPb (IBr) 3. J. Res. Many Body Syst. 2019, 8, 12-142.

104. Zhang, X.; Liu, H.; Wang, W.; Zhang, J.; Xu, B.; Karen, K.L.; Zheng, Y.; Liu, S.; Chen, S.; Wang, K. Hybrid Perovskite Light-Emitting Diodes Based on Perovskite Nanocrystals with Organic-Inorganic Mixed Cations. Adv. Mater. 2017, 29, 1606405. [CrossRef] [PubMed]

105. Sun, Y.; Peng, J.; Chen, Y.; Yao, Y.; Liang, Z. Triple-cation mixed-halide perovskites: Towards efficient, annealing-free and air-stable solar cells enabled by $\mathrm{Pb}(\mathrm{SCN}) 2$ additive. Sci. Rep. 2017, 7, 46193. [CrossRef] [PubMed]

106. Salado, M.; Kokal, R.K.; Calio, L.; Kazim, S.; Deepa, M.; Ahmad, S. Identifying the charge generation dynamics in Cs+-based triple cation mixed perovskite solar cells. Phys. Chem. Chem. Phys. 2017, 19, 22905-22914. [CrossRef] [PubMed]

107. Zhao, Z.; Gu, F.; Li, Y.; Sun, W.; Ye, S.; Rao, H.; Liu, Z.; Bian, Z.; Huang, C. Mixed-Organic-Cation Tin Iodide for Lead-Free Perovskite Solar Cells with an Efficiency of 8.12\%. Adv. Sci. 2017, 4, 1700204. [CrossRef]

108. Liu, J.; Ozaki, M.; Yakumaru, S.; Handa, T.; Nishikubo, R.; Kanemitsu, Y.; Saeki, A.; Murata, Y.; Murdey, R.; Wakamiya, A. Lead-Free Solar Cells based on Tin Halide Perovskite Films with High Coverage and Improved Aggregation. Angew. Chem. Int. Ed. 2018, 57, 13221-13225. [CrossRef] [PubMed]

109. Liu, X.; Yan, K.; Tan, D.; Liang, X.; Zhang, H.; Huang, W. Solvent engineering improves efficiency of lead-free tin-based hybrid perovskite solar cells beyond 9\%. ACS Energy Lett. 2018, 3, 2701-2707. [CrossRef]

110. Ke, W.; Stoumpos, C.C.; Zhu, M.; Mao, L.; Spanopoulos, I.; Liu, J.; Kontsevoi, O.Y.; Chen, M.; Sarma, D.; Zhang, Y. Enhanced photovoltaic performance and stability with a new type of hollow 3D perovskite \{en\} $\mathrm{FASnI}_{3}$. Sci. Adv. 2017, 3, e1701293. [CrossRef] 
111. Ke, W.; Stoumpos, C.C.; Spanopoulos, I.; Mao, L.; Chen, M.; Wasielewski, M.R.; Kanatzidis, M.G. Efficient lead-free solar cells based on hollow \{en\} MASnI3 perovskites. J. Am. Chem. Soc. 2017, 139, 14800-14806. [CrossRef]

112. Vegiraju, S.; Ke, W.; Priyanka, P.; Ni, J.; Wu, Y.C.; Spanopoulos, I.; Yau, S.L.; Marks, T.J.; Chen, M.; Kanatzidis, M.G. Benzodithiophene Hole-Transporting Mater. for Efficient Tin-Based Perovskite Solar Cells. Adv. Funct. Mater. 2019, 29, 1905393. [CrossRef]

113. Smith, I.C.; Hoke, E.T.; Solis-Ibarra, D.; McGehee, M.D.; Karunadasa, H.I. A layered hybrid perovskite solar-cell absorber with enhanced moisture stability. Angew. Chem. Int. Ed. 2014, 53, 11232-11235. [CrossRef] [PubMed]

114. Cao, D.H.; Stoumpos, C.C.; Farha, O.K.; Hupp, J.T.; Kanatzidis, M.G. 2D homologous perovskites as light-absorbing materials for solar cell applications. J. Am. Chem. Soc. 2015, 137, 7843-7850. [CrossRef] [PubMed]

115. Cao, D.H.; Stoumpos, C.C.; Yokoyama, T.; Logsdon, J.L.; Song, T.-B.; Farha, O.K.; Wasielewski, M.R.; Hupp, J.T.; Kanatzidis, M.G. Thin films and solar cells based on semiconducting two-dimensional ruddlesden-popper (CH3 (CH2) 3NH3) 2 (CH3NH3) n- 1Sn n I3 n+ 1 perovskites. ACS Energy Lett. 2017, 2, 982-990. [CrossRef]

116. Liao, Y.; Liu, H.; Zhou, W.; Yang, D.; Shang, Y.; Shi, Z.; Li, B.; Jiang, X.; Zhang, L.; Quan, L.N. Highly oriented low-dimensional tin halide perovskites with enhanced stability and photovoltaic performance. J. Am. Chem. Soc. 2017, 139, 6693-6699. [CrossRef] [PubMed]

117. Li, F.; Xie, Y.; Hu, Y.; Long, M.; Zhang, Y.; Xu, J.; Qin, M.; Lu, X.; Liu, M. Effects of Alkyl Chain Length on Crystal Growth and Oxidation Process of Two-Dimensional Tin Halide Perovskites. ACS Energy Lett. 2020, 5, 1422-1429. [CrossRef]

118. Ran, C.; Xi, J.; Gao, W.; Yuan, F.; Lei, T.; Jiao, B.; Hou, X.; Wu, Z. Bilateral interface engineering toward efficient 2D-3D bulk heterojunction tin halide lead-free perovskite solar cells. ACS Energy Lett. 2018, 3, 713-721. [CrossRef]

119. Shao, S.; Liu, J.; Portale, G.; Fang, H.H.; Blake, G.R.; ten Brink, G.H.; Koster, L.J.A.; Loi, M.A. Highly reproducible Sn-based hybrid perovskite solar cells with 9\% efficiency. Adv. Energy Mater. 2018, 8, 1702019. [CrossRef]

120. Marshall, K.P.; Tao, S.; Walker, M.; Cook, D.S.; Lloyd-Hughes, J.; Varagnolo, S.; Wijesekara, A.; Walker, D.; Walton, R.I.; Hatton, R.A. Cs 1-x Rb x SnI 3 light harvesting semiconductors for perovskite photovoltaics. Mater. Chem. Front. 2018, 2, 1515-1522. [CrossRef]

121. Gao, W.; Ran, C.; Li, J.; Dong, H.; Jiao, B.; Zhang, L.; Lan, X.; Hou, X.; Wu, Z. Robust Stability of Efficient Lead-Free Formamidinium Tin Iodide Perovskite Solar Cells Realized by Structural Regulation. J. Phys. Chem. Lett. 2018, 9, 6999-7006. [CrossRef]

122. Jokar, E.; Chien, C.-H.; Fathi, A.; Rameez, M.; Chang, Y.-H.; Diau, E.W.-G. Slow surface passivation and crystal relaxation with additives to improve device performance and durability for tin-based perovskite solar cells. Energy Environ. Sci. 2018, 11, 2353-2362. [CrossRef]

123. Weber, S.; Rath, T.; Kunert, B.; Resel, R.; Dimopoulos, T.; Trimmel, G. Dependence of material properties and photovoltaic performance of triple cation tin perovskites on the iodide to bromide ratio. Mon. Fur Chem. 2019, 150, 1921-1927. [CrossRef]

124. Jokar, E.; Chien, C.H.; Tsai, C.M.; Fathi, A.; Diau, E.W.G. Robust Tin-Based Perovskite Solar Cells with Hybrid Organic Cations to Attain Efficiency Approaching 10\%. Adv. Mater. 2019, 31, 1804835. [CrossRef] [PubMed]

125. Kieslich, G.; Sun, S.; Cheetham, A.K. An extended tolerance factor approach for organic-inorganic perovskites. Chem. Sci. 2015, 6, 3430-3433. [CrossRef] [PubMed]

126. Stoumpos, C.C.; Mao, L.; Malliakas, C.D.; Kanatzidis, M.G. Structure-band gap relationships in hexagonal polytypes and low-dimensional structures of hybrid tin iodide perovskites. Inorg. Chem. 2016, 56, 56-73. [CrossRef]

127. Fu, Q.; Tang, X.; Li, D.; Huang, L.; Xiao, S.; Chen, Y.; Hu, T. An efficient and stable tin-based perovskite solar cell passivated by aminoguanidine hydrochloride. J. Mater. Chem. C 2020, 8, 7786-7792. [CrossRef]

128. Ran, C.; Gao, W.; Li, J.; Xi, J.; Li, L.; Dai, J.; Yang, Y.; Gao, X.; Dong, H.; Jiao, B. Conjugated Organic Cations Enable Efficient Self-Healing FASnI ${ }_{3}$ Solar Cells. Joule 2019, 3, 3072-3087. [CrossRef]

129. Jin, Z.; Yu, B.-B.; Liao, M.; Liu, D.; Xiu, J.; Zhang, Z.; Lifshitz, E.; Tang, J.; Song, H.; He, Z. Enhanced efficiency and stability in Sn-based perovskite solar cells with secondary crystallization growth. J. Energy Chem. 2021, 54, 414-421. [CrossRef] 
130. Meng, X.; Wang, Y.; Lin, J.; Liu, X.; He, X.; Barbaud, J.; Wu, T.; Noda, T.; Yang, X.; Han, L. Surface-Controlled Oriented Growth of FASnI3 Crystals for Efficient Lead-free Perovskite Solar Cells. Joule 2020, 4, 902-912. [CrossRef]

131. Liu, X.; Wang, Y.; Wu, T.; He, X.; Meng, X.; Barbaud, J.; Chen, H.; Segawa, H.; Yang, X.; Han, L. Efficient and stable tin perovskite solar cells enabled by amorphous-polycrystalline structure. Nat. Commun. 2020, 11, 2678. [CrossRef]

132. Jiang, X.; Wang, F.; Wei, Q.; Li, H.; Shang, Y.; Zhou, W.; Wang, C.; Cheng, P.; Chen, Q.; Chen, L. Ultra-high open-circuit voltage of tin perovskite solar cells via an electron transporting layer design. Nat. Commun. 2020, 11, 1245. [CrossRef] [PubMed]

133. Hayase, S.; Ito, N.; Kamarudin, M.A.K.; Shen, Q.; Ogomi, Y.; Iikubo, S.; Yoshino, K.; Minemoto, T.; Toyoda, T. $\mathrm{Pb}$ free perovskite solar cells consisting of mixed metal $\mathrm{SnGe}$ perovskite as light absorber. In Proceedings of the Conference Presentation SPIE, San Diego, CA, USA, 18 September 2018.

134. Chen, M.; Ju, M.-G.; Garces, H.F.; Carl, A.D.; Ono, L.K.; Hawash, Z.; Zhang, Y.; Shen, T.; Qi, Y.; Grimm, R.L.; et al. Highly stable and efficient all-inorganic lead-free perovskite solar cells with native-oxide passivation. Nat. Commun. 2019, 10, 16. [CrossRef] [PubMed]

135. Ali, R.; Hou, G.; Zhu, Z.; Yan, Q.; Zheng, Q.; Su, G. Stable mixed group II (Ca, Sr) and XIV (Ge, Sn) lead-free perovskite solar cells. J. Mater. Chem. 2018, 6, 9220-9227. [CrossRef]

136. Ng, C.H.; Hamada, K.; Kapil, G.; Kamarudin, M.A.; Wang, Z.; likubo, S.; Shen, Q.; Yoshino, K.; Minemoto, T.; Hayase, S. Reducing trap density and carrier concentration by a Ge additive for an efficient quasi 2D/3D perovskite solar cell. J. Mater. Chem. A 2020, 8, 2962-2968. [CrossRef]

137. Nishimura, K.; Kamarudin, M.A.; Hirotani, D.; Hamada, K.; Shen, Q.; Iikubo, S.; Minemoto, T.; Yoshino, K.; Hayase, S. Lead-free tin-halide perovskite solar cells with 13\% efficiency. Nano Energy 2020, 74, 104858. [CrossRef]

(C) 2020 by the authors. Licensee MDPI, Basel, Switzerland. This article is an open access article distributed under the terms and conditions of the Creative Commons Attribution (CC BY) license (http://creativecommons.org/licenses/by/4.0/). 